\author{
WALDEN \\ UNIVERSITY \\ A higher degree. A higher purpose.
}

Walden University ScholarWorks

Walden Dissertations and Doctoral Studies

2019

\title{
Diffusion of Innovations and Labor Market Challenges: A Multiple Case Study from Angola
}

Édney Marco Cardoso dos Santos

Walden University

Follow this and additional works at: https://scholarworks.waldenu.edu/dissertations

This Dissertation is brought to you for free and open access by the Walden Dissertations and Doctoral Studies Collection at ScholarWorks. It has been accepted for inclusion in Walden Dissertations and Doctoral Studies by an authorized administrator of ScholarWorks. For more information, please contact ScholarWorks@waldenu.edu. 


\title{
Walden University
}

\author{
College of Management and Technology
}

This is to certify that the doctoral dissertation by

\author{
Édney Santos
}

has been found to be complete and satisfactory in all respects, and that any and all revisions required by the review committee have been made.

\begin{abstract}
Review Committee
Dr. Daphne Halkias, Committee Chairperson, Management Faculty

Dr. Kenneth Levitt, Committee Member, Management Faculty

Dr. Kathleen Barclay, University Reviewer, Management Faculty
\end{abstract}

Chief Academic Officer

Eric Riedel, Ph.D.

Walden University

2019 


\author{
Abstract \\ Diffusion of Innovations and Labor Market Challenges: \\ A Multiple Case Study from Angola \\ by \\ Édney Santos
}

MSc, University of Liverpool, 2014

LSc, Universidade Lusiada Angola, 2011

Dissertation Submitted in Partial Fulfillment

of the Requirements for the Degree of

Doctor of Philosophy

Management

Walden University

May 2019 


\begin{abstract}
A gap exists in the literature between general diffusion of technological innovations and socioeconomic development that results in an ambiguous connection between theory, academia, and professional practice. To inform governments in sub-Saharan Africa on how to achieve the diffusion of innovation for economic development through the voices of regional stakeholders, this qualitative multiple case study was conducted to gain deeper understanding on the views of stakeholders on rapid technology diffusion and its implication on labor market challenges within their regions of Angola. Information from semistructured interviews with 8 adult participants, male and female, born and residing in impoverished communities in Angola, and possessing knowledge regarding their experiences with the topic of the study, observational field notes, and archival data were collected to obtain information regarding specific stakeholders' experiences with the rapid diffusion of innovation. Identifiable themes emerged through thematic analysis of the textual data and cross-case synthesis analysis. A total of 7 categories that enclose a total of 17 themes were identified. The categories are (a) diffusion of innovations and adoption circumstances, (b) compatibility of technology with social values, (c) trialability within the cultural context, (d) adoption of technology, (e) innovation decision process factors, (f) trust in technology by community stakeholders, and (g) inclusive innovation for low-income stakeholders. Findings enhanced social change efforts by providing insights on the potential impact of the rapid diffusion of innovations among impoverished communities in sub-Saharan Africa and the implications faced by stakeholders on labor market challenges within their regions.
\end{abstract}


Diffusion of Innovations and Labor Market Challenges:

A Multiple Case Study from Angola

by

Édney Santos

MSc, University of Liverpool, 2014

LSc, Universidade Lusiada Angola, 2011

Dissertation Submitted in Partial Fulfillment

of the Requirements for the Degree of

Doctor of Philosophy

Management

Walden University

May 2019 


\section{Dedication}

I dedicate one part of this doctoral study to my wife and only friend, Aida, who has always been a constant source of support and light in my life. Though she was always complaining, I knew she wanted the best for me. To my son Édney Luani and daughter Taila Mayara I dedicate the second part of this study because I see myself reflected on them and as so, they have become a source of encouragement throughout this long journey. The last part of this study I dedicate to my parents, Sansão and Lourdes, who never doubted me and who have in time invested what they had to make me the man I am today. 


\section{Acknowledgements}

I express my immense gratitude to this one restless person, my committee chair, Dr. Daphne Halkias - You are an amazing person and much more than just a mentor. The love you express for your students, is like a father's love for his son. I have had and will always have the pleasure to have met you throughout this journey Dr. Halkias. I am also grateful to Dr. Kenneth Levitt, my committee member for his restless and valuable contributions to my work, and Dr. Kathleen Barclay, my university reviewer for her supervisory role and assertive contributions. To all my committee members, I appreciate

all the insights you have provided as you inspired me to become a better academic and professional. To my Lord and Savior "Christ" be the glory always. Love you all. 
Table of Contents

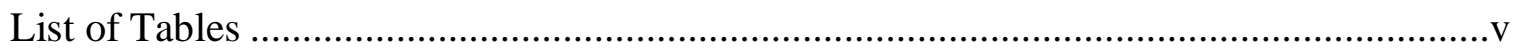

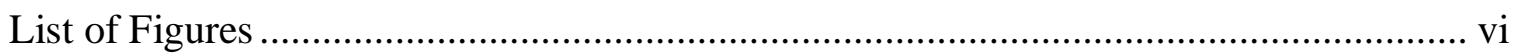

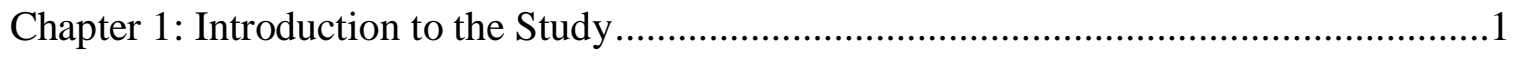

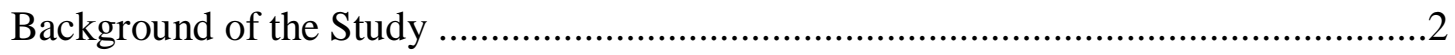

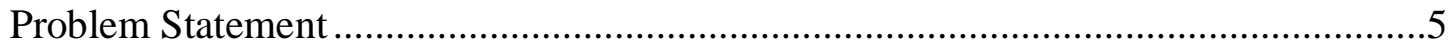

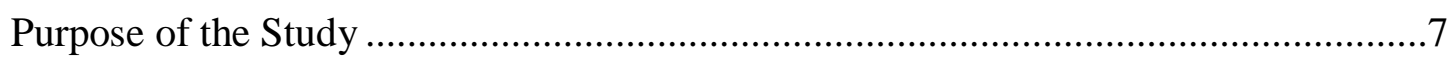

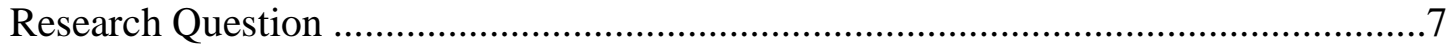

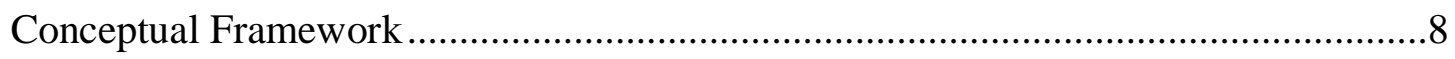

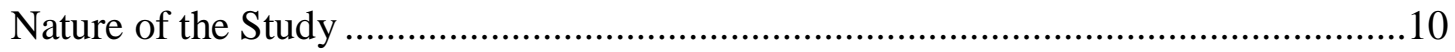

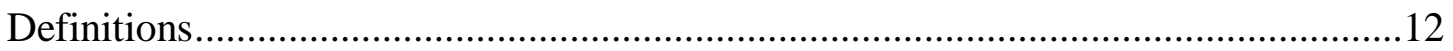

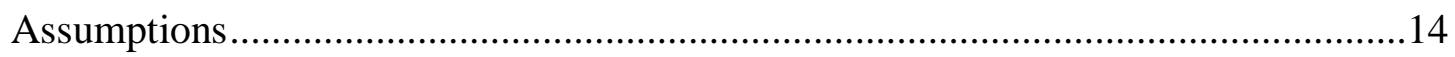

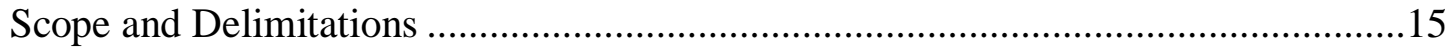

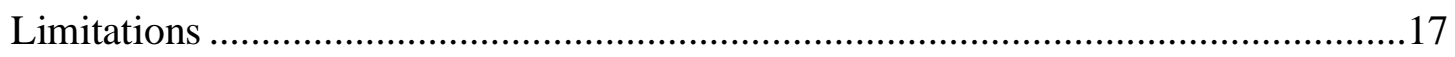

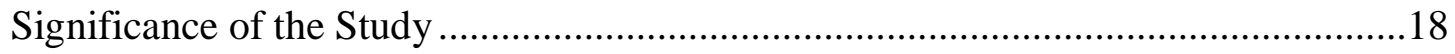

Significance to Practice.............................................................................. 19

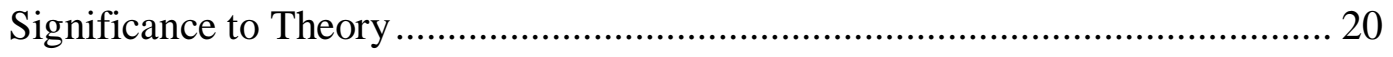

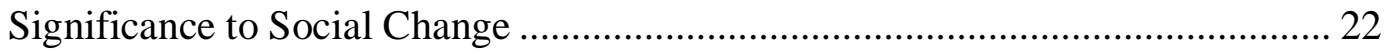

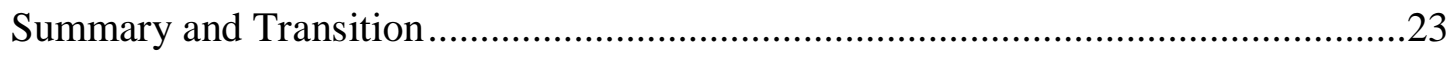

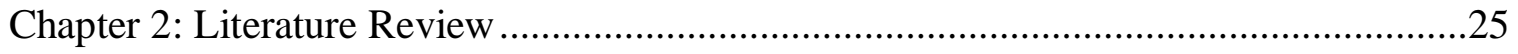

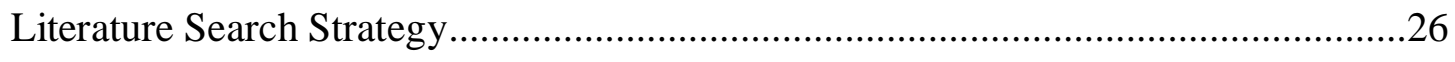

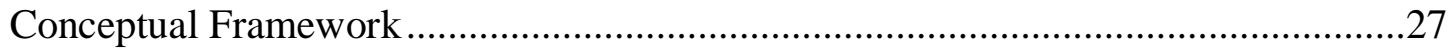




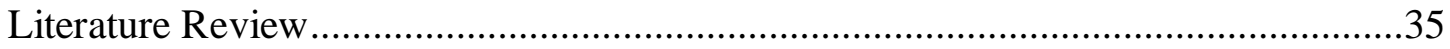

Labor Market Challenges in Sub-Saharan Africa .............................................. 35

Labor Market Challenges in Angola .............................................................. 38

The Diffusion of Innovation in Developing Countries ........................................ 43

The Promise and Challenge of Diffusion of Innovation in Sub-Saharan

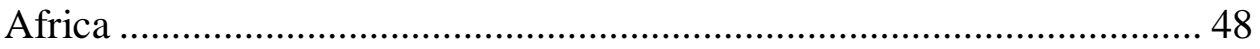

Challenges to Rapid Changes and Diffusion of Innovation................................... 54

Socioeconomic and Technology Challenges to Diffusion of Innovation in

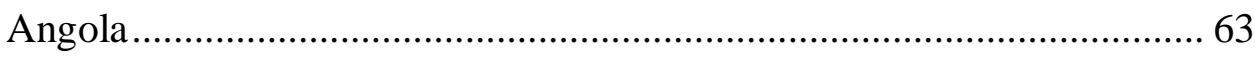

Stakeholders' Concerns on Rapid Diffusion of Innovations in Sub-Saharan

Africa

The Literature Gap in Studies on Rapid Diffusion of Innovations in Sub-

Saharan Africa 73

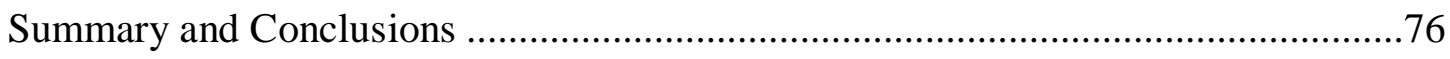

Chapter 3: Research Method....................................................................................78

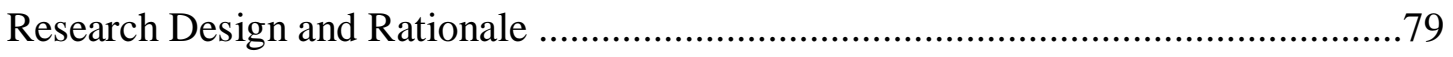

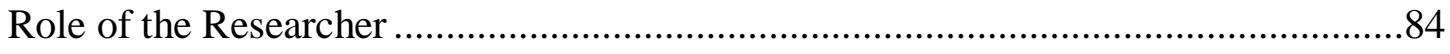

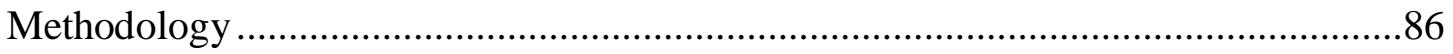

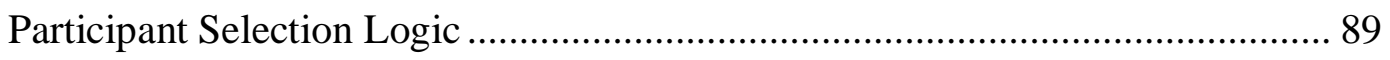

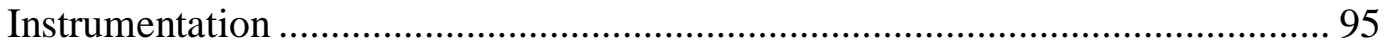

Procedures for Recruitment, Participation, and Data Collection ......................... 103

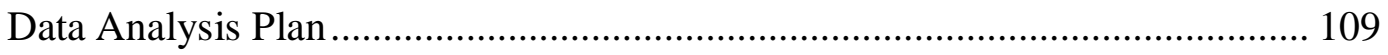




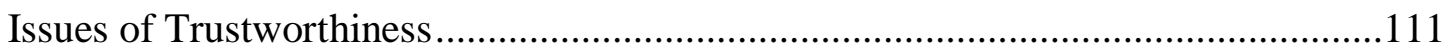

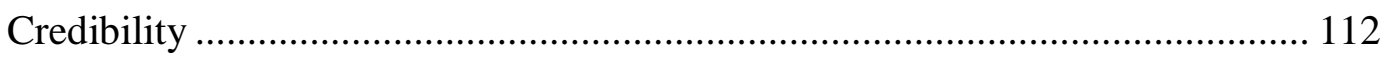

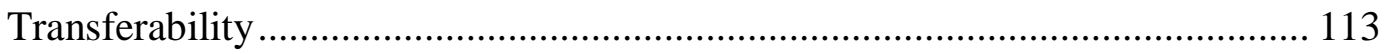

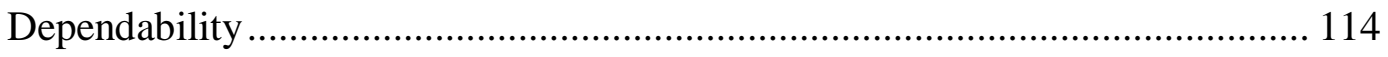

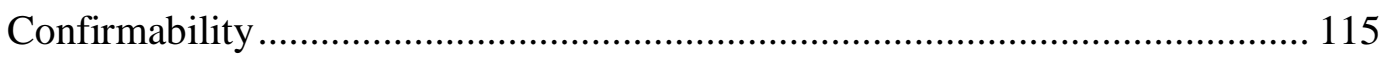

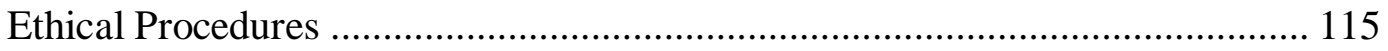

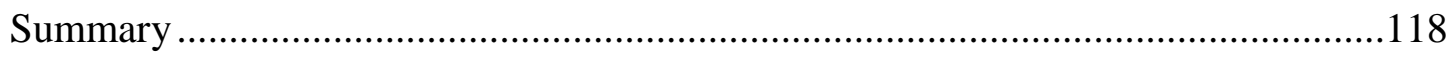

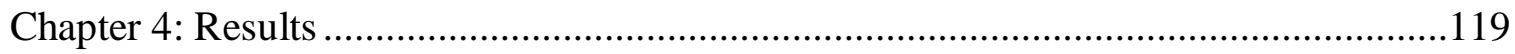

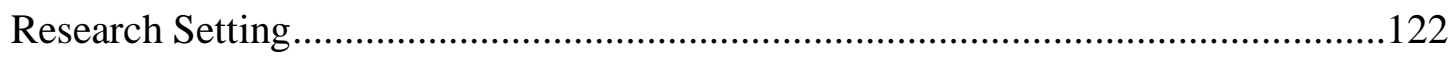

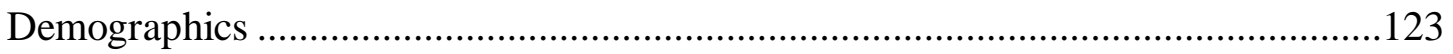

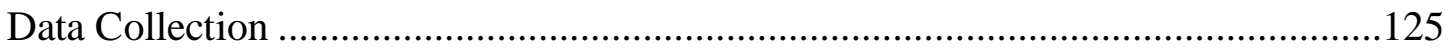

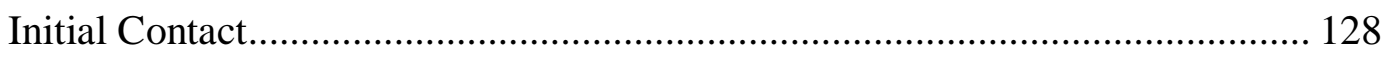

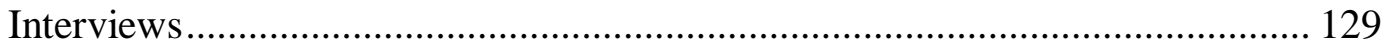

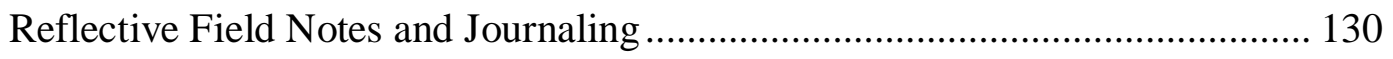

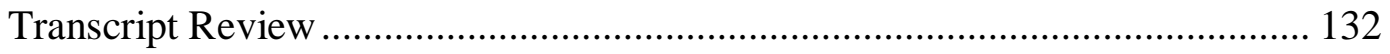

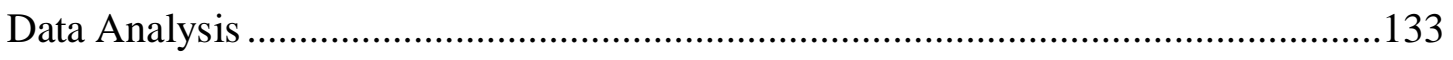

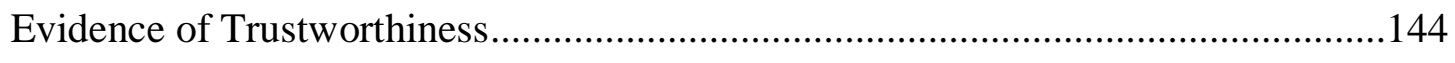

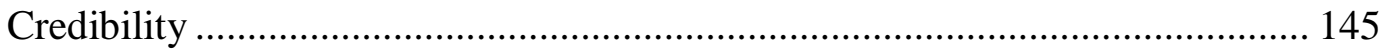

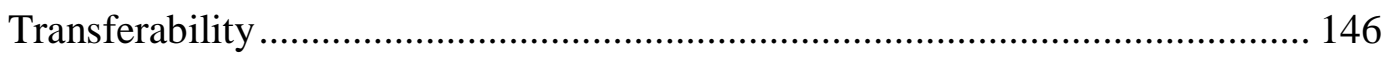

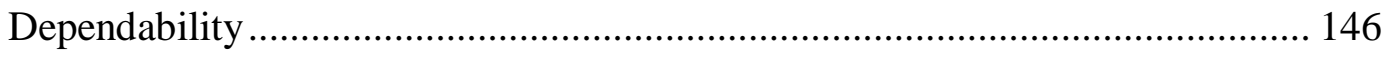

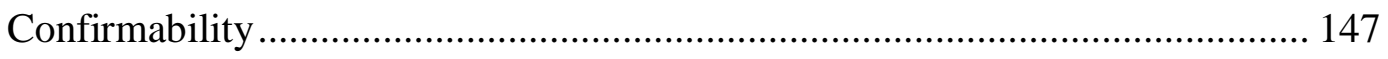

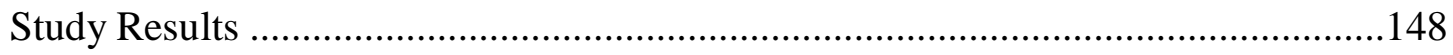


First Phase: Thematic Analysis of the Textual Data........................................ 150

Second Phase: Cross-Case Synthesis and Analysis ........................................ 168

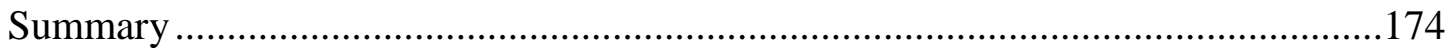

Chapter 5: Discussion, Conclusions, and Recommendations ............................................177

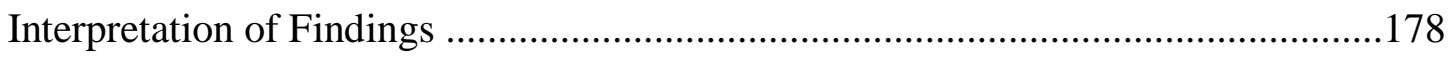

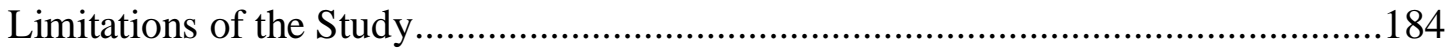

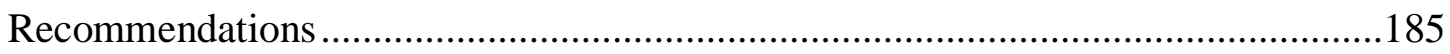

Recommendation 1: Quantitative Validation.................................................... 186

Recommendation 2: Qualitative Replication ................................................... 187

Recommendations for Future Research ........................................................ 188

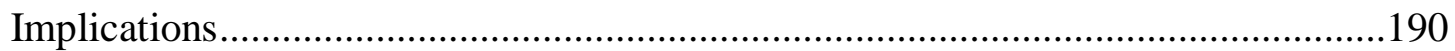

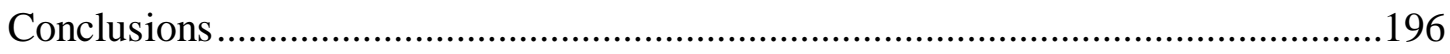

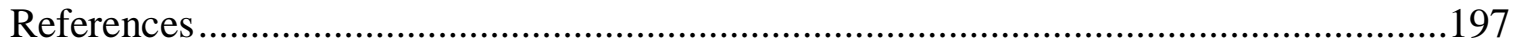

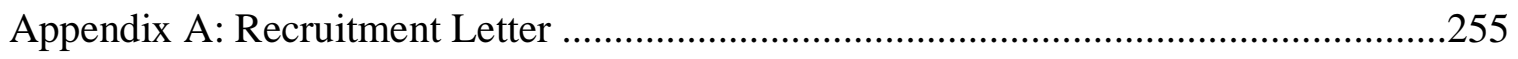

Appendix B: Interview Protocol ……………………...........................................256

Appendix C: Map of Angola with Research Site Provinces Indicated in Green .............257 


\section{List of Tables}

Table 1 Participants' Demographics and Characteristics ........................................... 124

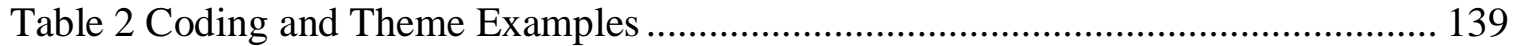




\section{List of Figures}

Figure 1. Multiple case analysis (theme frequency of occurrence by participant)........ 169 
Chapter 1: Introduction to the Study

Governments in the developing countries of sub-Saharan Africa, such as Angola, have failed to achieve the diffusion of innovation needed to spur on economic development by keeping regional stakeholders on the periphery of policy making, and not allowing the voices of impoverished populations to be heard on their fears related to technology and innovation (Dutz, Yevgeny, Esperanza, \& Dirk, 2014; Foster \& Heeks, 2013; Schillo \& Robinson, 2017). Amavilah (2016) argued that obstacles to technological progress and economic growth in some African countries cannot be properly explained without a profound understanding of the interplay between (a) relevant authoritative elements of religion and their role in the economic growth of civilizations, (b) the deinstitutionalization and loss of traditional economic institutions, and (c) the undervalued local knowledge in favor of foreign knowledge.

With a population of 29.25 million, the Angolan Institute of Statistics (Ine.gov.ao, 2018) registered the latest unemployment rate in the country hovering at $20 \%$ (TradingEconomics.com, 2018). Researchers agreed that the factors affecting labor market challenges and economic development in sub-Saharan African countries such as Angola are in part correlated to the diffusion of innovation (Kshetri, 2016; Niebel, 2018; Ovadia, 2014; Sirine, 2017; The World Bank, 2016b). Although technology can greatly benefit impoverished sub-Saharan Africans in the form of social change, rapidly diffused initiatives in the form of technology may also cause harm, spread fear, cause inequality, promote exclusion, and depress economic growth among impoverished populations 
(Kianian, Tavassoli, \& Larsson, 2015; Rivers, Rivers, \& Hazell, 2015; Sirine, 2017; The World Bank, 2016b).

In this chapter, I present the background literature leading to the problem statement formation including a description of the gap in the scholarly literature. Following is a presentation to a logical alignment between problem, purpose, and research questions and conceptual framework of the study. Finally, in this chapter I present the significance, assumptions, and limitations of the study, along with the definition of key terms used throughout this document.

\section{Background of the Study}

The African realization of the Millennium Development Goals (MDGs) did not show promising results for Africa's socioeconomic development (United Nations Development Programme [UNDP], 2014); yet, researchers reported that Africa has exhibited progressing results in terms of information and communications technology (ICT) adoption (Oluwatayo \& Ojo, 2018). Nevertheless, scholars argue that African developing countries still register a gap in the relationship between general ICT diffusion and innovation and socioeconomic growth and development (Asongu, Biekpe, \& Tchamyou, 2019; Evans, 2019; Tayo, Thompson, \& Thompson, 2015; Ugur \& Mitra, 2017). For some, the impact assessment of ICT adoption toward socioeconomic development is based on economic insufficiencies among categories of people and digital divides which are often defined as differences between access and use of ICT infrastructures mostly among impoverished sub-Saharan African populations (Aissaoui, 2017; Penard, Poussing, Mukoko, \& Piaptie, 2015). Others reported that the rapid 
diffusion of technological innovations causes industrial processes (manufacturing and production) to change, which in turn alters the relationship between economic growth and development (Grabowski, 2017). In the face of many challenges, certain African populations have come to perceive the adoption of ICT to be a multifaceted agent of exclusion because it tends to hinder socioeconomic development with replication patterns of social inequalities ranging from a disadvantaged community to an entire country (Oyedemi, 2012).

From the point of view of stakeholders in developing countries, the concept of digital divide was also conceived through the lens of uncontrolled proliferation of ICT in some African nations (Cruz-Jesus, Oliveira, Bacao, \& Irani, 2016), whereas others, due to the rather limited access to ICT infrastructures, especially in rural areas, lack the knowledge and capabilities to utilize technologies (Mumporeze \& Prieler, 2017;

Okunola, Rowley, \& Johnson, 2017). The patterns of the relationship between various economic imbalances and ICT adoption that promote the social divide have mostly been identified among individuals, households, businesses and their geographic locations (Cruz-Jesus et al., 2016; Okunola et al., 2017; Tayo et al., 2015). Researchers highlighted the importance of understanding the overall technological dualism between various social groups in African nations, and suggested that ICT adopters should shift away from the core economic impact of ICT use to focus on how ICT policies may affect the adopter's relationship with societal development and sustainability (Mumporeze \& Prieler, 2017).

Researchers pointed to technology and innovation as the catalyst elements of a developing country's economic growth because they induce social advancements 
(Shiferaw \& Hailu, 2016; Silva, Badasyan, \& Busby, 2018; Ugur \& Mitra, 2017). Yet, Vivarelli (2014) reported that the most massive technological unemployment in history had not occurred since the first industrial revolution. Faced with many controversies, researchers argued that technology is far less likely to be linked to job creation in the long run (Reiff, 2015; Ugur \& Mitra, 2017). Additionally, evidence indicated that technology adoption could be biased and for such reason it could displace unskilled workers, causing further joblessness (Amavilah, 2016). These perspectives often indicated that technology may constitute the downside of economic productivity for many developing countries, which most likely increases the rate of unemployment in the long-term and possibly worsens many other economic factors.

Some researchers believed that the economic imbalances in sub-Saharan Africa are tied to many of its countrys' institutional qualities, which reflect disparities and complex interaction among several factors through which governments play a key role (Adanu, 2017; Nakabashi, Pereira, \& Sachsida, 2013). One reason for the institutional complexity is the slow process required to create knowledge institutions that can transform national and regional economies. Researchers suggested that as key facilitators of technological innovations, African governments should combine the core elements that oversee the successful implementation of technological platforms between institutions and the industry (Biseswar, Mthembu, \& Ogembo-Kachienga, 2012; Grabowski, 2017). Although African governments seek to reduce the digital divide by investing on critical infrastructure (Oluwatayo \& Ojo, 2018), researchers highlighted the importance of identifying the commonalities in technological platforms that account for government 
support, policy frameworks, and knowledge transfers that provide strong links between industry and academia which are in turn relevant for policymakers and knowledge generators (Biseswar et al., 2012).

The factors that influence the adoption of technological innovations were also observed from the view point of a unified theory of behavior. Scholars suggested that the key to a successful diffusion of a technology in some developing countries resides in understanding a unified behavioral theory of acceptance and using technologies that measure the adopter's behavior toward a specific technology (Chaouali, Yahia, Charfeddine, \& Triki, 2016). The underlying assumption was that technology acceptance in a particular society and its effects on socioeconomic development is dependent on the economic conditions, government regulations, societal openness, and attributes of the country that facilitate the basic conditions for technology uptake (Pick \& Nishida, 2015). Additionally, in most African countries, technology uptake was also considered from the perspective of foreign direct investment (FDI) programs. It was reported that successful economies have established their development strategies on the adaptation of imported technologies (Alvarez \& Marin, 2013).

\section{Problem Statement}

Researchers at The World Bank (2016a) defined labor market challenges in developing countries as "declining rates of labor force participation, pockets of unemployment, underemployment and high informality" (p. 91) within regional communities. Researchers argued that uncertainty about employment opportunities experienced by developing countries including Angola, continues to be a rising factor of 
jobless economic growth (Campa, 2014; Shiferaw \& Hailu, 2016; Zachary, 2011). With a population of 29.25 million people, researchers at the Angolan Institute of Statistics (Ine.gov.ao, 2018) registered the latest unemployment rate in the country hovering at 20\% (TradingEconomics.com, 2018). Researchers agreed that the factors affecting labor market challenges and economic development in sub-Saharan African countries are in part correlated to the diffusion of innovation (Kshetri, 2016; Niebel, 2018; Ovadia, 2014). Diffusion is a special type of communication concerned with the spread of messages that are perceived as a new idea (Rogers, 2003). Although technology can greatly benefit impoverished sub-Saharan Africans and has been touted as a social change phenomenon across the continent, there is also the potential of rapidly diffused initiatives in the form of technology to also cause harm (Kianian et al., 2015; Rivers et al., 2015). The general problem is that the diffusion of innovations touted as a relief for labor market challenges in impoverished communities across sub-Saharan African countries proved ineffectual in the long term (Cruz-Jesus et al., 2016).

In Africa, technology has been perceived by various populations as a doubleedged sword, and scholars report challenges of rapid technology diffusion in Africa such as people's resistance to rapid changes, fear of the Internet being used for manipulative propaganda (Pierskalla \& Hollenbach, 2013), as means of manipulating the poor (Rivers et al., 2015), and fears technology will displace unskilled workers and cause further joblessness (Amavilah, 2016). Governments in the developing countries of sub-Saharan Africa such as Angola have failed to achieve the diffusion of innovation needed to spur on economic development by keeping regional stakeholders on the periphery of policy 
making, and not allowing the voices of impoverished populations heard on their fears related to technology and innovation (Dutz, 2014; Gudmundsdottir, 2010). The specific problem is that innovation policy initiatives in Angola to combat labor market challenges through technology diffusion continue to stall among impoverished communities, where local stakeholders' views on rapid technology diffusion remain absent and unaddressed by innovation policymakers (Danquah \& Amankwah-Amoah, 2017; Ramani, Thutupalli, \& Urias, 2017).

\section{Purpose of the Study}

The purpose of this qualitative multiple case study was to gain a deeper understanding on the views of stakeholders residing within impoverished communities in Angola on rapid technology diffusion and its implication on labor market challenges within their regions. To address this gap, and consistent with the qualitative paradigm, I used a multiple case study methodology to meet the study's purpose through multisource data collection, including semistructured interviews and archival data in the form of government labor reports (Yin, 2017), and reflective field notes (Merriam \& Tisdell,

2015). I conducted methodological triangulation of the study's multiple data sources, including semistructured interviews with eight participants, journaling/reflective field notes, and archival data to establish trustworthiness of the study's data analysis and findings (Denzin, 2009; Guion, Diehl, \& McDonald, 2011).

\section{Research Question}

The primary research question for this study was: How do the views of stakeholders, residing within impoverished communities in Angola, inform innovation 
policy makers on the implications of rapid technology diffusion on labor market challenges within their regions?

\section{Conceptual Framework}

For a more in-depth understanding of policy complexities in current regional innovation debates on diffusion of innovation, to guide the purpose of this study, I developed a conceptual framework that accounts for factors of economic geography in the diffusion of innovation process within low-income countries such as Angola (Coenen, Asheim, Bugge, \& Herstad, 2017). This study was framed by two key concepts that focus on the significance of stakeholders' views on rapid technology diffusion and its implication on labor market challenges within impoverished communities in sub-Saharan Africa: Rogers's (1995) concept of diffusion of innovations; Danquah and AmankwahAmoah's (2017) concept of human capital and innovation in sub-Saharan Africa.

Rogers (2003) defined the concept of diffusion within his seminal theory of diffusion as the process by which an innovation is communicated through certain channels over time among the members of a social system. The innovation process chain takes place across creation, diffusion, and adoption and a distinction must be made between the latter two, with adoption referring to the individual process experienced by an agent (person or organization) from initial introduction to a technology, idea, or product to its ultimate adoption (Coenen et al., 2017; Pick \& Sarkar, 2016; Rogers, 2010). On the other hand, the process of diffusion has to do with analysis of the dynamics playing a role in the way an innovation spreads among adopters. As the concept of innovation is recognized to play an increasingly important role in developing countries, a 
new research subtopic bridging innovation and management studies and development studies is attracting attention. Termed inclusive innovation and defined as a link between a new invention and its widespread adoption by low income consumers (Foster \& Heeks, 2013), I looked at how innovation impacts individuals belonging to the lowest income groups (Onsongo \& Schot, 2017).

Danquah and Amankwah-Amoah (2017) developed a conceptualization and operationalization of the term human capital and innovation in sub-Saharan Africa by using Becker's (1964) general human capital theory as their theoretical foundation. The general human capital theory provided the authors with a theoretical foundation to understand the role of individuals in accelerating processes of innovation and adoption of technology. Human capital theory is about the role of human capital in the production process and the incentives to invest in skills, including pre-labor market investments (in the form of schooling) and on-the job investments (in the form of training) (Becker, 1964). Human capital refers to an individual's knowledge, skills, and experiences, which can be utilized to foster innovation activity (Becker, 1964, 1994; Schultz, 1961). At present, few empirical studies have investigated human capital for innovation and adoption of technology (Danquah \& Amankwah-Amoah, 2017). Given the importance of this subject matter, scholars recommend further investigation on the role of human capital in the diffusion of innovation in sub-Saharan Africa be carried out at the individual country level (Danquah \& Amankwah-Amoah, 2017). 


\section{Nature of the Study}

The nature of this study is qualitative so that the methodology aligns with the intent of the study. Given that the study's purpose calls for a deeper understanding on the views of stakeholders, residing within impoverished communities in Angola, on rapid technology diffusion and its implication on labor market challenges within their regions, I used an exploratory multiple case study (Yin, 2017) meet the study goals. The goal of qualitative research is to explore experiences from the viewpoint of people living within a specific context; this method is associated with the constructivist paradigm (Cooper \& White, 2012). Social constructivists look to challenge people to be more critical of their understanding of the world and themselves, thus practicing objectivity when interpreting interactions between the individual and the environment (Burr, 2003; Gergen, 1973). Qualitative research methodologies used within the constructivist paradigm help to give a voice to victims of social oppression and to their experiences with dominant cultural and social groups (Cooper \& White, 2012).

A research method that is quantitative in nature could not address the purpose of this qualitative study because it does not call for operationalization, manipulation of empirical variables, or testing statistical relationships (Harkiolakis, 2017). In quantitative data analysis, observations are coded on to a quantitative scale and different kinds of numerical methods are used to draw conclusion on the coded data (Bengtsson, 1999).

Qualitative methods, on the other hand, are used to explore real world issues, meaning that observations are analyzed without the support of numerical methods. Adopting a qualitative research method allowed for the use of nonstandardized, 
adjustable approaches to data collection and analysis that was relevant to the purpose of this study in gaining a deep understanding of the views of a specific social group, stakeholders of impoverished communities, and living within a specific social context that being in Angola, a poverty-stricken and economically unstable nation in sub-Saharan Africa (Eriksson \& Kovalainen, 2015).

A multiple case study used to explore a social phenomenon can involve individuals living within a specific social context as separate units of study (Yin, 2017). When the data focus is only on individuals, the study's central phenomenon - in this case, stakeholders of impoverished communities in Angola - is the context and not the target of study (Eisenhardt \& Graebner, 2007; Flick, 2014; Yin, 2017). Therefore, the investigation becomes a study of individuals living within a community and not the whole of the community itself. In such a study, the optimum qualitative design to retrieve data with the goal of theory building is an exploratory, multiple case study design (Eisenhardt \& Graebner, 2007).

The unit of analysis in this study was the individual stakeholder from impoverished communities in Angola. I recruited the participants for this case study using purposeful criterion and network sampling strategies (Baxter \& Jack, 2008), and screened with the following inclusion criteria: (a) adults over the age of 18; (b) male and female; (c) born and residing in impoverished communities in Angola; and (d) possessing knowledge regarding their experiences with the topic of the study. I conducted eight indepth face-to-face individual interviews with participants recruited for this study. I also conducted methodological triangulation of the study's multiple data sources including 
semistructured interviews with eight participants, reflective field notes, and archival data to establish trustworthiness of the study's data analysis and findings.

Schram (2006) recommended a range of five to 10 participants for a qualitative study, stating that a larger sample size could be a barrier to an in-depth investigation of the phenomena under study. The multiple case study design supported the study of convergence and divergence of participants' experiences within and between cases (Yin, 2017).

\section{Definitions}

Diffusion of innovation: This term refers to a process by which an adopter passes from first knowledge to an attitude toward the decision to adopt or reject to implement the innovation which for its wider acceptance is grounded in five attributes: relative advantage, compatibility, complexity, observability, and trialability (Rogers, 1995).

Digital divide: This term refers to a state of inconsistencies, inequitable, and limited access to computing facilities and resources, ICT tools and contents between individuals, households, businesses, and geographical locations, as well as discrepancies between those having the skills, knowledge, and capabilities to utilize these resources (Okunola et al., 2017).

Human capital: This term refers to a conducive element for development of knowledge and a factor of production that facilitates domestic innovation and reflects the value of human capacities (AtiqurRahman \& Zaman, 2016).

Inclusive growth/development: This term refers to a set of socioeconomic approaches that oversee a country's structural and post structural development changes 
within a reflexive evolutionary policy design that addresses development issues by promoting transparency between governments and society (Schillo \& Robinson, 2017).

Jobless economic growth: This term refers to a market economy condition in which production processes are changed or improved mostly through the intervention of technology, automation and/or robotization, and other innovation processes to increase productivity and promote economic growth, yet, at the expense of job losses and/or displacement of unskilled labor (Campa, 2014).

Labor market: This term is often associated to labor market policies of supply and demand for labor and is a major component of any economy that helps ensure that a country's socioeconomic growth is translated into employment opportunities and where a list of policy priority areas that are intricately tied in with markets for capital, goods, and services, help jobs do the most for development (Tshempo \& Ishihara, 2016).

Local area/human networks: This term refers to a social learning process through which technology is disseminated and through which policy makers and stakeholders better understand their innovation ecosystem (Nakano, Tsusaka, Aida, \& Pede, 2018).

Low-income countries: This term refers to countries that have specific features and needs that shape their macroeconomic effects of fiscal policy and are characterized by an economy with a gross national income (GNI) per capita of $\$ 1,005$ or less (Shen, Yang, \& Zanna, 2018).

Rapid technology diffusion: This term refers to an accelerated rate at which a technological innovation (an idea, object, product, or a social practice) is spread among 
potential members of a population or social system over time through the use of an existing network infrastructure (Kreindler \& Young, 2014).

Socioeconomic development: This term refers to activities involving economic factors that result in the transformation of a country's production structure that promote economic growth and changes in social structure societal progress and is often measured in both social and economic terms, for example, growth in the number of jobs created and increase in life expectancy (Litwiński, 2017).

Stakeholder: In this study, this term refers to community stakeholders, defined as people, groups, organizations, or businesses that have interest or concern in the community and who can affect or be affected by the community's actions, objectives, and policies. Examples of community stakeholders can be residents, community groups, developers, government workers (and the agencies they represent), business owners, and neighborhood leaders (Hall \& Martin, 2005).

Technological innovation: This term refers to a change in technology that is manifested through the development or improvement of a product, object, or idea and its existing architecture, that either builds on existing or shifts to a different technological trajectory (Li, Lin, Cui, \& Qian, 2018).

\section{Assumptions}

My first assumption in the study was that the use of qualitative research methods would give me a better understanding of the everyday reality and experiences of the stakeholders regarding the rapid diffusion of technology on labor market challenges in their impoverished regions. Qualitative research focuses on describing participants' views 
or perspectives. Experience and meaning are the crucial aspects for reaching a deeper understanding of the participant's perspectives in a qualitative study (Daher, Carré, Jaramillo, Olivares, \& Tomicic, 2017).

My second assumption was that the participants that I selected for interviewing had some experience of the phenomena under investigation and would be willing to share their experiences, and express interest in understanding it. Guillemin et al. (2016) argued that understanding participants' motivations to participate can lead to more successful recruitment strategy. My third assumption was that policy initiatives on the diffusion of innovations in impoverished communities of Angola involving the voices of stakeholders, residing in these regions, could offer recommendations for research and policy in support of poverty alleviation, diffusion of innovations, and socioeconomic development in the local populations (Munyoka \& Maharaj, 2017).

\section{Scope and Delimitations}

The scope and delimitations are relevant to the research problem of innovation policy initiatives failing to combat labor market challenges in an Angola's impoverished community where local stakeholders' views on rapid technology diffusion remain absent and unaddressed by innovation policymakers (Amankwah-Amoah, 2016b; Danquah \& Amankwah-Amoah, 2017; Ramani et al., 2017). I chose this problem upon reviewing the literature of Amankwah-Amoah's (2016b) and Danquah and Amankwah-Amoah's (2017) research on the long-term effects of technology and innovation and on the role of the human capital in fostering knowledge to determine the capacity to adopt innovation. Danquah and Amankwah-Amoah's research in 45 sub-Saharan African countries over 
five decades (1960-2010) revealed a decline of $0.08 \%$ for innovation and a moderate increase of $1.7 \%$ of technology adoption. Reiff (2015) concluded that there is a gap in literature that clearly states that technological innovations often end up generating economic and societal gaps, resulting in an ambiguous connection between theory, academia, and professional practice.

In order to gain a deeper understanding on the views of stakeholders, residing within impoverished communities in Angola about rapid technology diffusion and its implication on labor market challenges within their regions, the interview processes involved only those participants with some knowledge and insights into the study's central phenomena. The field investigations were, therefore, based on the study of individuals identified as affected by rapid technology diffusion in their region, that is, individuals that lived within a specific community and not the whole of the community itself. The inclusion criteria for the sample of this study were (a) adults over the age of 18, (b) male and female, (c) born and residing in impoverished communities in Angola, and (d) possessing knowledge regarding their experiences with the topic of the study.

The scope of transferability of this study is framed by Rogers's (1995) concept of diffusion of innovations and Danquah and Amankwah-Amoah's (2017) concept of human capital and innovation in sub-Saharan Africa. These key concepts determine the extent to which findings of this qualitative research are useful to other populations in different contexts. Though considered analogous to generalization, it does not carry the same meaning as that of statistical generalization (Connelly, 2016). The scope of transferability in this study was supported by rich data including a detailed description of 
the context, location, and of the people that were studied (Anney, 2014). Interview or research aspects that may hamper the transferability of results were avoided.

\section{Limitations}

In this multiple case study, the first potential key limitation was associated to the participants' limited experiences about the study's central phenomenon which if not adequate, could not have been reflective of the challenges faced and shared by the target population. I mitigated this limitation with observation in which a much sharper understanding of the participants' knowledge about the topic of interest was developed. Another limitation was the sample size which could have been small and may not be representative of the entire population. I mitigated this limitation through careful interpretation of the data and strong conclusion of results (Hacksow, 2008). The third limitation was associated with research bias, during the selection of participants and during interview or data collection. According to Pannucci and Wilkins (2010), participant selection bias usually occurs when the outlined criteria used to recruit each participant is inherently different, and data collection or interview bias occurs when information is solicited, recorded, and/or interpreted. I mitigated selection bias by selecting participants using rigorous criteria in which participants originated from the same general population. Data collation or interview bias was mitigated by standardizing the interviewer's interaction with the participants through the use of an interview protocol.

Qualitative research cannot make casual inferences because alternative explanations cannot be ruled out (Simon \& Goes, 2013). This multiple case study was 
about gaining a deeper understanding of each individual participant as unit of analysis within a specific context which in terms of transferability may not reflect the behavior of similar entities in a different context (Berg et al., 2017). Thus, transferability of research results is always a limitation in qualitative research which in this study was mitigated by including a detailed description of the context, location, and of the people that were studied (Anney, 2014).

\section{Significance of the Study}

The significance of a study addresses the need to fill a gap in theoretical knowledge (Merriam \& Tisdell, 2015). Governments in the developing countries of subSaharan Africa often ignore the voices of impoverished populations on hesitancy to accept technology diffusion within their local communities (Dutz et al., 2014;

Gudmundsdottir, 2010). This research is important to gain a deeper understanding on the views of stakeholders, residing within impoverished communities in Angola, on rapid technology diffusion and its implication on labor market challenges within their regions. This study is significant in that it may lead to a better understanding of the phenomena being studied and provide information-rich data and recommendations for future studies and policy initiatives (Patton, 2014). This study has implications for theory, practice, and positive social change.

The issue of mistrust of technology diffusion in most impoverished populations across sub-Saharan Africa is due to a belief that the government certification of the technology is based on rent seeking and private gains. Fosu and O'Connell (2006) and Fosu (2017) observed that this has remained the bane of African countries as political 
elite make national policies for private gains instead of public interest. In this case, impoverished populations become skeptical about adopting a technology and in cases where they must adopt, hence remaining quite cautious in making the decision to adopt (Fosu, 2017). To ensure the success of technology transfer it is necessary to understand the barriers of the adopter country to new technologies and/or knowledge, especially in the case of countries with sharp regional differences (Wang, Bai, \& Cheng, 2017; Whitfield, Therkildsen, Buur, \& Kjær, 2015). Although there are dozens of idiosyncratic factors that may affect a country's economic development (Noman, Botchwey, Stein, \& Stiglitz, 2011), regions are vital and crucial for the long sustainability planning of growth or productivity (Wheeler, 2009).

\section{Significance to Practice}

In practice, the Angolan growth rate is expected to be on average just $2.7 \%$ between 2016-2020, with the risk of social unrest rising due to the lack of social, health, and educational conditions especially in the most remote regions of the country (Economist Intelligence Unit, 2016). According to OECD researchers (OECD, 2014), the Angolan population demanded 4.5 million tonnes of grain per year, but the country can only produce about $55 \%$ of corn, $20 \%$ of rice and $5 \%$ of wheat it needs (OECD, 2014). According to Herrington and Kelly (2014), minimal competition, innovation, and product improvement existed amongst businesses in Angola, presupposing the importance of more high-tech enterprises. An improvement of Angola's present state calls for diversification of its economy, entrepreneurial education and training, business support services to sustain its economic growth so it can effectively compete in the regional and 
global markets. With the world collapse of crude oil price at the end of 2014, the Angolan economy has been badly affected due to the lack of diversification of productive sectors that depend largely on the oil sector, resulting in an economic crisis for Angola (OECD, 2017).

Despite recent reforms by the new elected presidency, the country continues to face enormous developmental challenges from unemployment to inequality in the living conditions across a large segment of its population (Angola Press Agency [ANGOP], 2013; Da Rocha, 2011; The World Bank, 2017b). In such an unpredictable state of everyday life for Angolans, the rapid diffusion of technology attempted by the government and private enterprise was met with local communities' resistance to rapid changes and fear of the Internet being used to manipulate the poor (Lawson, 2015) and displace unskilled workers resulting in further joblessness (Amavilah, 2016). This study is significant for practice because I obtained research results that include the voice of the poor to innovation policy makers in Angola, and other African countries characterized by poor institutional quality (Efobi \& Osabuohien, 2015). Governments in sub-Saharan Africa may achieve the results that have eluded them in the technology innovation area by involving stakeholders on the periphery of policy making than just those emerging from more central government agencies (Dutz et al., 2014; Gudmundsdottir, 2010).

\section{Significance to Theory}

From the perspective of technology diffusion theory, countries, regions, branches, and sectors are often used as analytical categories for selection environments, yet, they may fuel integration and innovation in different dimensions (Leydesdorff, Cooke, \& 
Olazaran, 2002). In this perspective, the diffusion of technology is critical for the sectoral and regional growth patterns (Castaldi \& Sapio, 2009; OECD, 2012). But according to the OECD (2012), the diffusion of technology does not happen at the same pace in every region, since productivity growth is not homogenous across countries or regions (Cozza, Ortega-Argilés, Piva, \& Baptista, 2012; Noman et al., 2011).

The disproportionate innovative efforts by the public and especially by the private sector in regions of sub-Saharan Africa reinforce the technology gap between regions enhancing a cohesion gap (Landabaso, 1997). A cohesion gap between regions are regional disparities resulted of differences in productivity and competitiveness aggravated by distinct innovation efforts in regional structures of production (Landabaso, 1997). While the theoretical literature on technology diffusion has produced contributions to seminal theories such as that of Rogers's (1995) technology-related studies on the diffusion of innovations, it excluded theoretical studies on the factors that inform technology diffusion in impoverished regions of sub-Saharan Africa (Andrés, Amavilah, \& Asongu, 2016). This study is significant to theory in that it made an original contribution to Rogers's seminal theory and concept of diffusion of innovations. The study's results guided further research in technology adoption and innovation diffusion within Angola, a nation faced with poor human capital development and an increasing proportion of the world's poorest people as well as unemployment (Ovadia, 2014; United Nations Economic Commission for Africa [UNECA], 2016). 


\section{Significance to Social Change}

This study is important because it addresses an under-researched area on why innovation policy initiatives calling for technology diffusion in Angola continue to stall rather than combating labor market challenges in impoverished communities (Danquah \& Amankwah-Amoah, 2017; Ramani et al., 2017). Political parties, businesses, families, universities, non-governmental organizations (NGOs), and civil organizations are portrayed as the key institutional players that contribute to the developmental potential of any social change initiative. Technology, and specifically the appearance of new forms of innovations, can affect social change in as much as it allows existing products and practices to be transformed (Andrés et al., 2016). Unfortunately, obstacles to social change through technological progress of African countries have been reinforced by the devaluation of local knowledge and overvaluing of foreign knowledge. In the information and communication technology field, local area networks have been considered essential, respected, and even deemed as irreplaceable (Amavilah, 2016).

Although there have been significant variations across countries in recent years, Africa has risen at a faster pace in areas such as the rise in oil revenue, yet fallen behind in promoting and supporting social change, such that inequality of both income and wealth remains widespread. In search to understand the deep causes of slow growth and change in African countries, economists have tended to overstress the importance of quantifiable economic factors (Sirine, 2017). This quantification of local economic factors has neglected the economic history of Africa. When the social impact of historical events in Africa, like the Atlantic Slave Trade and colonialism, are unaccounted for in 
research on diffusion of innovation among local communities, the overall performance picture itself remains incomplete given the critical voices of agents/stakeholders/potential users that must be accounted for through qualitative research remain absent (Amavilah, 2016; Ojo, 2015).

When institutions in a developing country devalue and undervalue local knowledge, acceptance of an innovation in that country becomes difficult (Amavilah, 2016). For technology diffusion to succeed at the local level, its compatibility with the existing social norms and trialability within a context of existing cultural practices is imperative. Additionally, technology diffusion must prove to a local community that it will be a good fit with local needs, local demand, local resources, local skills, and/or local knowledge (Lawson, 2014; Pillania, 2011). Despite government oppression, civil society still exists in Angola. Should the government begin to include civilians in policy decisions, there is a vibrant civil society ready to participate and the outlook for positive social change can be deemed hopeful (Amankwah-Amoah, 2016b). This study brought to the research foreground the voices of local populations on technology diffusion in impoverished regions of Angola, representing a promising avenue of social change by shedding a light on effects of human capital on innovation and technology diffusion.

\section{Summary and Transition}

In this chapter, I described the alignment of the study regarding the background of the literature that leads this paper into the research problem and purpose of the study. The research question is guided by the conceptual framework which followed a logical alignment between problem statement and purpose of the study followed by significance, 
assumptions, and limitations of the study, along with the definition of key terms used throughout this document. In addition, I provided insights on the potential impact of the rapid diffusion of innovations among impoverished communities in sub-Saharan Africa and the implications faced by stakeholders on labor market challenges within their regions.

In Chapter 2, I cover what this study perceives to be the most common factors influencing the job market in the sub-Saharan African region, from a detailed perspective of informal markets (Ojo, 2015) and from the unbalanced proliferation of ICT across regions. Further, the literature review explores topics closely related to the labor market challenges faced by the Angolan population, ranging from the post slave trade and postwar period reforms to stressing out ICT innovations and the role of human capital through various social applications. I identified a literature gap regarding how the rapidly diffused initiatives in the form of technology which can benefit impoverished subSaharan Africans can also cause social harm (Kianian et al., 2015; Rivers et al., 2015), resulting in an ambiguous connection between theory, academia, and professional practice is clearly identified and presented. 
Chapter 2: Literature Review

While many sub-Saharan African countries described technology and innovations as the elements best used to combat the labor market challenges (Silva et al., 2018; Ugur \& Mitra, 2017), more work is required to understand the different barriers to rapidly diffused innovation and technology which may also cause harm in the form of social disruption in local communities (Kianian et al., 2015; Matthews, 2017; Rivers et al., 2015). These contrasts drove governments in sub-Saharan Africa to stall in the diffusion of innovation needed in local communities to spur on economic development (Dutz et al., 2014; Gudmundsdottir, 2010). Reiff (2015) reported that there is no current literature that clearly defines the socioeconomic benefits of technological innovations among impoverished communities, resulting in an ambiguous connection between theory, academia, and professional practice.

The specific problem is that innovation policy initiatives in Angola to combat labor market challenges through technology diffusion continue to stall among impoverished communities, where local stakeholders' views on rapid technology diffusion remain absent and unaddressed by innovation policymakers (Danquah \& Amankwah-Amoah, 2017; Ramani et al., 2017). The purpose of this qualitative multiple case study was to gain a deeper understanding on the views of stakeholders residing within impoverished communities in Angola, on rapid technology diffusion and its implication on labor market challenges within their regions. 


\section{Literature Search Strategy}

The purpose of this narrative literature review is to summarize previous and current knowledge about diffusion of technological innovations in developing countries and provide readers with a comprehensive overview of the gap in literature that will help place the discipline into perspective. This narrative approach allows for a wider perspective into the research topic because it allows for the synthesis of text-based understanding of the study's central phenomenon to provide a strong description of the predominant issues identified in the body of literature (Lam, Kwong, Hung, Pang, \& Chiang, 2018). My decision to undertake a narrative approach was based on the diversity of the literature review in a discipline area which has been organized to gain a wide perspective on the challenges and experiences of stakeholders of Angola's impoverished communities.

The materials and articles used in this research originated primarily from scholarly peer-reviewed journals. The Walden University research library and many other library databases and search engines were used to conduct the literature review. The databases include Emerald Insight, ABI/INFORM Collection, ScienceDirect, Business Source Complete, Wiley Online, PsycINFO, SocINDEX, Academic Search Complete, ProQuest, ACM Digital Library, IEEE Xplore Digital Library, and Google Scholar. I focused primarily on the last 5 years to ensure that the analysis made was based on the most recent articles. The key terms used were diffusion of innovation, technology diffusion, technological economic growth, technological employment, jobless economic 
growth, information and telecommunications technology (ICT), digital divide, socioeconomic development, developing countries, labor market, and human capital.

Most of the key terms used were coupled together in order to get additional and more directive results. The combined search terms included diffusion of innovations and developing countries, technological employment and economic growth and sub-Saharan Africa, jobless and technology and developing countries, jobless economic growth and technology, digital divide and economic development and sub-Saharan Africa, technology and social development, human capital and labor market and sub-Saharan Africa, technology and employment challenges and developing countries. The search strategy involved using the terms above with all sort of combinations in all the databases noted above. This approach returned a wide variety of sources within various disciplines of literature to identify peer-reviewed articles on the topic and confirm the need for the rationale of this study. Today, a review of the diffusion of innovation literature is very important given that results confirm that ICTs in developing countries work better once coupled with factors such as human capital (Albiman \& Sulong, 2016).

\section{Conceptual Framework}

For a more in-depth understanding of policy complexities in current regional innovation debates on diffusion of innovation, a conceptual framework should be developed that accounts for factors of economic geography in the diffusion of innovation process within low-income countries such as Angola (Coenen et al., 2017). This study is framed by two key concepts, Rogers's (1995) concept of diffusion of innovations and Danquah and Amankwah-Amoah's (2017) concept of human capital and innovation in 
sub-Saharan Africa, which focuses on the significance of stakeholders' views on rapid technology diffusion and its implication on labor market challenges within impoverished communities in sub-Saharan Africa.

Rogers (1995), in his seminal theoretical work on the diffusion of innovations, proposed that relative advantage, compatibility, complexity, observability, and trialability are important attributes of an innovation for its wider acceptance. Acceptance of an innovation in a developing country in turn depends on its compatibility with the existing social norms and trialability within a context of existing cultural practices, a good fit with local needs, local demand, local resources, local skills, and/or local knowledge (Lawson, 2014; Pillania, 2011). The innovation process chain takes place across creation, diffusion, and adoption and a distinction must be made between the latter two, with adoption referring to the individual process experienced by an agent (person or organization) from initial introduction to a technology, idea, or product to its ultimate adoption (Coenen et al., 2017; Pick \& Sarkar, 2016; Rogers, 2010). The process of diffusion has to do with analysis of the dynamics playing a role in the way an innovation spreads among adopters.

The diffusion of innovation incorporates the adoption process of many people over a period of time (Rogers, 1995). Given the risk of innovation and its related cost and accumulative nature, ground-breaking innovation is not as likely to take place in lowincome countries, where innovation of an imitative and incremental nature may instead come into play. As innovation is recognized to play an increasingly important role in developing countries, a new research sub-topic bridging innovation and management studies and development studies is attracting school attention. Termed inclusive 
innovation and defined as a link between a new invention and its widespread adoption by low income consumers (Foster \& Heeks, 2013), scholars performing research into this sub-topic investigate how innovation impacts individuals belonging to the lowest income groups (Onsongo \& Schot, 2017).

Economic and management sciences literature carry a wealth of evidence on how important knowledge in general and ICT innovation in particular is to economic development (Asongu, Boateng, \& Akamavi, 2016; Kwan \& Chiu, 2015). There is agreement among scholars regarding mutual influence of the flow between knowledge and economic development. Neoclassical economic development models regard knowledge and technology as public goods that develop independently of the economic system. In contrast, new economic development has been grounded in endogenous interpretations as well as neo-Schumpeterian views of economic development (Howells, 2005). In keeping with such a new perspective on growth models, technological advancement has been regarded as the result of active citizen engagement and/or investment that is realized through mobilizing necessary resources associated with human capital (Romer, 1990).

As an interdisciplinary field, research and literature on diffusion of innovation is wide ranging and marked by heavy fragmentation (Nath \& Murthy, 2018). The different approaches to diffusion of innovations can be easily discerned and distinguished through their different focuses and perspectives on particular aspects of diffusion. Economics, marketing, anthropology, and sociology offer major contributions, with a leading theory relevant to the topic of this research being Rogers's (1995) diffusion of innovations 
theory. Examining innovations from a multitude of perspectives, this noteworthy work has continuously evolved and influenced many research initiatives (Coenen et al., 2017). Rogers's theory has provided a foundational basis for the development of many models that endeavor to elucidate the factors that contribute to whether or not individuals and/or organizations adopt and share an innovation (Efobi \& Osabuohien, 2015).

Rogers's (1995) defined innovation as an idea, a practice, or an object that an individual or other adopter perceives as new; it considers the processes of innovationdevelopment and innovation-decision, the attributes of innovations as well as their rates of adoption, the various categories of adopters, and topics related to leadership and change agents and innovation in firms (Melkote, 2006). Rogers also emphasized how trust between actors, which often is not captured in empirical estimations, may be associated with different forms of innovation. In fact, trust has an important function of binding and bridging mechanism in social relations that ultimately may facilitate information exchange and collective knowledge creation (Matthews, 2017). It should be noted here that Rogers (1995; Rogers, Medina, Rivera, \& Wiley, 2005) often used the terms innovation and technology as synonyms, defining technology as a design for instrumental action that reduces the uncertainty in the cause-effect relationships involved in achieving a desired outcome.

The innovation-decision process, according to Rogers (1995), is the process through which an individual or other decision-making unit passes from first knowledge of an innovation to forming an attitude toward the innovation, to decision to adopt or reject to implement the idea. Rogers noted that diffusion researchers in the past tended to regard 
all innovations as equivalent units from the viewpoint of study and analysis. That all innovations are not equivalent units is evidenced by the fact that some new products fail and others succeed.

Hall's (2004) review on diffusion of innovation claimed that most of the studies that have looked at the diffusion of innovations in developed countries used some variations of the theoretical framework provided in Rogers's (1995) seminal book Diffusion of Innovations. Rogers (2003) conceptualized the factors that influence the diffusion of innovations and described the attributes that affect the decision of potential adopters of innovations. According to Rogers (2003), diffusion is the process by which an innovation is communicated through different channels in a certain period of time among the members of a social system. Three factors are involved in the diffusion: the innovation must have a nature suitable for the context in which it is spreading, vectors of communication diffusion must be in place in order to transmit information, and stakeholders within a social system must assemble a network or system which implements the innovation. Rogers (2003) based his work on studying and observing the diffusion of innovations in developed countries. Outdated or resource-constrained national innovation systems in developing countries do not meet the original objectives for which they were designed. Diffusion and creation of innovation in developing countries is also restricted by weak institutional relationship between private and public sectors (Coenen et al., 2017).

Theoretical researchers agreed that the factors affecting economic growth and social development in sub-Saharan African countries are in part correlated to technology 
innovation (Kshetri, 2016; Ovadia, 2014). Although technology can greatly benefit impoverished sub-Saharan Africans and has been touted as a social change phenomenon across the continent, researchers also argued about the potential of rapidly diffused initiatives in the form of technology to also cause harm (Kianian et al., 2015; Rivers et al., 2015). Sub-Saharan Africa has not experienced an adequate amount of technological diffusion, which could be traceable to low investment in education and research activities (Efobi \& Osabuohien, 2015). Before a technology can be adequately adopted and accepted in the society as suitable to enhance human effort, the technology must be adequately diffused, and before any technology can be adequately diffused in the society, the question of benefit comes to play (Rogers, Takegami, \& Yin, 2001). This is crucial because economic agents will be ready to invest resources in $R \& D$ when they are sure that they can get returns.

Danquah and Amankwah-Amoah (2017) developed a conceptualization and operationalization of the term human capital and innovation in sub-Saharan Africa by using Becker's (1964) general human capital theory as their theoretical foundation. Becker's (1964) theory provided a theoretical foundation to understand the role of individuals in accelerating processes of innovation and adoption of technology. Human capital theory is about the role of human capital in the production process and the incentives to invest in skills, including pre-labor market investments (in the form of schooling) and on-the-job investments (in the form of training). Human capital refers to an individual's knowledge, skills, and experiences, which can be utilized to foster 
innovation activity (Becker, 1964, 1994; Felício, Couto, \& Caiado, 2014; Kwan \& Chiu, 2015; Schultz, 1961).

Human capital has a significant effect on productivity growth because of its role in determining an economy's capacity to diffuse technological innovation among all population segments (Romer, 1990; Schillo \& Robinson, 2017; Zanello et al., 2015). At present, few empirical studies investigated human capital for innovation and adoption of technology (Danquah \& Amankwah-Amoah, 2017). These studies were mostly focused on the developed OECD countries, with only a few studies on developing countries (Ang et al., 2011; Danquah \& Ouattara, 2014). The empirical evidence largely concurs that human capital strengthens a country to develop its own technological innovation, and also increase its capacity to adopt the already existing knowledge to enhance productivity and economic growth. Given the importance of this subject matter, further investigation is recommended on the role of human capital in the diffusion of innovation in subSaharan Africa be carried out at the individual country level (Danquah \& AmankwahAmoah, 2017).

Today's economists expected development in low-income countries to be modern, contemporary, and inclusive in nature, without preferences to any specific group or stakeholder (Altenburg, Lundvall, Joseph, Chaminade, \& Vang, 2009). Yet, a study conducted by Lingelbach, Sriram, Mersha, and Saffu (2015) on the economic development and diffusion of innovation in impoverished sub-Saharan African countries, revealed political preferences to certain groups as well as human capital differences, resulting into some kind of digital divide. Non-inclusive economic and technological 
development ignites conflicts between rich and poor, rural and urban, educated and uneducated, upper and lower social classes, indigenous and modern societies in these low-income African countries (Danquah \& Amankwah-Amoah, 2017). The diffusion of innovations must be supported by social values to propel regional economic development in impoverished regions of sub-Saharan Africa and local stakeholders drive such changes (Nipo, Bujang, \& Hassan, 2017).

Amavilah (2016) argued that obstacles to technological progress and economic growth in some African countries cannot be properly explained without a profound understanding of the interplay between (a) relevant authoritative elements of religion and their role in the economic growth of civilizations, (b) the deinstitutionalization and loss of traditional economic institutions, and (c) the undervalued local knowledge in favor of foreign knowledge. The diffusion of innovations model is concerned with how innovation, defined as new knowledge or practices, is spread through a population (Lawson, 2014; Pillania, 2011; Rogers, 2004). Scholars concur that religion and economic sciences in general do mobilize knowledge, while technology, as a multidimensional agent of social change, applies knowledge through its innate characteristic that allows it to be diffused through any social system. For the hopeful message of technology to be diffused within impoverished African communities, it must be understood and accepted from the perspective of local human networks (Sirine, 2017; Stier, 2017). 


\section{Literature Review}

\section{Labor Market Challenges in Sub-Saharan Africa}

Researchers at The World Bank (2016a) defined labor market challenges in

developing countries as declining rates of labor force participation, pockets of unemployment, underemployment and high informality within regional communities. From a sub-Saharan Africa perspective, the concept is often related to informal market economies that have existed prior to slave trade and colonialism and are rooted in capitalist economic systems without any ties to modern capitalist development or government regulations (Ojo, 2015; Medina, Jonelis, \& Cangul, 2017; Mramba, Rumanyika, Apiola, \& Suhonen, 2017; Ogbuabor \& Malaolu, 2013). Some researchers characterized this type of market as marginal, lacking knowledge and skills to compete in the formal market and therefore contributing to a widespread of regional unemployment (Chen, 2014). Others considered it as the response to poverty and unemployment, a driver for job formation, an incubator for potential businesses, and promoter of the formal market (Nguimkeu, 2014). But in natural resource-based economies as it is with many sub-Saharan African countries, employment creation is not left to one economic agent of significance alone, say for instance the public bureaucracy but also to the informal sector from which regional dwellers derive their livelihoods (Papyrakis, 2014; Salla, 2016).

Porta and Shleifer (2014) argued that the expansion of the formal market should lead to a decline of the informal, yet, at the expense of massive job losses due to the massive unskilled and uneducated labor force of the informal market. According to economists, the informal sector in developing countries absorbed the majority of the 
workforce; about $60-90 \%$ of the overall employment statistics is concentrated in this market (Nguimkeu, 2014). Researchers at the OECD showed that informal economic activities can restrain a country's economic growth by negatively impacting the quality of jobs, yet in sub-Saharan Africa it accounts for three-quarters of jobs (Munro, 2011). In spite of the workforce volume of the informal market, researchers reported that this sector produced only $10-40 \%$ of a developing country's GDP (Nguimkeu, 2014). Thus, the uncertainty about formal and informal employment opportunities continued to be a rising factor of jobless economic growth in sub-Saharan Africa (Campa, 2014; Shiferaw \& Hailu, 2016; Zachary, 2011).

Researchers characterized the living conditions of many African communities as poor, with overcrowded housing, high levels of unemployment and underemployment, deficient urban services such as sanitation, electricity, access to water, education, and health and a widespread on insecurity (Duflo, Galiani, \& Mobarak, 2012). Researchers at The United Nations Habitat report from 2016 (UN-Habitat, 2016), showed that in subSaharan Africa about 55\% of the urban population is still living in slums without access to basic services. Researchers characterized Africa as the continent where the economy's main backbone is agriculture, with the largest percentage of the people being poor farmers (Assefa, Alemneh, \& Rorissa, 2015). Researchers at the International Labour Organization (ILO, 2012) and the OECD (2014), revealed that about 60-65\% of the African population relies on farming and agriculture as their main occupation. Many of the African macroeconomic policies are too heavily focused on export commodities leaving them over-dependent on a few industries (Chinembiri, 2010; ILO, 2012), and 
thus, job creation and labor productivity becomes vulnerable to global financial crisis (Duygun, Isaksson, \& Kaulich, 2016).

It is argued that labor market challenges in sub-Saharan Africa are the results of technological advances and innovations attributes (Kshetri, 2016; Ovadia, 2014). In subSaharan Africa ICTs have been considered as the main determinant of economic growth with positive and significant impact on labor productivity (Cruz-Jesus et al., 2016;

Lovrić, 2012). Yet, the effective role of ICTs in sub-Saharan Africa can only be perceived if one understands the barriers of the adopter country beyond simple access to technology, especially in the case of countries with significant regional differences. Researchers highlighted that heterogeneity across different regional communities exert a negative impact on a country's socioeconomic development, regions therefore, play an important role for the long-term sustainability planning of growth and productivity (Norman \& Stiglitz, 2012; Whitfield et al., 2015). Researchers' reports from the OECD showed that the access to ICT infrastructures does not happen at the same pace across every region because productivity and growth are not homogenous across countries or regions (Cozza et al., 2012; OECD, 2012).

Most regions are composed by old and unsuitable institutional structures, lack of law and regulations, scarce capital, lack of technological education, inappropriate supply behavior of economic agents, and a huge disparity between the livelihood of the rich and poor (Chattopadhyay \& Mondal, 2016; Lovrić, 2012; Nguimkeu, 2014). Instead of inclusive access to ICT infrastructures and services, access is rather inequitable (CruzJesus et al., 2016; Mutula, 2008; Salla, 2016). Some scholars argued that employment 
opportunities in sub-Saharan Africa are somewhat limited because of the fixed human capital stock since only a small number of migrated technology-educated laborers can find jobs (Chattopadhyay \& Mondal, 2016). Yet, such obstacles were continuously reinforced by the devaluation of local knowledge and overvaluing of foreign knowledge (Amavilah, 2016). Researchers then consider important the complex social issues surrounding various sub-Saharan African populations, including economic background, access to housing and other social infrastructures, access to materials, social resources, training and education (Freiman, Martinovic, \& Robichaud, 2018; Gudmundsdottir, 2010).

\section{Labor Market Challenges in Angola}

With a population of 29.25 million people, the Angolan Institute of Statistics registered the 2018 unemployment rate in Angola at 20\% (Ine.gov.ao, 2018; TradingEconomics.com, 2018). Fertile in natural resources, Angola is an oil and gas production dependent economy from which related activities account for $85 \%$ of its GDP (Silva, Roque, \& Caetano, 2015). Angola is located on the west coast of southern Africa with an area of $1,246.700 \mathrm{~km}^{2}$ that was discovered by the Portuguese explorers in 1482 , becoming then a trade link with Southeast Asia and India and later a major source of slave trade for Portugal's colonies in Brazil and Caribbean (Nakabashi et al., 2013; Ojo, 2015; Silva et al., 2015). With the end of the slave trade by 1878 (Ball, 2017), an uprising between Angolan national liberation movements in 1950 led to a civil war conflict that lasted 27 years, which culminated to Angola's independence in 1975 and the end of the armed conflict by 2002 (Baumgartner, 2016a; Silva et al., 2015). 
The end of the armed conflict led the Angolan government to engage in post-war reconstruction programs financed mainly from the oil revenues (Baumgartner, 2016a; OECD, 2014; Silva et al., 2015). Among the reconstruction priorities were public policy reforms, consolidation of institutions, establishment of a fiscal system, infrastructure constructions, and the development of an economic diversification program (Cortes, Roberto, \& Dias, 2014; Neto \& Jamba, 2006; Taylor, 2014). Yet, a situation report suggested that most of these reforms were more a reflection of the need to adapt to change to maintain the neopatrimonialism control of the state rather than genuinely open Angola's political space to ideas of good governance (Roque, 2011).

Researchers claimed that there was mismanagement of public funds being routinely made that characterized the corruption in Angola as rife, with an economy based on rent-seeking, generating high levels of social inequalities, and with strong preferences for resource redistribution (Africa News Service [ANS], 2014; Barros, 2012; Kolstad, Wiig, \& Chivunda, 2017; Warf, 2017). A study conducted in 178 countries by the Heritage Foundation (2014) on rule of law, fiscal dependency, government spendings, regulatory efficiency, and open market, found Angola as a repressed country scoring 47.7 points out of 100 (ANS, 2014). The researchers also highlighted the existence of a weak rule of law regime, with low quality institutions that are mainly focused on protecting the power of the political elite and that altogether undermine the successful implementation of critical reforms (Bennett, Faria, Gwartney, \& Morales, 2017; Kurronen, 2015). Angola was listed in the international transparency reports among the most corrupt countries in the world, ranking in the $5^{\text {th }}$ position in sub-Saharan Africa (Transparency.org, 2014). 
The forward projections of the Angolan government regarding its economy growing amongst the higher growth rate economies worldwide, made it highly vulnerable to corruption and oil price shocks since it relied on oil revenues alone for its economy backbone (Bhattacharyya \& Hodler, 2010; Baumgartner, 2016a; International Monetary Fund [IMF], 2015).

Despite the financial efforts, the remarkable recovery for over 40 years of independence, increase in oil production and investments in many sectors Angola was still being regarded as one of the world's richest poor countries ((Baumgartner, 2016a; OECD, 2014; Power, 2011). In return for oil supplies, Angola became China's most strategic trade partner in Africa with a bilateral trade volume of US $\$ 24.8$ billion in 2010 with an FDI program to help rebuild Angola war-torn infrastructure (Alden \& Large, 2015; Cain, 2017; Power, 2011; Tembe \& Xu, 2013). Yet, it was reported that there is an absence of employment opportunities in the oil industry and the population has benefited little from it with almost no forward or backward linkages with the onshore economy, as such, researchers regarded the Angolan oil industry as an enclave (Golub \& Prasad, 2016; Power, 2011). In spite of the creation of a Special Economic Zone (ZEE) to stimulate growth and alleviate the unemployment pressure, a reduction in the country's unemployment rate was still not visible (The World Bank, 2016a).

With 28.35 million people, Angola is a low-income country characterized by a young population with a total labor force of 12.29 million people aged 15 to 64 , with a growth rate of $3.85 \%$ in 2010 and a decrease of 3.39\% in 2017 (The World Bank, 2017b). According to the Angolan Institute of Statistics (Info-Angola.com, 2018), over 16 million 
people are concentrated in urban areas, whereas less than 10 million lived in the rural areas with agriculture as the dominant activity (OECD, 2015). Research suggests that the decline in the importance of agriculture in the rural areas may be due to the expansion of non-farm activities as processes of economic development (Davis, Di Giuseppe, \& Zezza, 2017). Some researchers believed that the concentration of the large population in the urban areas was due to the fact that the civil war forced a significant migration of people from the countryside that generated an urban growth of $15 \%$ from 1970 to $62 \%$ in 2014 (OECD, 2015). Others were convinced that the different social classes (Udelsmann, 2017), the weakened educational system, and the nonpromotion of local content composes the chronic of the high rate of unemployment since the skilled-labor market was very tight with a labor force mean for education of 4.4 years, in line with low human development countries (Ovadia, 2014; Tordo, Warner, Manzano, \& Anouti, 2013).

Researchers at the OECD (2015) showed that the labor market conditions in urban areas have deteriorated over the years, along with the population's living conditions. In spite of the efforts to reduce poverty, the UNDP poverty report for 2013 showed poverty as being particularly high among the urban slum populations of Angola (Barros, 2012; UNDP, 2013), ranked $149^{\text {th }}$ out of 187 countries in the 2014 UNDP report index. The lack of jobs was the most pressing issue in the whole of Africa majorly due to health issues and lack of employable skills (OECD, 2014). A more recent report from OECD researchers revealed that Angola still needs urgent investments in its human capital, majorly in the health and education sectors (OECD, 2017b). UNDP researchers for 
Angola listed the human inequality coefficient situated at $36.6 \%$ and characterized in the low human development category (UNDP, 2016).

The national industrialization program highlighted seven key subareas from which Angola should concentrate investments in order to transition from a least developed country to a middle-income category to better combat poverty and unemployment (OECD, 2017b). Yet, a few structural bottlenecks were still hindering Angola's labor market along with economic diversification and consequently the wellbeing of the Angolan population (OECD, 2017a). Among the subsectors were the share of manufacturing value added in the Angola GDP that remained low at 8.6\%; the entrepreneurial activities that stand low at $21.5 \%$ hindered by heavy infrastructure deficiencies; the agriculture sector which covers $70 \%$ of the population and accounted for only $12 \%$ of the GDP; and industrialization declined by $3.9 \%$ (OECD, 2017b). Included in the report was that the agriculture sector was weakened by low productivity due to low use of fertilizers, difficulties in accessing credit, low managerial skills, broken access roads, limited access to electricity and irrigation schemes.

Researchers suggested that a country's geographic distribution can have an indirect influence on the economic performance through its role on institutional development (Bennett \& Nikolaev, 2016). Despite Angola being a member of the Economic Community of Central African States (ECCAS) and Southern Africa Development Community (SADC) and its geographical location offering potential for inter-regional trade in mining and agriculture, and in spite of over 45 signed commercial trade agreements being made, Angola export earnings declined by 34\% (OECD, 2017b). 
Imports fell by 55\% which depreciated the local currency (the Kwanza) and limited the consumer demand; exports declined by $34 \%$ and FDI programs declined significantly (OECD, 2017b).

According to researchers, natural resources may lower a country's economic performance and the efficiency of the public sector regarding employment because they foster rent-seeking activities (Bhattacharyya \& Hodler, 2010). Heavy dependence on exports was pointed as one of the factors that hindered development and industrialization because the volatility of this sector can make other labor sectors less competitive (Baumgartner, 2016a; Habiyaremye, 2013). Scholars argued that slavery and bonded labor system can exert a persistent impact over centuries and can create social structures that impede the development even long years after independence (Bezemer, Bolt, \& Lensink, 2014). Another important market challenge to emphasize is that the structures inherited from colonialism were mainly focused on the production and extraction of basic raw materials (Warf, 2017). Thus, in the post-independence era almost everything was owned by the state and the Angolan economy did not have autochthonous entrepreneurs that could address the world market challenges so as to lead the necessary diversification of the Angolan economy (Neto \& Jamba, 2006; Unruh, 2012).

\section{The Diffusion of Innovation in Developing Countries}

Rogers (1995) in his seminal theoretical work on the diffusion of innovations proposed that relative advantage, compatibility, complexity, observability, and trialability are important attributes of innovation for its wider acceptance. Acceptance of an innovation in a developing country in turn depends on its compatibility with the existing 
social norms and trialability within a context of existing cultural practices, a good fit with local needs, local demand, local resources, local skills, and/or local knowledge (Lawson, 2014; Pillania, 2011). Researchers believe that if such factors are accounted for, innovation will certainly induce inclusive structural change, poverty reduction, increase multi-sectoral productivity, growth, and socioeconomic development since growth and development are expected to be inclusive in nature (Asongu, 2015; Asongu \& Nwachukwu, 2018a; Asongu \& Nwachukwu, 2018b; Ciarli, Savona, Thorpe, \& Ayele, 2018; Gumede, 2017). Yet, scholars argued that for developing countries where agriculture accounts for $60 \%$ of the continent's workforce, ICT innovations are producing nothing more than weak and ambiguous evidence of its role toward economic growth (Niebel, 2018; OECD, 2017).

The literature on economic development suggested that sub-Saharan Africa can achieve growth and inclusive development when structural changes occurs through the interplay of labor productivity and technological innovations across different sectors (Page, 2012). The literature also stressed that ICT innovations constitute the backbone of sustained long run growth and are a potential enabler of productivity (Cirera, Lage, $\&$ Sabetti, 2016; Niebel, 2018; Osakwe \& Moussa, 2017). According to Schmidt and Huenteler (2016), ICTs can help developing countries shift from traditional methods of productivity by speeding up learning processes and knowledge creation according to their local demands. Despite the adoption of technology and associated learning processes being declared difficult to measure, researchers have considered education and 
technological innovation policies to be the key areas to Africa's development (Norman \& Stiglitz, 2012).

Technological innovations have long been regarded as the most significant criterion of growth and development for both developed and developing countries, and education as the means to getting to know and achieving the desired innovations (Hamidi, Ghorbandordinejad, Rezaee, \& Jafari, 2011). Yet, researchers highlighted the importance of identifying the commonalities in technological platforms that account for government support, policy frameworks and knowledge transfers (Biseswar et al., 2012). These commonalities provide strong links between industry and academia which are relevant for policymakers and knowledge generators (Biseswar et al., 2012; Osakwe \& Moussa, 2017). Industry because it contributes to structural change, firstly, because it is a high value-added multisector that generates labor and, secondly, oversees large productivity differences between sectors, and that often requires reallocation of man labor power from less efficient to more efficient firms (Page, 2012). It also promotes product diversification, sophistication, and competitiveness which further influences productivity and growth and redefines a country's export structure, leading it to achieving a higher income per capita (Page, 2012).

The elasticity of ICT in sub-Saharan Africa is nonetheless positive; the impact on the other hand, is very small (Cirera et al., 2016). The reasons for the weak and ambiguous empirical evidence on the impact of ICT innovations in developing countries vary. Researchers argued that it may be driven by the lack of high-quality micro- and macro-level data on ICT, of appropriate level of human capital, of budgetary provisions 
in research and development, late ICT adoption, lack of supporting infrastructure (Cirera et al., 2016; Niebel, 2018; Osakwe \& Moussa, 2017; Saidi \& Douglas, 2017).

Researchers concluded that in order to sustain Africa's growth needs, there is a need to increase technological capabilities and know-how, some researchers even argued that innovations in its every aspect is all that is required for Africa (Adesida \& Karuri-Sebina, 2013; Schmidt \& Huenteler, 2016).

It has been argued that a wider understanding of science, technology, and innovations within a social context that is determined by stronger cultural values and beliefs, local practices and needs is what lacks in Africa (Saidi \& Douglas, 2017). Researchers have continuously shown that social values, culture, and norms are the dynamic constructs for labor productivity and represent the fundamental source of economic development (Li, Park, \& Selover, 2017). This suggests that a better understanding of the relationship between social inequality and growth should lead to a better conception of the impact of ICT diffusion of innovations on the socioeconomic development of developing countries (Aissaoui, 2017). The interplay between ethnic groups, the undervalued local knowledge in favor of foreign, and the deinstitutionalization of the traditional economic institutions has also been highlighted as one of the major obstacles to technological diffusion and economic growth in some African countries (Amavilah, 2016). The overall goal is that the relationship between technology, innovations, and the society should be contextualized, strengthened, and driven in the notion of solving the very problems and challenges faced by the immediate local populations (Saidi \& Douglas, 2017). 
In developing countries, technological innovations often function as multidimensional agents of social change that focuses on applying knowledge to its immediate user community. The model for user acceptance of technological innovation is often based on two theoretical constructs, perceived usefulness and perceived ease of use (Lee, 2013). For some African countries, researchers suggested that technological progress should be understood from the perspective of local human networks (Amavilah, 2016). A recent research emphasized this concept from a social learning perspective as means to disseminate technological innovations through social learning networks particularly in production sectors (Díaz-josé, Rendón-medel, Govaerts, Aguilar-Ávila, \& Muñoz-rodriguez, 2016; Nakano et al., 2018). Researchers then suggested that in today's globalized world, Africa requires that conventional forms of ICT diffusion and knowledge generation be of inclusive nature, context driven, human centered, effective, accountable, result oriented, and utmost able to generate social benefits (Saidi \& Douglas, 2017).

In a general sense, economic development through ICT provisions is not automatically translated into higher levels of social progress, and the policies that promote growth through ICT have to be complemented with other policy measures to foster social inclusion (Osakwe \& Moussa, 2017). One reason for this hard translation is that many ICT policy makers struggle to convert these nuanced concepts into practical policy interventions that should underpin development and betterment in the lives of the most disadvantaged (Diga et al., 2013). In many developing countries the government acts as the key facilitator of innovations; in Africa, governments have been connoted by a 
weak institutional relationship between public and private sector (Asheim, Coenen, Bugge, \& Herstad, 2017; Biseswar et al., 2012). Researchers considered a collaboration between government and other research councils to be a strategic move, which places innovation at the center of the key players/stakeholders in policy formulation, knowledge generation, and diffusion (Biseswar et al., 2012).

Innovators recognize the role of technology in fostering innovation and the challenges needed to create the structural support for a robust ecosystem for innovations yet, they are also aware that the element of novelty creates both economic and social uncertainties (Rogers, 2003). In developing countries, some of these uncertainties were said to be linked to knowledge sharing and learning processes (Nicotra, Romano, \& Del Giudice, 2014). Chen (2014) noted that part of these uncertainties are strongly related to the imbalances of technological advances especially in what refers to the creation of jobs and extensive use of capital-intensive technology. Yet, the literature on poverty and ICT in Africa suggested that key mechanism to support the adoption of innovations amid such uncertainties, lies in making ICT content, services, and infrastructure more accessible and suitable to low-literacy impoverished communities (Diga et al., 2013). Researchers, therefore, considered the demographic and socioeconomic profile of the people, such as income, gender, age, education, and so on, to make decisions to adopt technological innovations as long as these factors address their specific household needs (Tigabu, 2017).

\section{The Promise and Challenge of Diffusion of Innovation in Sub-Saharan Africa}

The elements that promote economic development and social prosperity in sub- 
Saharan Africa have been referred to as being linked to the diffusion of innovations (Kshetri, 2016). Technology, particularly, has been widely promised as the catalyst element for economic progress and social innovations among Africa's underdeveloped countries (Matthews, 2017; Mokyr, Vickers, \& Ziebarth, 2015). The role of diffusion of innovations in sub-Saharan Africa that could ultimately benefit African populations and promote economic prosperity is fundamentally built on different trends—notably, on the role of major sectors such as the entrepreneurship sector, the agricultural sector, and on the water and energy sector (Asongu \& Nwachukwu, 2018b; Glover, Sumberg, \& Andersson, 2016; Stambouli et al., 2014). According to the authors, these sectors are the ones that ultimately sustain the standard of living of every African population by directly combating unemployment and preventing poverty.

GhaffarianHoseini, Tookey, GhaffarianHoseini, Naismith, and Rotimi (2016) noted that the problem does not lie in the scarcity of resources, but in the inequitable distribution of the available resources. Some researchers suggest that the efficient allocation of economic resources is determined by region-specific and costs for doing business (Asongu \& Nwachukwu, 2018b). These are often driven by a plethora of factors, namely entrepreneurship, capital, labor, markets, infrastructure system, ICT, and so on.

For most African countries, technological innovations have become a prerequisite and the promise for achieving a fairer and more sustainable development. It has been reported that innovations can secure a future of equitable distribution of resources among different sectors such as telecommunications, health, education, and more important economic sectors such as that of water, energy, and agriculture (Glover et al., 2016; 
Tigabu, 2017). But from Matthews's (2017) perspective, the concept of diffusion of innovations does not just use the word technology, it oversees constructs beyond the word technology. Innovations can be conceived as the outcome from a useful and productive engagement of human capital and relevant resources (Oluwatobi, Efobi, Olurinola, \& Alege, 2014). As means for adaptation and improvement, innovations seek to find solutions to common problems usually through the development and practical applications of new knowledge, materials, and tools across different regional sectors and economic applications (Glover et al., 2016; Matthews, 2017).

Researchers in Africa's entrepreneurship sector, for example, suggested that worldwide economy integration is indispensable for Africa's development in an era of globalization (Oluwatobi et al., 2014). Scholars argued that the economic trend that is prevalent in African is strongly dependent on investments in new technology, hightechnology industries, and skilled labor, which are essential ingredients for the development of a knowledge-based economy (Tchamyou, 2016). Additionally, literature showed that the growing unemployment rate would be mostly accommodated by the entrepreneurship from the private sector which exceeds $50 \%$ of the young labor force and remains among the highest in Africa (Brixiova, Ncube, \& Bicaba; 2015; Ncube, Shimeles, \& Verdier-Chouchane, 2013). The promises are that the promotion of knowledge-based entrepreneurship holds high potential for the improvement and development of other sectors such as that of agriculture, water and energy, and technology (Tchamyou, 2016). For Tchamyou (2016), the value-added technology-based services in these sectors are essential for economic prosperity and adaptation to the 
challenges of unemployment, poverty, and globalization.

In the technology sector for example, more particularly in the mobile telephony coupled with internet, Reed (2016) noted an around one billion user increase in the subscription of this service, projected to reach 1.33 billion by 2021 . These technologies promise significant business opportunities and development that can build up service delivery systems that harness mobile technologies (Amankwah-Amoah, Osabutey, \& Egbetokun, 2018). The knowledge constraints, however, especially the lack of technology skills and poor basic infrastructure constitute the major barriers to firm-level innovation and knowledge construction in the African continent (Adeyeye, Egbetokun, Opele, Oluwatope, \& Sanni, 2018).

The agricultural sector in Africa for example, is currently the continent's largest employer accounting for $60 \%$ of the entire continent's workforce (Minde et al., 2015; OECD, 2017). Countries in the sub-Saharan region did not catch the advances in technology and are for this reason characterized as having an ineffective agriculture and inadequate infrastructure (Baumgartner, 2016b). Additionally, technological development in this segment competes with other high-profile sectors such as education and health for policy attention and investment (Glover et al., 2016). Despite the deficiencies, this sector was conceived as a fluid assembly of both technical and social change components (Crane, 2014).

The educational challenges, on the other hand, confront the entire agri-food system development in sub-Saharan Africa. It is estimated that between the years 2010 and 2040 approximately 712 million youth will enter the labor market in sub-Saharan 
Africa (Minde et al., 2015). Though the sector does not require higher technological education than post-farm segments, researchers reported that only $6 \%$ of this number are university graduates and only this specific percentage will be able to respond to the top tier agri-food system labor force (Minde et al., 2015).

The water and energy sectors have been challenges for sub-Saharan Africa's socioeconomic development. Though these sectors constitute the basic elements toward sustainable development, sub-Saharan Africa has lagged far behind in providing its population with access to electricity infrastructure (Stambouli et al., 2014). Researchers revealed that only $14 \%$ of rural and $63 \%$ of urban residents were electrified until the year of 2010 (Nicolina et al., 2013).

There is a growing promise that renewable energy technologies can meet the needs of the African poor countries and ensure environmental sustainability, as long as local governments support the widespread diffusion of these technologies (Tigabu, 2017). Local governments believe that by investing in emerging technologies they will be addressing environmental sustainability challenges and at the same time creating local conditions for innovation and enhance global competition (Amankwah-Amoah et al., 2018). The lack of access to modern energy services and infrastructures still, therefore, remains one of the top daunting development challenges affecting at least 600 million people in Africa (Traoré, Markley, \& Zebdi, 2017). Economic growth is an approximate indicator of human well-being and development, and researchers believe that such development necessitates access to modern energy technologies (Calvin, Pachauri, De Cian, \& Mouratiadou, 2013). 
With the advent of globalization and the proliferation of knowledge economies, researchers have regarded institutions as adequate channels for technology transfer, trade, investments, and knowledge flows (Oluwatobi, Ola-David, Olurinola, Alege, \& Ogundipe, 2016). Yet, it is reported that in Africa, there is a significant gap in the amount of infrastructure needed to support these institutions' economic and technological activities that can help them deliver their sustainable development goals (Mckinsey, 2016). According to Egbetokun, Atta-Ankomah, Jegede, and Lorenz (2016), the infrastructure gap in terms of electricity for example, has lagged behind compared to other developing regions with a huge inequality in terms of rural-urban coverage estimated in 31 billion dollars per year. Mckinsey (2016) estimated that projections on Africa's infrastructure development to support institutions on the diffusion of innovations will remain comparatively low in relation to other developing economies. According to Salami, Kamara, and Brixiova (2010), the constraints on infrastructure accounted for at least $75 \%$ of total agricultural jobs in Africa's subregion.

Tigabu (2017) argued that the decision to adopt innovations in the aforementioned economic sectors in sub-Saharan Africa is based on the community's characteristics and technical attributes. On an earlier study, Kabanda (2014) mentioned that innovations as a process are usually embedded in the local conditions of the developing country. These include the adopter's socioeconomic and demographic profile such as financial condition and education as well as the fears that technology will not meet the adopter's needs in terms of costs and technical problems (Gebreegziabher, Mekonnen, Kassie, \& Köhlin, 2012; Tigabu, 2017). 


\section{Challenges to Rapid Changes and Diffusion of Innovation}

Lewis's (2013) in his seminal work on economic growth suggested that innovation is among the basic means to boost a country's economic development. Researchers suggested that for Africa, innovations would require a rapid and effective adoption of technologies that have the capacity to unlock the potential of industries, combat poverty and unemployment by fostering entrepreneurship and inclusive development (Amankwah-Amoah, 2014). Danquah (2012) on the other hand, believed that human capital and domestic ICT policies form the important factors that determine the capacity to rapidly absorb and implement new and effective technologies in Africa's impoverished communities.

The human capital perspective. Within the concept of human capital, Danquah (2012) found that for developing countries, human capital accompanied with government policies are prerequisites to ICT roles in fighting poverty through faster innovation initiatives (Albiman \& Sulong, 2016; AtiqurRahman \& Zaman, 2016). Researchers defined human capital as individual's knowledge, skills, expertise, and abilities that allow for rapid changes to be put in action which can further result in economic growth through formal education (Felício et al., 2014; Kwan \& Chiu, 2015). Empirical evidence largely demonstrated that human capital enhances the ability of a country to develop technical innovation and also increase the capacity to adopt already existing knowledge (Danquah \& Amankwah-Amoah, 2017). A study conducted by Amankwah-Amoah (2016a) in subSaharan Africa, revealed that the concept of human capital represents a promising avenue to shed light on innovation and on the rapid adoption of technologies in impoverished 
communities.

Due to the lack of important development factors including affordable educational systems and infrastructures, certain African populations have come to perceive technology as a double-edged sword (Rivers \& Rivers, 2013; Tchamyou, 2016). Scholars reported challenges of rapid technology diffusion in Africa such as people's resistance to rapid changes and fear of the Internet being used for manipulation and propaganda (Pierskalla \& Hollenbach, 2013). Fears have also been reported regarding potential negative impact of ICTs disclosure on the poor when modern ICTs such as communications systems are controlled by powerful groups and rapid integration into the global economy could result in exploitation (Diga et al., 2013; Njoh, 2018). While the key aspects of human capital is knowledge and skills embodied in people, researchers suggest that skilled individuals have the advantage of accelerating productivity with technological innovations (Danquah \& Amankwah-Amoah, 2017). Unskilled workers, on the other hand, are left in a disadvantageous position, causing their further disqualification, exclusion, and consequently unemployment (Aissaoui, 2017; Mutula, 2008; Oyedemi, 2012). Considering the aforementioned scenario, Kruger (2017) suggested that technological progress may be biased with respect to certain production factors through cross-region, social, and technological differences that could either benefit the skilled or the unskilled worker. In sub-Saharan Africa, social inequalities that resist change and resulted in limited access to ICTs infrastructure and inadequate education have been extensively discussed (Park, Choi, \& Hong, 2015). In his study, Oyedemi (2012) revealed that the concept has been regarded as an important barrier to 
social inclusion, affecting many African families in what concerns income, health services, gender inequalities, and so on.

Researchers, therefore, agreed that the rapid technological absorptive capacity of a country is in turn dependent on the level of education and flow of literacy, and advanced human skills of the host economy (Glas, Hübler, \& Nunnenkamp, 2015). The lack of adequate human capital, inclusive and equitable quality education and literacy poses one major setback for Africa's rapid change on the diffusion of innovation segment (Amavilah, 2016; Asongu \& Le Roux, 2017). Asongu and Nwachukwu (2018a) argued that societies that have pursued policies driven toward a knowledge economy have done so with an adequate level of human capital and quality education systems. According to the authors, these have been documented as valuable assets at enhancing inclusive development that are more likely to successfully confront the challenges of resistance that today's globalization poses to development.

The domestic ICT policies perspective. According to The World Bank (2012) reports, in most developing countries, particularly those of low-income, the decreased investment was accompanied by a policy vacuum. Danquah (2018) suggested that policy initiatives be directed toward boosting national efficiency by focusing on domestic stakeholders' capacity to absorb technology in order to reduce the vacuum. Albiman and Sulong (2016) suggested that government policies be combined with human capital to function as prerequisites to ICT roles in driving economic growth in developing countries. The authors also added that policy makers should formulate policies that ensure that investments focus on ICT channels, namely, human capital, institutional 
quality and on local stakeholders' investment.

Recent literature on ICT policy initiative stated that ICT in advanced economies such as that of Asia, North America, and Europe, is reaching levels of saturation, and that there is more room for ICT penetration in sub-Saharan Africa (Afutu-Kotey, Gough, \& Owusu, 2017; Asongu, 2013). Amankwah-Amoah (2016b) and Asongu, Le Roux, and Biekpe (2018) believe that this promising potential should be leveraged and implemented in combination with community stakeholders and policy makers to ensure formulated policies address the challenges that hinder local development. Danquah (2018) adds that the lack of adequate scholarly attention on new technologies utilizations in sub-Saharan Africa constitutes a factor that hinders policy initiatives on rapid technology development.

Literature has long suggested that policy formulation entails research and development activities with focus on human development and building of infrastructures (Amankwah-Amoah, 2016b). Yet, for some researchers, the problem resided in the translation of socioeconomic and political nuances affecting ICT provisions in developing countries (Gomez \& Pather, 2012). Mothobi and Grzybowski (2017) highlighted that the development of infrastructures constitutes the ground foundation to measure ICT policy outcome, apart from just macroeconomic development variables.

The World Bank (2012) prospectus estimated that from the year of 2010 focus on ICT policy implication and analysis for Africa would be highly needed. The report also suggested that as the African core economics sectors deepen, policy and regulatory development tends to become more difficult due to the speed of technological change. 
Diga et al. (2013) suggested that the first point of contact should be a top-down delivery of infrastructures that would lead to a positive impact on people's lives with economic benefits. Policy makers aligned with this approach would then have to favor the supplyside interventions focusing at maximizing the efficiency of technology roll-out and the capabilities of the ICTs being delivered, enabling the integration of poor people's communities into global trade networks. Chen, Wakeland, and Yu (2012) suggested that the solution to an effective ICT policy formulation and implementation would probably involve the contributions of all of the interested parties with forward-looking activities by governments to help foster technology utilization and economic development.

The economic and institutional perspective. Within the context of sub-Saharan Africa, the promises for better socioeconomic activities have been said to reside within its institutions because they comprise a system of policies and regulations that have the ability to direct economic operations that further imply innovations (Oluwatobi et al., 2014). Yet, African researchers revealed a significant gap in the amount of infrastructures needed to support these institutions' economic and technological activities that can help them deliver sustainable development goals (Mckinsey, 2016). For such reasons, institutions in Africa have been characterized as embryonic and their development very challenging (Fosu, 2013). Rohracher, Truffer, and Markard (2009), suggested that by analyzing the institutional context of the target country including infrastructure, labor market conditions, business operational risks, logistics, mining, and so on, may help identify and assess the strategies and pathways for the future of innovation systems. According to the Business Monitor International's (BMI, 2018a) research on 
infrastructure, Angola suffers from inadequate financial infrastructure and a very weak energy supply that serve as deterrents to businesses aiming to enter the market. A SWOT analysis conducted by the BMI in 2018, revealed the following:

1. Corruption in Angola remains high and there is an unfriendly business environment that hinders foreign and domestic private investment;

2. As an oil and gas production dependent economy with related activities accounting for $85 \%$ of its GDP (Silva et al., 2015), the 2015/2016 slump in the crude prices has negatively affected revenues, causing the government to cut infrastructure spendings (BMI, 2016); and

3. Electricity supply and transport networks are still underdeveloped and the continued low crude prices continue to threaten the government's ability to invest in infrastructure.

The BMI researchers on an infrastructure research report estimated $2.5 \%$ of real growth for that year of 2016 and a 5.1\% growth for the 10-year forecast (BMI, 2016). The 2018a report registered a marginal reduction of the forecast in industry growth to $4.0 \%$ from $4.1 \%$ due to the removal of Angola's currency peg to the U.S. dollar which according to the reports will see a spike in inflation and potentially undercut industry growth and also deter investments (BMI, 2018a). The researchers concluded that the country's heavy reliance on oil revenues with low levels of foreign investment hinders its ability to diversify its economy and the wider development of infrastructure assets (BMI, 2018a). 
Researchers at The Human Capital Research Platform (2015) within the context of the labor market risks in Angola revealed that the unemployment rate in Angola decreased to $25 \%$ in 2013 from 26\% in 2011, which characterized Angola by a chronic and overwhelming imbalance between the supply of and demand for jobs (Human Capital Research Platform, 2015). Angola has one of the least attractive labor markets in Southern Africa, a factor that according to the BMI (2018b) report, significantly hinders the country's economic progress and diversification efforts. The report also reveals that the lack of investments in education with a very small portion of the Angola labor force that has not even completed secondary education, without any international recognized university, makes the country have one of the poorest labor forces in the Southern African region (BMI, 2018b).

The major weaknesses and threats in the SWOT analysis conducted by the BMI researchers in 2018 (BMI, 2018b) on the Angola labor market risks revealed the following:

1. Over $80 \%$ of the working-age population are employed in the agricultural sector, and therefore do not possess vocational skills that are highly required to Angola's extractives-orientated economy;

2. The low life expectancy diminishes the size of the labor force and increases costs;

3. A low education attainment rate generates huge gaps in urban versus rural and female versus male, consequently the poor-quality education fails to equip students with the adequate skills to find jobs; 
4. The high minimum wages drive up employment costs and the high unemployment rates decrease consumer demand; and

5. The restrictions established by the government on hiring foreign knowledge increases the cost of hiring expatriates, leaving businesses reliant on training lowskilled Angolan workers.

On average, the researchers at BMI state that despite having one of the largest working-age population in the Southern region with a relatively high formal workforce participation about $60 \%$, Angola performs poorly in terms of the size and costs of its labor force (BMI, 2018b). Additionally, the $60 \%$ of the labor force being employed in the formal sector is significantly reduced if other sectors that boost the highest employment rates in Angola are assessed. Despite that, the report states that the country also performs poorly in relation to the labor flexibility due to the extreme difficulty that Angola law imposes to hire foreign skilled workers (BMI, 2018b).

The BMI (2018e) research on the country risk report reveals that the economy is subject to instability including high inflation, currency fluctuations, and commodity price shocks. The Angolan economy has a huge structural dependence on oil revenues with oil exports accounting for $90 \%$ of total exports and around $70 \%$ of total government budget revenues (BMI, 2018c). Angola is currently struggling with one of the highest debt servicing cost in Africa, a margin above which the IMF considers sustainable (BMI, 2018c). The inflationary pressures persist and may be exacerbated through imported price pressures because Angola's narrow economy relies mostly on foreign goods. An eventual 
decline in the crude prices will put further pressure on government budget and trade deficits (BMI, 2018c).

Researchers at the BMI (2018d) on the logistics risk report, revealed that Angola's potential to position as a regional trade hub is hindered by the heightened levels of bureaucracy and time required to import and export goods. Angola's transport network is the poorest in the Southern Africa region which is considered a logistic risk. The limited supply of water poses risks to businesses operations. The market growth is heavily dependent on the international price of the crude oil which renders the entire economy vulnerable to external price shocks. Researchers concluded that all businesses in Angola are faced with severe logistical risks from the availability and reliability of basic utilities (BMI, 2018d).

The rigidities in the current economic environment and institutional setup in most sub-Saharan African countries and the fact that infrastructure services are about $100 \%$ more expensive compared to other regions makes African countries hard for technology uptake (Egbetokun et al., 2016). Most African countries have been reported to have old and unsuitable institutional structures, lack of law and regulations, scarce capital, lack of adequate education, inappropriate supply behavior of economic agents, and a huge disparity between the livelihood of the rich and poor (Chattopadhyay \& Mondal, 2016; Lovrić, 2012; Nguimkeu, 2014). Mudombi and Muchie (2014) and Ndichu, Blohmke, Kemp, Adeoti, and Obayelu (2015) concluded that due to the informal mechanisms of most African institutions such as the lack of control of corruption and accountability, and the fact that institutions have become less important sources of knowledge, Africa is not 
favorable for any meaningful innovation (Osabutey, Williams, \& Debrah, 2014).

\section{Socioeconomic and Technology Challenges to Diffusion of Innovation in Angola}

The recently-established Policy of Science, Technology and Innovation of Angola (Política Nacional de Ciência, Tecnologia e Inovação [PNCTI], 2011; published in Portuguese) highlighted significant information on the state of science, technology, and innovation within the country. The report rereleased expert policymaker and scientific opinion on a lack of coordination between the various stakeholders of research and scientific, technological development and innovation, on how technology initiatives and endeavors should be dispersed within the National System of Science, Technology and Innovation (SNCTI) in order to reach the wider Angolan population (Ngunga, 2018). This lack of coordination among national stakeholders, including the impoverished citizenry, which makes up $48 \%$ of the whole population (Multidimensional Poverty Index [MPI], 2018), continues to challenge the optimum diffusion of innovation across Angola. International reporting agencies such as the BMI (2017) insist that inconsistent technology development activities and practice results in a lack of national infrastructure across all of Angola's provinces, thwarting broad range integrated actions toward innovation and technology development (BMI, 2017a).

New numbers were published in 2018 for Angola by the Oxford University's leading center on multidimensional poverty, Oxford Poverty \& Human Development Initiative (OPHI, 2018). The global Multidimensional Poverty Index (MPI) monitors 10 indicators, such as school attendance, child mortality, and safe drinking water. These indicators are grouped across three dimensions: education, health, and standard of living 
(Asongu \& Kodila-Tedika, 2017). This is the first time Angola's MPI has been updated since 2001 , showing that $48 \%$ of the country's population were classified as poor across 18 provinces. Angola's updated MPI suggested the country achieved a significant reduction in poverty over the last 15 years. According to Angola's 2001 MPI, more than $77 \%$ of the population was multidimensionally poor (Fosu, 2017). Among the 10 indicators, the largest contributors to poverty in Angola today are deprivations in years of education (16\%), followed by school attendance (15\%) and nutrition (11\%). All indicators improved significantly since 2001. The MPI complements income measures (OPHI, 2018). The latest available World Bank figures for income poverty in Angola, from 2008, showed that $36.6 \%$ of the population is income poor (World Bank, 2018). Angola's population is currently estimated at 29.25 million. Angola's MPI was calculated with Demographic and Health Surveys (DHS) data collected between 2015 and 2016 by the National Institute of Statistics. The goal of publication of these statistics by The World Bank (2017) and the OPHI (2018) is for economists and policymakers to utilize the MPI's statistics to guide public policy and investments to fight poverty, the pivotal challenge to diffusion of innovation in Angola (OPHI, 2018).

The numbers in the 2014 census which estimated the Angolan population size hovering at 25.789 .024 , revealed that $62 \%$ of this number constituted the population living in the urban areas, whereas $37.4 \%$ living in the rural areas. Among the 18 provinces (Bengo, Benguela, Bie, Cabinda, Cunene, Huambo, Huila, Cuando Cubango, Cuanza Norte, Cuanza Sul, Luanda, Lunda Norte, Lunda Sul, Malange, Moxico, Namibe, Uige, and Zaire), the capital province of Luanda and the province of Cabinda exhibited 
the highest sustainability values, $38 \%$ and 33\% respectively (EFFA, 2016; Ine.gov.ao, 2014). About $72 \%$ of people corresponding to about three quarters of the population are concentrated in only seven provinces of the country (EFFA, 2016, p. 32; Ine.gov.ao, 2014). Among these, five are in the south-central region of the country, with $39 \%$ of inhabitants corresponding to two fifths of the country's population. The province of Luanda is the most populous with $27 \%$ of the people representing little more than a quarter of the population of the country. The provinces of Huíla, Benguela, and Huambo with more than 2 million residents, with $10 \%, 9 \%$, and $8 \%$ respectively. With less than 2 million people each, are the provinces of Cuanza Sul with 1.881 .873 residents, Uíge with 1.483.118, and Bié with 1.455.255 (EFFA, 2016; Ine.gov.ao, 2014). The Angola secretary to the institutional affairs recognized the challenges of raising the rate of urbanization of the population of major urban centers competing with other conjunctural and structural factors have not always been accompanied by measures of urban organization, control, and management (Angonotícias.com, 2015).

The census also revealed that of the $100 \%$ (5.442.685) of the population living in urban areas, only $55.7 \%$ (2.997.548) were employed; of the $100 \%(2.445 .137)$ of the population residing in the rural areas, only $44.9 \%$ were employed (EFFA, 2016, p. 59; Ine.gov.ao, 2014). The unemployment rate for these urban areas were of 76,6\% and $23.4 \%$ for the rural areas respectively. The economically active population in the urban areas constitutes $60.3 \%$ of the entire urban population, while in the rural areas only $35.9 \%$ of the population is economically active. Lunda Norte and Lunda Sul were the provinces that exhibited the highest rate of unemployment, $43 \%$ and $39 \%$ respectively. 
The employment rate is the ratio of the employed population aged 15 years and over to the total population aged 15 years or over. This important indicator measures the ability of a country's economy to provide employment for the country's growth. In 2014, the employment rate for the entire Angolan territory hovered at 40\% (EFFA, 2016, p. 61; Ine.gov.ao, 2014). The recent numbers from the TradingEconomic (2018) showed that the unemployment rate in Angola dropped to $19.9 \%$ in 2016 and increased to $20 \%$ in 2018. Agriculture and fishing are the most represented economic activities in the country, concentrating mainly in the province of Cuanza Sul with $70 \%$. The predominant sectors of the province of Luanda are commerce (10\%), administrative and support services $(8 \%)$, transportation, construction (7\%), and storage and communication (6\%). By 2014 , only $46 \%$ of the households had practiced some agricultural activity. The BMI report suggests that the potential created by the country's large working-age population is fairly irrelevant, given that the only major exporting industry in the country is the oil sector, which is capital and not labor-intensive (BMI, 2018f).

Despite the relatively high rates of urbanization that provide investors with a more accessible workforce (BMI, 2018f), and despite several efforts to integrate ICTs in Angola's education system (Oloruntoba \& Muchie, 2019; PR Newswire, 2013), Angola still has one of the least attractive labor markets in the Southern region, with a significant lack of investment in education, research, and development by the Angolan government (Oloruntoba \& Muchie, 2019), with significant gaps in rural versus urban educational attainment (BMI, 2018f). These numbers place the country in the second-to-last place out of 13 Southern African countries with the worst education system, with only $16 \%$ of the 
entire population aged 6 to 17 having completed primary and secondary school education, and only $20 \%$ out of $100 \%$ for tertiary education which is still below the Southern African regional average of $12.3 \%$ (BMI, 2018f). Net enrolment rates at secondary school level currently stand at a very low $13.5 \%$ and $8.5 \%$ in 2015 for tertiary education - the lowest out of all 13 Southern African countries. The estimations are that a little over $20 \%$ of the Angolan labor force has obtained secondary education or above (BMI, 2018f).

Access to basic sanitation is reserved to only $60 \%$ of the entire territory with $82 \%$ covered in the urban areas and only $26 \%$ in the rural areas; the province of Cunene is well below the national average, with only $12 \%$ of households using adequate toilets (EFFA, 2016, p. 71; Ine.gov.ao, 2014). Only 32\% of households have access to electricity from the public network: $50.9 \%$ is attributed to the urban areas and only $2.2 \%$ of the rural population have access to public electricity network. Only $44 \%$ of households have access to appropriate sources of drinking water. Among the provinces, there is a significant difference in access to appropriate drinking water. The province of Cunene has the lowest value, where only $23 \%$ of the population has access to drinking water, followed by Lunda Norte at 26.7\%, Lunda Sul at 28\% (EFFA, 2016, p. 70; Ine.gov.ao, 2014).

About $37.5 \%$ of the Angolan population over the period of 2013 to 2014 had access to broadband cellphone communication; $10.2 \%$ had access to Internet, and only 9.9\% had access to computers (EFFA, 2016, p. 58; Ine.gov.ao, 2014). BMI researchers revealed that the Angolan mobile market with only two major mobile operators, grew by 
just $0.7 \%$ to reach a little over 14.4 million subscriptions (BMI, 2017b). The mobile market duopoly has continuously resulted in negative consequences for investment, innovation, and consumer choice, and the fixed-line market has shown no growth over the last few years (BMI, 2017b). Further, the report suggests that Angola's mobile market has stalled. The strong adoption of mobile data services by regional standards is now due to concentrated usage of mobile services among Angola's wealthier consumers in urban areas, while many rural communities are still excluded from network coverage or unable to afford the very high cost of traditional voice services (BMI, 2017b). Researchers at the BMI also predict that the number of broadband subscribers which are heavily dependent on the government through the incumbent operator to invest on the terrestrial networks will increase from $2.5 \%$ to $3.1 \%$ by end of 2021 with a penetration rate of $4.4 \%$ (BMI, 2017b).

OECD researchers believed that sectoral issues on innovation and integration in less technology developed African countries include the aspects of the manufacturing and agriculture sectors with the knowledge flows accounting with the informal economy sector (Oloruntoba \& Muchie, 2019). These contributors concluded that while innovation may be a national or regional undertaking, strong dynamics of innovation generation in regions are crucial for achieving national and regional growth objectives (OECD, 2013). Their application, however, is best understood when the productivity and manufacturing sectors of these countries increase interaction with more advanced countries in term of imports of capital goods that embody technological knowledge (Oloruntoba \& Muchie, 2019). Policymakers consider regional dimensions and actors that can support innovation 
that is relevant for their specific regional context. The economic and innovation ties often span regional administrative borders to include international, thus, promoting crossborder regional innovation policies (OECD, 2013).

OECD countries have always struggled to know how best to promote regional innovation (OECD, 2013). Some researchers suggest that in the context of African developing countries with a special case to Angola, the challenges of education, income, and life expectancy play a crucial role in the creation of innovative and technical knowledge, in advancing the living conditions of millions of individuals (Goncalves, Oliveira, \& Cruz-Jesus, 2018), and in the promotion of regional integration (Oloruntoba \& Muchie, 2019; Ngunga, 2018). For Angola, university education can produce significant benefits, such as technology catch-up that may lead the country to a rapid economic growth (Ngunga, 2018). However, the struggles of Angolans have strong roots on the purpose of perpetuating the African values; and these are fueled by cultural traits that exhibit a number of differences that span throughout the country (Ngunga, 2018). These cultural traits often lead to a digital divide and promotion of inequality between regions and individuals between regions within countries, which according to Goncalves et al. (2018) are in part fueled by differences in income and educational levels.

\section{Stakeholders' Concerns on Rapid Diffusion of Innovations in Sub-Saharan Africa}

The diffusion of innovations must be supported by social values to propel regional economic development in impoverished regions of sub-Saharan Africa and local stakeholders drive such changes (Nipo et al., 2017). On one hand ICTs have shown to promote socioeconomic growth, but on the other hand researchers report that the linkages 
between ICTs and the promotion of individual or community quality of life remain uncertain (Adera, Waema, \& May, 2014). In the whole of Africa, agriculture has been characterized as the economy's backbone, with the largest percentage of the people being poor farmers (Assefa et al., 2015). Researchers at ILO (2012) and OECD (2014) revealed that about $60-65 \%$ of the African population relies on agriculture as their main occupation. For technology diffusion to succeed at the local level, its compatibility with the existing social and economic norms and trialability within a context of existing cultural practices is imperative and must be able to prove to a local community that it will be a good fit with local needs, local demand, local resources, and local skills (Lawson, 2014; Pillania, 2011).

For stakeholders particularly smallholder farmers, rural communities in subSaharan Africa are plagued with constraints, from poorly farming organization, limited access to market, inadequate financing, weak infrastructure such as poor access to electricity, absence of irrigation systems, to poor access to communication infrastructure, roads and transport networks (Porter, 2014; Sheahan \& Barrett, 2014). Generally, smallholder farmers' concerns fall under a few major factors namely, (a) on the rate at which technological innovations shape their local communities because innovations tend to replace traditional labor practices which can cause exclusion; (b) on the potential socioeconomic benefits and constraints; (c) on the lack of skilled labor or cost associated with the availability of skilled labor; (d) on the limited access to cash resources such as bank credit; and (e) on lack or limited access to proper infrastructure (Abdallah, 2016; Kolade, Harpham, \& Kibreab, 2014; Langyintuo \& Mungoma, 2008; Moser \& Barrett, 
2003; White, Labarta, \& Leguía, 2005).

The successful socialization with ICT requires stakeholders' engagement, as it allows them to provide input into and deliberate on the use of ICTs in their communities (Saidi \& Douglas, 2017). In the rural regions of sub-Saharan Africa smallholder farmers have been credited as the major stakeholders that promote economic development by providing around $80-90 \%$ of food in developing countries (Sobratee \& Bodhanya, 2017; Stewart et al., 2015). Agricultural technologies have, therefore, been considered key to poverty alleviation in sub-Saharan Africa, yet, Mwangi and Kariuki (2015) argued that the diffusion of new technologies in the sector remains low in developing countries. The reasons vary, ranging from economic and social to institutional factors (Akudugu, Guo, \& Dadzie, 2012; Silva \& Broekel, 2016).

For underdeveloped economies like the ones of sub-Saharan African countries, improving the productivity and sustainability of smallholder farmers is crucial to increase individual income and alleviate poverty. Yet, stakeholders have shown concerns regarding the availability and affordability of these technologies and on expectations of long-term profitability promised by these new technologies (Silva \& Broekel, 2016). For smallholder farmers achieving productivity increases depends largely on agricultural intensification usually through automated or mechanized systems. Researchers suggested that agriculture intensification implies a production system that is characterized by either high inputs of capital and labor or heavy usage of technologies which are heavily reliant on the availability of banking credit (Abdallah, 2016; Kolade et al., 2014; Sheahan \& Barrett, 2014). Unfortunately, sub-Saharan African countries lag behind in supplying 
financial aid to poor and vulnerable farmers (Abdallah, 2016; Kasirye, 2013). Africa has been characterized as a fundamental source of inefficiency in credit with collateral impact in the form of valuable assets like land, farms, cattle, and so on (Abdallah, 2016). In developed markets, access to bank credit has been said to facilitate the diffusion of new technologies and production methods (Bircan \& Haas, 2015).

Stakeholders' concerns have also been directed toward the potential socioeconomic benefits and constraints as innovations tend to replace traditional labor practices and production methods. Unfortunately, traditional agricultural practices in subSaharan Africa still rely in human power (Sheahan \& Barrett, 2014). Stewart et al. (2015) argued that technological interventions in the farming business emphasize the introduction of new methods of production such as biotechnological agricultural innovation, products, materials, and services that according to Ton et al. (2013) may lead to the conceptions of new industries. Concerns therefore fall under the need for training interventions, building capacities for technical skills and understanding, acquiring new managerial practices with emphasis on facilitating knowledge transfers on topics of technology and innovation in agriculture that may benefit farmers and create linkages with other firms and institutions (Stewart et al., 2015).

The failure to promote agricultural growth and sustainable development in the rural regions of sub-Saharan Africa has also been associated to the challenges pertaining to geographic remoteness and sparseness of the rural communities while setting up agricultural communications network (May, Karugia, \& Ndokweni, 2007). These included poor or limited access to communications infrastructure such as access to phone 
lines, internet connections that causes economic circumstances for both providers and members in the agriculture industry. For this reason, researchers believe that it is pertinent that specific areas within the agriculture business be address by ICT policy. Mwangi and Kariuki (2015) suggested that in order to enhance technology adoption by farmers, it is important that policy makers and investors of new technology understand farmers' needs as well as their ability to adopt technology in order to come up with technology that will suit them. These pertain to poverty and end-user competencies, knowledge management and information generation, research and development, the price of technology and the cohesion between government departments directly affecting ICT initiatives and policies on access to micro-credit institutions (Kolade et al., 2014).

\section{The Literature Gap in Studies on Rapid Diffusion of Innovations in Sub-Saharan}

\section{Africa}

The innovation process chain takes place across creation, diffusion, and adoption and a distinction must be made between the latter two, with adoption referring to the individual process experienced by an agent (person or organization) from initial introduction to a technology, idea, or product to its ultimate adoption (Coenen et al., 2017; Pick \& Sarkar, 2016; Rogers, 2010). Yet, the process of diffusion has to do with analysis of the dynamics playing a role in the way an innovation spreads among adopters. Given the risk of innovation and its related cost and accumulative nature, groundbreaking innovation is not as likely to take place in low-income countries, where innovation of an imitative and incremental nature may instead come into play.

Very few researchers have listed the visible benefits of the rapid growth of ICT 
diffusion in low-income countries that focus on human development and align with ICT policies with some wider development-planning objectives. A study by Diga et al. (2013) emphasized the need to consider multidimensional models of poverty in which to incorporate ICTs in Africa. The context in which these models were analyzed, focused on two major constructs, namely on the institutional arrangements and on policy mechanisms to end monopolism in African societies so as to reduce the digital divide generated by ICTs on the poor when ICTs are controlled by powerful groups (Diga et al., 2013). According to the authors, the discourse focused on delivering infrastructure that would impact people's lives by focusing on macro-economic benefits, rather than including a diverse mix of micro-level factors underpinning improvement in the life of the most disadvantaged. The development of infrastructure to support ICT policies has been extensively discussed by Amankwah-Amoah (2016b).

The policy mechanisms addressed by Diga et al. (2013) and Gurumurthy (2010) involved liberating control of ICTs from repressive governments to ensure inclusion of marginalized groups. One of the models of poverty highlighted by Diga et al. (2013), included making ICT contents more accessible to the poor by facilitating both contents and services in local language to suit low-literacy communities. Yet, the authors acknowledge that there is lack of significant engagement with the content of these policies. In his study, Amankwah-Amoah (2016b) argued that the lack of collaboration between local stakeholders and local government makes it difficult for policies to become effective and even implemented.

The findings of Diga et al. (2013) revealed that ICT policy interventions with a 
continued dominance in economic factors coupled with a technology deterministic policy tend to increase the capabilities amongst the most disadvantaged by downplaying social factors. For practical implications the study emphasized the importance of participative approaches to ICT implementations that if well adapted by policymakers could lead to a more contextually anchored ICT supported poverty alleviation within different dimensions of poverty. May, Dutton, and Munyakazi (2014) investigated six dimensions of poverty using an econometric model to demonstrate that ICTs can contribute positively to poverty reduction. Yet, researchers argued that studies on ICT on poverty reduction in sub-Sahara Africa remain incomplete and stakeholders often question if ICTs are a worthwhile option for poor communities (May et al., 2014).

Researchers argued that today a similar gap still exists between ICTs expectations and evidence of the contribution of internet technologies to development and poverty alleviation in developing countries (Galperin \& Viecens, 2017). With continuous research emerging in Africa in the diffusion of innovations literature, within a context of pervasive corruption, unreliable infrastructure, and shortage of skills, scholars are focusing on maximizing the value of ICTs rollout among impoverished communities. The innovators who have succeeded in Africa flout the conventional wisdom by building franchises to serve the poorest communities of the population; internalizing risk to create strong, selfsufficient, and low-cost enterprises (Christensen, Ojomo, \& Van Bever, 2017).

While the theoretical literature on technology diffusion has produced contributions to seminal theories such as that of Rogers's (1995) technology-related studies on the diffusion of innovations, it excluded theoretical studies on the factors that 
inform technology diffusion in impoverished regions of sub-Saharan Africa (Andrés et al., 2016). A literature gap also exists on research in technology adoption, the rapid diffusion of technological innovations, and the labor market challenges within Angola, a nation faced with poor human capital development and an increasing proportion of the world's poorest people as well as unemployment (Ovadia, 2014; UNECA, 2016).

\section{Summary and Conclusions}

With a population of 29.25 million, the Angolan Institute of Statistics (Ine.gov.ao, 2018) registered the latest unemployment rate in the country hovering at $20 \%$ (TradingEconomics.com, 2018). Researchers agree that the factors affecting labor market challenges and economic development in sub-Saharan African countries such as Angola are in part correlated to the diffusion of innovation (Kshetri, 2016; Niebel, 2018; Ovadia, 2014; Sirine, 2017; The World Bank, 2016b). In some sub-Saharan African countries, the labor market response is tied to the technological composition of the country's industrial sector (Alvarez \& Marin, 2013; Shiferaw \& Hailu, 2016). The adverse impact of technology on either creation and/or displacement of jobs has been a matter of controversial discussions among economy disciplines. Economy theories suggested that technology reduces the amount of production resources including capital and labor (Vivarelli, 2014). But the long-term contradictory effects of the diffusion of technological innovations have also been observed from futurologist perspectives outlining the social consequences of technological automation and robotization (Campa, 2014).

Technology as a multidimensional agent of social change applies knowledge through its innate characteristic that allows it to be diffused through any social system or 
body (Rogers, 2003). Technological progress in developing African countries can best be understood at the intersection of governments, citizens, and economic actors that represent an ecosystem of stakeholders that can disseminate technological innovations within a local human network (Díaz-josé et al., 2016; Nakano et al., 2018; Omwenga, 2016; Stier, 2017).

In Chapter 3, I discuss the methodology for the qualitative, multiple case study designed to fulfill the purpose of the study and provide data for the central research question. The sampling rationale and method followed by the method of data collection is also detailed in the chapter. Finally, the logic for the study and methodological support for the data collection and analysis is provided. 


\section{Chapter 3: Research Method}

The purpose of this qualitative multiple case study was to gain a deeper understanding on the views of stakeholders residing within impoverished communities in Angola on rapid technology diffusion and its implication on labor market challenges within their regions. I used semistructured interviews with a sample of Angolan stakeholders residing within impoverished communities in Angola to meet the purpose of this research. I additionally used ICT policy documents in the form of government labor reports as well as reflective field notes to explore the specific stakeholders' experiences on the rapid diffusion of innovations and labor market challenges within their regions.

I conducted eight in-depth, face-to-face individual interviews with Angolan stakeholders residing within impoverished communities in Angola. A gap in research literature is identified among scholars in African developing countries on the relationship between general ICT diffusion of innovations and socioeconomic development (Aissaoui, 2017; Tayo et al., 2015; Ugur \& Mitra, 2017). Other researchers have also examined the linkages between ICTs and the promotion of individual or community quality of life (Adera et al., 2014; Diga et al., 2013; Kariuki, 2015; Saidi \& Douglas, 2017). Despite all the previous studies, this research is original and significant in that it addresses an underresearched area on innovation policy initiatives calling for technology diffusion in Angola that continue to stall rather than combating labor market challenges in impoverished communities (Danquah \& Amankwah-Amoah, 2017; Ramani et al., 2017). By doing so, the results may lead to a better understanding of the phenomena and provide 
information-rich data and recommendations for future studies and policy initiatives with implications for theory, practice, and positive social change.

This chapter includes detailed information on the research method and rationale for conducting an exploratory multiple case study, and also the central research question that guided this empirical investigation. In this chapter, I present a foundational rationale for the participant selection strategy, data collection strategies and data analysis, the role of the researcher, ethical considerations, and a summary on main points of the research method.

\section{Research Design and Rationale}

From a theoretical perspective, research questions are elaborated to provide answers to a phenomenon under study within the context of the empirical setting (Ketokivi \& Choi, 2014). In a qualitative multiple case study, the context and the phenomenon are deemed inseparable and the examination of these interrelated elements aimed at producing a deeper understanding of the cases being conducted (Gaus, 2017). Yin (2017) and Morgan, Pullon, Macdonald, McKinlay, and Gray (2017) argued that the context and phenomena are inextricably linked and that research questions are developed within real-world settings. Under such conditions, Browne and Keeley (2014) suggested that the right questions be asked in order to address the purpose of the study and drive the research strategy. Consistent with the purpose of this research, the central research question was as follows: How do the views of stakeholders, residing within impoverished communities in Angola, inform innovation policy makers on the implications of rapid technology diffusion on labor market challenges within their regions? 
Recording the experiences of Angolan stakeholders on the rapid diffusion of innovation and the labor market challenges within their impoverished regions offered insights into why innovation policy initiatives calling for technology diffusion in Angola, continue to stall rather than combating labor market challenges in impoverished communities. Researchers in sub-Saharan Africa indicated that the relationship between ICTs and the promotion of individual or societal quality of life in terms of human capital and labor market remains uncertain. Stakeholders' perspectives on the long-term benefits of ICTs in rural regions are, therefore, a continuous concern.

More recent research often failed to address whether the issues with ICTs benefits, social exclusion, digital divide, or inclusive development is linked to ICT utilization in Angolan rural and impoverished communities due to the absence or lack of stakeholders' engagement in government ICT policy initiatives. Saidi and Douglas (2017) suggested that stakeholder participation in government policy formulation is of paramount importance to change sub-Saharan Africa's current ICT framework, since it would allow them to provide inputs into and deliberate on the use of ICTs in their communities. Investigations of the experience of stakeholders and technological diffusion in sub-Saharan Africa revealed valuable insights into the interplay between ethnic groups, local undervalued knowledge, and on the deinstitutionalization of the traditional economic institutions (Amavilah, 2016).

Diga et al. (2013) and Gurumurthy (2010) proposed policy mechanisms to combat the digital divide that has proliferated throughout most African developing societies. The 
authors proposed that liberating some control of ICTs usage from repressive governments would benefit those impoverished and marginalized communities. Pierskalla and Hollenbach (2013) argued that certain African populations tend to resist to rapid technological innovations, and internet technology among these populations is often perceived as a means for manipulation and control. But as per Matthews's (2017) perspective, technology oversees many social constructs beyond the simple word technology, and technological innovations can often be conceived as the outcome from a useful and productive engagement of human capital and relevant resources (Oluwatobi et al., 2014).

Over $60 \%$ of African stakeholders rely on agriculture (Assefa et al., 2015); their needs for technological utilization tend to be directed toward enhancing and intensifying their means of production in order to alleviate poverty (Abdallah, 2016). Lawson (2014) and Pillania (2011) suggested that the compatibility with the existing social norms and trialability within a context of existing cultural practices accounting for local skills is of paramount importance for the local communities to succeed in ICTs uptake. Many researchers have come to agree that the potential benefits promised by the diffusion of technological innovations should be leveraged through the interplay of community stakeholders and policy makers so that formulated policies address the challenges that hinder local development (Amankwah-Amoah, 2016b; Asongu et al., 2018). Yet, Danquah (2018) suggested that the lack of scholarly attention on new technologies in sub-Saharan Africa hinders policy initiatives on rapid technology development. 
The nature of this research is qualitative, which aligns with the purpose of the study which was to provide data that answer the central research question, and in turn drives the research on a constructivist paradigm. Social constructivists challenge people to be more critical of their understanding of the world and themselves (McWilliams, 2010; Peck \& Mummery, 2017), thus practicing objectivity when interpreting interactions between the individual and the environment (Burr, 2003). Qualitative research methodologies used within the constructivist paradigm helped to give a voice to victims of social oppression and to their experiences with dominant cultural and social groups (Cooper \& White, 2012).

I used a qualitative method to meet the purpose of the study and answer the central research question pertaining to stakeholders' challenges on the rapid diffusion of technological innovation and labor market challenges within their regions. The qualitative research method facilitates the use of nonstandardized and adjustable approaches to data collection and analysis that were relevant to the purpose of this study in gaining a deep understanding of the views of a specific social group, stakeholders of impoverished communities, and living within a specific social context that being in Angola, a poverty-stricken and economically unstable nation in sub-Saharan Africa. A quantitative research method could not address the purpose of this qualitative study since it did not call for operationalization, manipulation of empirical variables, or testing statistical relationships. Denzin (2009) suggested that a qualitative methodology allows for the gathering of evidence on issues from the perspective of the people living within a given setting and experiencing a specific social phenomenon. 
Qualitative methods are used to explore real world issues by providing scholars with the ability to explore the various reasons that govern a social context. I used purposeful criterion and network sampling as qualitative sampling strategies. This sampling strategy helped ensure an in-depth understanding of the data collected from each case (Klenke, 2016). Qualitative researchers oversee an impartation of an understanding of life experiences as the researcher interacts with people within a specific and meaningful social context (Cooper \& White, 2012). Rather than opting for a quantitative approach, which might focus on an account of events or behaviors, qualitative researchers attempt to explore how participants make meaning of these events and how this understanding leads to behavior and new experiences (Eriksson \& Kovalainen, 2015).

Yin (2017) suggested that the multiple case study approach allows the researcher to navigate between cases and explore the differences within and between each case. With a multiple case study, comparing and contrasting cases leads to robust results when using inductive theory where methods and design are rooted in the methodological literature. Stake (2013) established that multiple case study methodology does not quite fit all research purposes, but mainly for those advancing theory generation and theory extension. Extension studies, such as the present study, not only provide replication evidence but also extend the results of prior studies in new and important theoretical directions. When the data focus is only on individuals in a multiple-case study design, the study's central phenomenon - in this case the views of the individual stakeholder from impoverished communities in Angola - is the context and not the target of study. In a 
multiple case study, the case itself may be a person, event, entity, or other unit of analysis. When people are the unit of analysis, a single case focuses on one individual, whereas a multiple case study focuses on more than one person (Yin, 2017).

The unit of analysis in my study was the individual stakeholder from impoverished communities in Angola. Based on Yin's (2017) case study design and interpretation of the multiple case study, the case itself may be a person. This approach is often used in business and management studies in the scholarly literature such as in Brown (2017) with airport managers, Hamlett (2014) with manufacturing managers, Komodromos (2014) with university employees, and Neubert (2016) with tech firm owners. Using Yin's (2017) multiple-case study approach allows researchers to replicate the same findings across multiple cases by tracing the differences and similarities between and within cases and study results created in this way are considered robust and reliable (Yin, 2017). The multiple-case study design allows for comparing and contrasting data within and between cases and Stake (2013) wrote that multiple cases notably lead to studies with methodological rigor when adhering to recommendations from the methodological literature.

\section{Role of the Researcher}

As the central and primary instrument in this researcher study, it was my responsibility to maintain rigor as well as credibility in every aspect of the research. The versatility provided by the qualitative research methods allows the researcher to obtain credible findings within a range of methodologies which align with the purpose of the research study being conducted (Yin, 2017). Qualitative research carries an exploratory 
nature driven by the sensitivity of the context and setting of the research (Ravitch \& Carl, 2016; Reiter, Stewart, \& Bruce, 2011). My ethical research relationship with the participants in the field was of paramount importance for the successful conclusion of this study.

Constructivist researchers consider that the fundamental and critical attitude of the researcher toward the world (Burr, 2015), whom as the adopting person is compelled to understand it in order to go about within it (Peck \& Mummery, 2017). Within the constructivist research paradigm, the findings of the research process are usually influenced by empirical observations that are resulted from the researcher's predisposition. The researcher's moral or ethical position, the philosophy that explains how scientific knowledge is derived, and the sense of how objects' relationships are defined along with the goals of the study influence the scope of the research and the path of the researcher (Masud, 2018). The concept of reflexivity has been part of qualitative research methods in organizational research for several decades (Haynes, 2012) and is a critical portion of data analysis within the constructivist paradigm (Stake, 2013). Trustworthiness of the data is protected from reflexivity-generated bias by relying on other sources of evidence to corroborate any insight of participants, and to search for contrary evidence as diligently as possible (Alvesson \& Sköldberg, 2017).

The research participants provided the adequate context framework and the research design allowed me to capture attitudinal nuances and maximize the credibility of the investigation. I conducted an effective management of reflexivity to evaluate my role as the researcher regarding positionality. In a qualitative research study, the researcher's 
ability to effectively perform a critical self-analysis in order to identify how research enquiry and findings are affected by positionality determines the trustworthiness and accuracy of the study (Berger, 2013). As the researcher during research, I was aware to not unduly influence the research participants but took otherwise a position of either empathy or apathy toward the experience of the participants.

An in-depth interview in a multiple case study is considered a reliable method of data collection because it represents a conversation between the researcher and the study participants that can provide useful information and reveal common themes (Rubin \& Rubin, 2012). I implemented several data collection methods over a period of 4 weeks for methodological triangulation purposes. It was my role as researcher to understand the social constructivist connection between myself, the participants, and the body of knowledge on the role of practitioner as I gained knowledge from others. While explaining the research study to participants, I took considerations to not introduce bias and accepted each participant separately as a case study, which I further used for case comparison. As a researcher, my role as an observer included note-taking, selecting images and artifacts, handling, analyzing, interpreting data according to the research's design and I ensured that all participant information, including identities and real name remained confidential.

\section{Methodology}

Yin (2017) stated that a multiple case study investigating a social phenomenon can involve individuals living within a specific social context, each as separate units of analysis. The key to understand the complexities tied to the social context under study is 
said to lie within the behavioral interaction of variables that compose a larger system (Stake, 2013). The data focus for this study was set on individuals and thus individuals were the study's central phenomenon. In this case, stakeholders of impoverished communities in Angola were the context and not the target of study (Eisenhardt \& Graebner, 2007; Yin, 2017). This study involved individuals living within impoverished communities in Angola and not the whole of the community itself. In such a study, the optimum qualitative design to retrieve data with the goal of theory building is an exploratory multiple-case study design (Eisenhardt \& Graebner, 2007).

During the identification and recruiting of participants, I used the replication logic concept discussed by Yin (2017). Yin (2017) indicated that each case should be seen as a distinct experiment and unit of analysis. According to Schmidt (2017), replication is one of the most important tools in science results since a single observation cannot be trusted because it may not reflect a regularity that can be found again. Case studies do not usually involve manipulation or experimental control; therefore, the approach was suitable for aim of this study, which was to gain a deeper understanding of stakeholders' views on the rapid diffusion of technological innovation and labor market challenges within their regions. Further, Eisenhardt and Graebner (2007) suggested that replication offers contrasts that may further theoretical constructs.

I recruited the participants for this case study using purposeful criterion and network sampling strategies for identification and selection of information rich cases that were of interest to the phenomenon of study (Baxter \& Jack, 2008; Patton, 2014). The inclusion criteria for participants selection was (a) adults over the age of 18, (b) male and 
female, (c) born and residing in impoverished communities in Angola, and (d) possessing knowledge regarding their experiences with the topic of the study (Merriam \& Tisdell, 2015; Patton, 2014; Stake, 2010). As the researcher, I conducted eight in-depth face-toface individual interviews with the recruited participants. Schram (2006) recommended a range of five to 10 participants for a qualitative study, stating that a larger sample size could be a barrier to an in-depth investigation of the phenomena under study. Merriam and Tidsdell (2015) determined between six to 10 participants as being enough to identify common themes and practical applications in qualitative research.

The multiple case study design supported the study of convergence and divergence of participants' experiences within and between cases (Yin, 2017). To achieve this end, the concept of methodological triangulation was used to assess the data sources of the phenomenon of interest to get richer, fuller data, and get help to confirm results of the research (Wilson, 2014). Jack and Raturi (2006) and Schwarzenegger (2017) argued that data sources are usually deployed under the assumption that weaknesses inherent in one data source will counterbalance via strengths in another, strengthening the credibility of the study. When the data process was completed, a cross-case synthesis technique for data analysis was utilized. Merriam and Tisdell (2015) and Yin (2017) recommended such procedure when analyzing data in a multiple case study in order to strengthen the trustworthiness of the collected data (Merriam \& Tisdell, 2015; Yin, 2017). Finally, the data collection process was launched through the development of an appropriate participant selection logic. The participant selection logic ensured that participants 
fulfilled the minimum or necessary recruitment criteria requirements, which promoted the credibility of the study (Merriam \& Tisdell, 2015).

\section{Participant Selection Logic}

Population. This multiple case study called for a deeper understanding of stakeholders' views on rapid technology diffusion's implication on labor market challenges within impoverished communities in Angola. In order to provide data to fill the study's identified literature gap, the population of this study was the greater group of local community stakeholders within these impoverished communities that were able and willing to provide opinions and perceptions on why technology diffusion continues to stall among these identified communities. By choosing several such impoverished communities as identified by the MPI Poverty Index (2018) rather than the stakeholders of a single community to comprise the study's population, I used maximum variation sampling to identify a heterogeneous sample of participants (Benoot, Hannes, \& Bilsen, 2016). Maximum variation sampling in qualitative research relies on researcher's judgment to select participants with diverse characteristics to ensure the presence of maximum variability within the primary data, which in this multiple case study were the responses to the interview protocol (Palinkas et al., 2015).

Given that this multiple case study research called for a deeper understanding of stakeholders' views on the rapid technology diffusion and its implication on labor market challenges within their regions, the population from which this study's participants were selected were stakeholders from impoverished communities in Angola that were willing and able to share their views on the phenomenon of study (Amankwah-Amoah et al., 
2018; Gomez \& Pather, 2012). As per the 2018 African Development Bank (AfDB, 2018a), Angolan economic growth slowed to $0.1 \%$ in 2016 but recovered to a growth of estimated $2.1 \%$ in 2017 due to strong performance in sectors such as agriculture. Despite the country's economic progress, persistent structural challenges exist pertaining to weak institutions, weak agricultural productivity, inadequate infrastructure, limited qualified human resources in respect to science and technology that still hinder inclusive growth and economic diversification (Ngunga, 2019).

Sampling criteria. Sampling is a cornerstone of research integrity and qualitative researchers recognize that some research informants/participants are better suited to provide key insight and understanding than others (Abrams, 2010). The choice of a sampling population in qualitative research is based on the specificity and implementation of an appropriate research methodology (Tracy, 2010). I recruited participants for this multiple case study using purposeful criterion and network sampling (Baxter \& Jack, 2008; Patton, 2014), with inclusion based on the following criteria: (a) adults over the age of 18, (b) male and female, (c) born and residing in impoverished communities in Angola, and (d) possessing knowledge regarding their experiences with the topic of the study. The network purposeful sampling technique was implemented wherein I solicited from initial selected candidates, other potential contributors who meet the inclusion criteria (Merriam \& Tisdell, 2015).

The goal of purposeful sampling is to select information rich cases that provide enough insight to answer the research questions (Emmel, 2013). Since case studies do not involve manipulation or experimental control, the purposeful sampling, horizontal 
network sampling was utilized as it is a respondent driven sampling strategy that works by selecting an initial small number of participants from the target population which are then studied and asked to recruit up to three new contacts (Merriam \& Tisdell, 2015; Patton, 2014; Stake, 2010). The horizontal network sampling approach ensured the exposure of some hard to locate participants (Geddes, Parker, \& Scott, 2018). The approach was suitable for this study in order to gain a deeper understanding of stakeholders' views on the rapid diffusion of technological innovation and labor market challenges within their regions.

The data collection process followed eight in-depth face-to-face individual interviews that I conducted; the selected population and the sample size were vital to the success of this research study. The in-depth interviews were considered reliable methods for intersectionality investigation and useful for addressing constituencies while providing diversity (Ritchie, Lewis, Nicholls, \& Ormston, 2013). In meeting the study's participant inclusion criteria, the candidates were able to provide opinions and perceptions about their experience as Angolan stakeholders, residing within impoverished communitieswho are faced with challenges regarding the rapid diffusion of technological innovations and the labor market in their region.

Sampling selection. This research study purposefully selected Angolan stakeholders, residing within several impoverished communities in Angola whose innovation policy initiatives to combat labor market challenges through technology diffusion continue to stall within their region. Although the participants' capacities to absorb ICTs and deal with its challenges differ at some point and may share 
characteristics of marginalization with other already powerful and controlling elite (Diga et al., 2013; Njoh, 2018) such as the knowledgeable and skilled in more sustainable regions (Aissaoui, 2017; Mutula, 2008; Oyedemi, 2012), the latter groups were not included in this study. The optimal case study consisted of eight Angolan stakeholders, residing within Angolan impoverished communities to ensure proper and quality data collection. Eight in-depth interviews were conducted, each with each individual study participant that resulted in a distinct understanding of their perceptions within their realworld context (Ritchie, 2013). Cumming-Potvin (2013) added on this by suggesting that both researcher and participant can enhance these themes through harmony of selfawareness and social and cultural consciousness.

The aim of this multiple case study was the precise description or reconstruction of cases (Flick, 2014). The term case can be understood as a person, a social community, or an institution as the case of analysis. The unit of analysis I identified in this study was the stakeholder, residing within several impoverished communities in Angola whose views on rapid technology diffusion and labor market challenges remain absent and unaddressed by innovation policymakers. Each in-depth interview enabled each unit of study to provide rich information that could link the data to the underlying theoretical proposition which further established a framework to compare the cases (Tsang, 2013; Yin, 2017). Further, the aim of the study, availability of time, material resources, and the reliability of the information determined the sufficiency of the sample size (Guetterman, 2015). 
Qualitative research oversees constructs beyond a simple theoretical value. According to Cooper and White (2012) and Tsang (2013), these constructs form the qualities that lie beyond statistical properties; without these constructs research would simply be confined to tangible factors. This study oversaw a deep analysis of attitudes, behaviors, and perceptions, which often shape the experiences of Angolan stakeholders, residing within several impoverished communities in Angola, whose views regarding the rapid diffusion of technological innovations remain absent and unaddressed by innovation policymakers.

Sampling strategy. Since the selection of participants usually occurs among marginalized groups, for identification and recruitment of participants in this multiple case study the concept of replication logic discussed by Yin (2017) was used. The concept states that each case in a multiple case study is treated or considered as a distinct experiment and as a single unit of analysis (Eisenhardt \& Graebner, 2007; Flick, 2014). Researchers have considered replication logic as a major tool in science results because one single observation cannot be trusted as it may not reflect a regularity that can be found again (Bonett, 2012).

The vital success of this study was within the selected population and sample size. The integrated survey on the well-being of the Angolan population, conducted by the Institute of Statistics (Ine.co.ao, 2013), showed that between 2008 and 2009 the index of poverty for the entire Angolan territory accounted for $72 \%$ of the country's rural areas filled with residencies. Thus, study participants (stakeholders) were randomly selected from two distinct impoverished communities that are characterized by an elevated rate of 
rural density and that aggregate the socioeconomic characteristics such as high rate of unemployment, difficulties in access to basic sanitation, low rate access to electricity, and mostly dependent on a variety of economic activities without much expression.

Within this separate group of people, perceptions, observations, and the experiences of participants' views on rapid technology diffusion of technology and labor market challenges within their regions were questioned to gain sufficient insight for an in-depth study of this phenomenon. The goal was that, once the sample had been purposefully selected, I would establish rapport with the research participants. Utilizing network and criterion sampling strategies (Baxter \& Jack, 2008), I therefore travelled to two different impoverished communities in Angola in the region of Cuanza Sul named Porto Amboim and Sumbe (see Appendix C for map of research site locations), to make personal contact with community stakeholders and recruit a sample of participants meeting the inclusion criteria of my population: (a) adults over the age of 18, (b) male and female, (c) born and residing in impoverished communities in Angola, and (d) possessing knowledge regarding their experiences with the topic of the study (Merriam \& Tisdell, 2015). These specific communities in Angola are among the ones with the highest rate of unemployment, low literacy, lack of infrastructure, and low economic activity (BMI, 2017a, 2018f; Ine.gov.ao, 2013, 2014; EFFA, 2016). In those communities, I conducted eight in-depth face-to-face individual interviews with participants recruited for this study. The multiple case study design supported the study of convergence and divergence of participants' experiences within and between cases (Yin, 2017). 
It was critical that within the context of Angolan rural culture, community stakeholders met me in person and trusted my motivations as a researcher before I could hope to recruit them as viable candidates that would provide the data needed to answer the central research question. Developing a dialogue relationship with participants enabled the gathering of data through rich descriptions and attitudes of each study participant (Guetterman, 2015), it also gave me as the researcher, the opportunity to map analysis in a manner congruent with the conceptual and theoretical framework (Gildersleeve \& Kuntz, 2010). The social constructivist paradigm examines the jointly constructed understanding of the world. Thus, the constructivist impact of this research study hinged on a close collaboration between the researcher and those participants who have lived experiences to provide descriptive data rather than abstract concepts (Galbin, 2014). The in-depth interviews were used to understand the barriers faced by each case or unit of analysis (Aljohani \& Blustein, 2018), which provided greater flexibility when participants were questioned within a strategy that allowed questions to be addressed until saturation was reached (Eriksson \& Kovalainen, 2015).

\section{Instrumentation}

The ultimate task of a social researcher is to instrumentally solve social problems (Waloszek, 2017). Thus, the ultimate purpose of using specific instrumentation in a multiple case study is to be able to collect sufficient data from multiple sources so as to answer the study's research question (Yin, 2017). But considering the different measurement approaches and the question developed in relation to the study topic, it was of paramount importance that all the responses were examined together with the selection 
of participants. Utilizing instruments for a specific population subgroup requires consideration of culture and language, cognitive demands, and potential response errors (Dean, Caspar, McAvinchey, Reed, \& Quiroz, 2007). Instrumentation utilized in any social research must also be aligned with the purpose of the research study to contribute original data to the study's conceptual framework.

Collecting data from specific populations requires that the researcher acquires community knowledge that will make the process culturally sensitive and appropriate (O'Hegarty et al., 2010). Thus, it became of paramount importance to choose the appropriate instruments that would produce themes to support the insights that would result from studying Angolan stakeholders' experiences on their views of rapid diffusion of technology and labor market challenges within their regions. This study used three sources of data: (a) a semistructured interview protocol (see Appendix B) whose items were designed and standardized by a previous researcher; (b) ICT policy documents in the form of government labor reports; and (c) reflective field notes (Merriam \& Tisdell, 2015) that were kept by the researcher throughout the data collection process.

This study's interview guide which consisted of semistructured questions and probes that explored Angolan stakeholders' views of rapid diffusion of technology and labor market challenges within their regions was designed and validated by a professor whose research works on diffusion of innovation in African underdeveloped countries were also guided by seminal author Rogers's (1995) concept of diffusion of innovations. The interview guide utilized was also supported by Danquah and Amankwah-Amoah's (2017) concept of human capital and innovation in sub-Saharan Africa, and Foster and 
Heeks (2013) concept of inclusive innovation that defines the link between a new invention and its widespread adoption by low income consumers looking at how innovation impacts individuals belonging to the lowest income groups (Onsongo \& Schot, 2017). The semistructured interview method and protocol was intended to enhance the researcher's ability of meaning making of the phenomenon by understanding it from the participant's point of view (Kvale, 1995; Ravitch \& Carl, 2016).

I aligned the developed interview protocol with the purpose of my study, which was to explore the views of community stakeholders in an impoverished region on the Niger-Nigeria border that are overpowered by outside ideas and processes, and are seen by locals as coercing people, threatening their indigenous livelihoods and usurping community autonomy (Matthews, 2017). Matthews met the purpose of his ethnographic study when he and his family lived in a mud house in a village near the populous town of Maradi, Niger between 1991 and 2005, where he conducted 140 in-depth interviews with community stakeholders. For the participant sample, Matthews chose "farmer-led innovation for the basic research agenda in order to determine if and how farmers were introducing or diffusing new techniques in a village where agency-based innovation had been failing for decades" (2017, p. 228). Regarding his role as a researcher in a setting where he and his wife raised their children, Matthews stated,

I distance myself from the processes that I observed in order to present a dispassionate analysis of diffusion processes to the scientific community. My personal connection to the community urged me to expose ways that development assistance was usurping community autonomy and worsening conditions for the 
very people it was supposed to help. The tension between scientific objectivity and commitment to justice for the poor is evident throughout this paper. (2017, p. 229)

After a discussion between my Committee Chair and the professor who developed the protocol, it was deemed appropriate that the interview protocol (Appendix B) could be utilized to provide data for meeting the purpose of my multiple case study and provide data in answering my central research question within the Angolan context. I obtained written permission to use the interview protocol in my study, and given that the interview protocol questions were field tested and validated by the same individual, no pilot study was required to repeat this process.

The initial section of the protocol consisted of pre-interview questions that situate the study participant within a socioeconomic and demographic sphere. The interview questions and probes in this study were valuable in collecting primary data on the individual viewpoint from each study participant regarding Angolan stakeholders' experiences on their views of rapid diffusion of technology and labor market challenges within their regions. The interviews were held in an informal conversational style in a way that I best felt to approach the stakeholders within two impoverished communities of one region of Angola. The study focused on the use of an interview protocol whose sections are the result of a previously constructed work that has been validated and utilized in published and peer-reviewed research studies (Matthews, 2017).

The second instrument used for data collection in this study was document analysis in the form of government labor/policy reports (Green \& Thorogood, 2018; Yin, 
2017). These government labor and/or policy reports aimed at uncovering the cultural, political, and socioeconomic frames that make certain courses of policy initiatives possible and others unthinkable (Green \& Thorogood, 2018). These government reports framed problems, facts, and solutions affecting the provision of socioeconomic welfare of the populations. These are regarded by researchers as secondary sources, data sets that already exist prior to conducting the research study which is contrast to the primary data which are generated or collected by the researcher (Green \& Thorogood, 2018).

These government policy reports drew on a variety of documents (Green \& Thorogood, 2018), such as social and economic reports that function as networking mechanisms designated as capacity documents to create, sustain, and mediate social relationships that have also been observed in welfare, policing, education, medical, and economic settings in the field of study for background context on the setting addressed in the research (Prior, 2016). Case study research particularly involves utilizing documentary and material sources, also called background information in addition to data from interviews and observations. These secondary data sources were part of the corpus that was analyzed and used to orientate the researcher in refining the research question and design (Green \& Thorogood, 2018).

In most countries, government agencies devote considerable resources to collecting data from the population and communities and have the advantage of having far greater resources than many academic researchers. Given the resources needed to produce primary data, the use of government reports as a secondary source of data collection has also been regarded as strategically feasible (Green \& Thorogood, 2018). 
These policy reports were used in this research study not just from a realistic perspective in which these documents are a source of what governments in sub-Saharan Africa (particularly in Angola) do, but also from a constructionist perspective (Green \& Thorogood, 2018). The goal in using these documents was to have them function as actors. Research suggests that documents often make a difference in social arrangements since they interact with humans so as to shape and pattern what humans actually do (Bazerman, 1997; Prior, 2016).

The third instrument used for data collection from research participants in this study was reflective field notes (Phillippi \& Lauderdale, 2017). Field notes are essential for rigorous qualitative research because they provide an additional layer of rich data to be interpreted and analyzed. They are often used to promote insights into how social interactions function that help decipher the reasons behind cultural actions (Kozinets, 2017). Predominantly, field notes resulted from observations are based on the constructivist paradigm that acknowledges the importance of context and the coconstruction of knowledge between the researcher and the participant (Mulhall, 2003). Their use in qualitative research aids in constructing rich description of the study context including interviews and document's valuable contextual data (Phillippi \& Lauderdale, 2017), and they are often considered to be a mechanism of casual relationship that exposes the variations of fieldwork data in both cause and effect with its origins in areas of social life (Katz, 2014).

As I entered the field, I was aware that I had no predetermined notion as to the discrete behaviors I was going to observe (Mulhall, 2003). I therefore focused on 
achieving a level of thick description that would give me the flexibility to work inductively, ask additional questions, and conduct follow-up observations (Maharaj, 2016). In the course of gathering observational data, field notes allowed me as the researcher to record the participants' verbal and nonverbal expressions and behavior within the context in which the research study occurred (Flick, 2014). Field notes are targeted at gathering information that will frame the study in place, time, and population (Phillippi \& Lauderdale, 2017).

Because qualitative data collection carries an inductive and emergent nature, it is useful to take notes on many types of social experiences including social groups, resources, and events that emerge from the data collection process. The analysis process resulted from the observational data serves to inform the collection of other self-report data such as in the semistructured interviews (Yin, 2017). Utilizing field notes simultaneously with semistructured interview methods is favorable because of the subtle nature of knowledge transfer, the frailty of recollection and how it can be incorporated behaviorally. In order to capture the unmitigated response from the research participant during data collection, it is important that the interactions and responses be unfiltered so that raw emotions as well as intense feelings and sensitivity of the context are conveyed in the data. Observation in qualitative research is valuable since it informs about the influence of the physical environment. It was also very important that the positions, perceptions, and responses of the research participants followed as uninterrupted. The finer intricacies of the human experience are a key element to unveil ethnographic studies and the inscriptions in field notes will be the portal through which these facets become a 
part of the records (Mulhall, 2003). Drawing from an ethnographic work, Mulhall (2003) offered a few practical suggestions on different types of field notes as per her personal schema. These include:

1) Structural and contextual/organizational features - these refer to what the actual setting and environment look like and how they are used;

2) People - how they behave, interact, dress, move;

3) The daily process of activities;

4) A special event;

5) A dialogue;

6) An everyday diary of events as they occur chronologically_both in the field and entering the field; and

7) A personal/reflective diary - this includes both the thoughts of the researcher about going into the field and being there, and reflections of the researcher on his/her own life experiences that might influence the way in which the researcher filters what he/she observes.

The development of reflective field notes prompts the beginning of the data analysis process in studies driven by the qualitative research method (Kozinets, 2017). Similar research studies such as that of McKinlay, Morgan, Gray, Macdonald, and Pullon (2017), where a multiple case study design using observational research methods to explore the research questions within real-world settings, launched a sequential order of data collection, data analysis, and synthesis (Yin, 2017). 
Finally, the validity of the instruments used in this research study depended on the issue of transferability, which is similar to external validity, as both notions are involved with the amount to which the outcomes of one study can be useful to other settings (Merriam \& Tisdell, 2015). This often posed challenges and limitations for many qualitative studies as findings are usually limited to specific physical settings and individuals (Berg et al., 2017), and as a result, it is plausible that the outcomes from this research can be applicable to individuals beyond the participant group (Anney, 2014; Stake, 2013).

\section{Procedures for Recruitment, Participation, and Data Collection}

For size and saturation purposes, between five to 10 research participants were recruited for this qualitative multiple case study. Recruiting between five to 10 individual stakeholders for in-depth face-to-face interviews to gain a deeper understanding on the views of stakeholders, residing within impoverished communitiesin Angola, on the rapid technology diffusion and its implication on labor market challenges within their regions was adequate to attain data saturation (Fusch \& Ness, 2015; Merriam \& Tidsdell, 2015). Saturation is reached when very little additional data are being found whereby $\mathrm{I}$, as the data collector, can develop new themes or when data collection ceases to yield new information (Glaser \& Straus, 1967; Saunders et al, 2017; Yin, 2017). I began to observe and code for data saturation at the conclusion of the fifth interview. Because there was no large variance of responses appearing anymore, I felt no need to use the same recruitment procedures to gather more participants for collection of interview data. 
To ensure the emergence of important themes and practical interpretations, data collection became the result of eight in-depth semistructured interviews conducted with eight Angolan stakeholders, residing within impoverished communities in Angola, whose views regarding the rapid diffusion of technological innovations remain absent and unaddressed by innovation policymakers (Cooper \& White, 2012). The in-depth, semistructured interviews are conversational in nature and were configured in a way to make the study participant feel comfortable to contribute honestly during data collection (Ashton, 2014). Apart from decreasing the feeling of formality, this approach allowed me as the interviewer to capture the essence of the experience of the study participant which further relayed to the participant the importance of their responses to the study being conducted (Davis, 2016). The in-depth interview process featured each interviewee as more of an informant using the observations, opinions, and suggestions rather than closed responses to direct questions aligned with a theoretical proposition. The inquiries were designed to analyze both the current and the past disposition of each interviewee as well as nonverbal behaviors and nuances centered on each discussion (Yin, 2017).

The eight multiple case study interviews provided sufficient replication design to convince the reader of a general phenomenon, displaying similar results within the propositions of the study (Yin, 2017). I obtained further evidence for this case study from other sources, each with an array of data and insight; direct observation, interviews, and participant recollection, digital journals, and seminal literature on the research topic helped to strengthen the validity and reliability of the research study (Yin, 2017). I brought together the data collected from these different sources during data analysis, with 
the sole purpose of sharpening the understanding of the phenomena being scrutinized (Baxter \& Jack, 2008). Besides interviews and government labor/policy reports, I analyzed, coded, and recorded electronically personal notes from each interview so that concepts could be defined, validity and reliability improved, and coherence provided between the research questions to the ultimate conclusions of the study (Yin, 2017).

The data collection segment of this research study consisted of in-depth face-toface interviews, reliant upon Institutional Review Board (IRB) approval by Walden University. Eight Angolan individuals (stakeholders) were actively selected and directly approached in public and private settings (UCLA, 2012) using purposeful criterion and network sampling strategies (Baxter \& Jack, 2008; Patton, 2014) within impoverished communities in Angola who fulfilled the criteria for the study to refer others who also potentially met the criteria. The recruitment approach was done in person before providing the invitation letter since great part of the Angolan population is made up of people that are not easy to reach through social network platforms due to the limited access to Internet and ICTs services infrastructures (Cruz-Jesus et al., 2016; Mumporeze \& Prieler, 2017; Okunola et al., 2017; Oluwatayo \& Ojo, 2018; Salla, 2016).

I invited those who responded positively to participate in the study through a recruitment letter that was handed over personally (Appendix A). I asked those who accepted the invitation to provide other contact information through which they could be reached for communication purposes. Following Walden's IRB approval, I provided each potential participant with a recruitment letter that invited them to take part in the study. Additionally, I provided them with a consent form that included an explanation of what 
the study entailed; the procedure, the option to withdraw; the possible risks or discomfort associated with participation; the time limit; a statement of voluntary participation and no consequences for refusal; rights to confidentiality; and the benefit of this study to the Angolan impoverished communities and society in general.

The central focus of the qualitative method is to gain in-depth understanding of the knowledge and experiences of the research study's participants (stakeholders of impoverished communities in Angola). I was mainly engaged in the production of data relevant to the interviewees' experiences regarding the issue being investigated. The study's participants—stakeholders of several impoverished communities in Angolawere identified and selected using the network sampling strategy within impoverished regions of Angola. Participants selected for this qualitative multiple case study were experienced stakeholders who were above 18 years of age, born and residing in impoverished communities in Angola, and possessing knowledge regarding the rapid diffusion of technological innovations and its impact on the labor market challenges within their regions. In the event that the recruitment process resulted in fewer participants than what was proposed, I would seek out more individuals (stakeholders) within same region who would meet the recruitment criteria until eight potential participants were met.

The methods used for data collection in this study were semistructured interview, ICT policy documents in the form of government labor reports, and reflective field notes (Merriam \& Tisdell, 2015). The purpose of this exploratory multiple case study was to gain a deeper understanding on the views of stakeholders, residing within impoverished 
communitiesin Angola, on rapid technology diffusion and its implication on labor market challenges within their regions, an (Yin, 2017). The selection of various stakeholders meeting the inclusion requirements ensured variability of the data collected. The interview guide included open-ended questions aligned with the issue under study. The questions were presented to capture the study participants' backgrounds and ideas, perception and thoughts, opinions and values, as well as their behaviors regarding the rapid diffusion of technological innovation and the challenges they promote in the Angola's labor market from the point of view of the stakeholder residing in impoverished regions (Patton, 2014; Yin, 2017).

During the interview process, each participant's responses were recorded and transcribed using Microsoft Word processing. The semistructured interviews were designed to probe the views of Angolan stakeholders, residing within impoverished regions in Angola on the implication of the rapid diffusion of technology in the Angolan labor market. The interview questions focused on detailed information regarding each interviewee's disposition and background, allowing the researcher to investigate participants' views, values, and behaviors (Patton, 2014; Yin, 2017).

The Walden IRB granted approval prior to starting the data collection process which I carried out in person. Data collection took place on a daily basis until eight indepth interviews were conducted. Each data collection event had a duration of 30 to 40 minutes, in which data were recorded on a digital audio recorder and responses and reflective handwritten notes recorded on an observer note sheet (Katz, 2014; Neuman, 2011). 
Microsoft Word processing software was used to transcribe interviewees' responses and Microsoft Excel software to electronically document, record, analyze, and categorize the data collected from each interview. By transcribing the interviews, the researcher was able to accurately record answers in a permanent form as a matter of record in order to conduct thematic analysis (Yin, 2017). Microsoft Excel has been recommended by researchers (Bree \& Gallagher, 2016) as the appropriate spreadsheet software for documenting interview schedules, recording research themes, and organizing questions and participants numerically to better ensure confidentiality. Handwritten notes offered valuable confirmation of the views expressed by the participants, so they were kept during each interview since they are critical in capturing cues and nonverbal behaviors which provides added depth in insight (Katz, 2014). These research notes, combined with the other data collection methods described in this paper, helped me gather evidence and improve construct validity via methodological triangulation (Guion et al., 2011).

Following the interview process, each participant was given a copy of the transcript of their interview for the purpose of checking the collected data. Terms of confidentiality were also made clear and known to the participants, additionally no attributable label such as name or distinguishable characteristic were given; any discernible information was stored separately from data (Yin, 2017). Peer-reviewed, historical, and seminal papers on the study's central phenomenon were combined with the transcription review and analysis to elaborate a database wherein the findings of this research will be of aid to those who seek replication while conducting similar research in 
the future (Yin, 2017). Once the data collection process terminated, participants were informed that the materials associated with the research study are for strict research purposes and that they will be destroyed after 7 years.

\section{Data Analysis Plan}

In a multiple case study, once the focus of the study has been determined, the empirical inquiry is supported by the appropriate theoretical propositions and sample size. This ensures that adequate data in the qualitative data are gathered to answer the how and why of the study phenomena and how the study authenticates themes and trends that emerge from among the interviewees' responses in a manner supported by seminal literature (Yin, 2017; Zainal, 2007). Angolan stakeholders over the age of 18, male and female, born and residing in impoverished communities in Angola, and possessing knowledge regarding their experiences with the topic of the study made up the participants for this study. To achieve this end, the appropriate data gathering methods were used to facilitate efficient data collection, and categorization of information beyond the semistructured questions and responses.

The findings of the research study were grouped together to support analysis of the data provided by the interviewees regarding their experiences with the rapid diffusion of technological innovations and labor market challenges within their impoverished regions. The main data analysis tool of this study was Yin's (2017) cross-case synthesis process that was used to analyze both the process and contents of the interviews and the documented data (Merriam, 2014; Yin, 2017). The cross-case synthesis data analysis technique has been recommended by researchers when conducting multiple case studies 
because, first, the process aids in providing external validity and trustworthiness of the data which in turn enhances the research by providing more vigor and second, the process helped me develop models and themes based on the data (Hatch, 2002; Merriam \& Tisdell, 2015; Yin, 2017).

There were series of proofs that helped validate the strength and reliability of this research study. I conducted coding analysis using a directive process so I could catalogue various themes by marking common relationships across multiple cases (Patton, 2014). In addition to binding data sources, the codes bridged themes across a variety of methodologies including interviews, field notes, and historical literature (Patton, 2014). I conducted methodological triangulation to strengthen the rigor of the study and promoted a more aggregate consideration of the data (Yin, 2017). In utilizing methodological triangulation with multiple data sources including reflective field notes and archival data, I developed a database by recording and categorizing similar key words, thoughts, views, and sentiments (Yin, 2017). Once interviews were organized and coded, content analysis took place which in turn helped distinguish between the content that was to be included from the content that was to be omitted to facilitate the base for the delineation of patterns aided by theoretical suppositions (Hatch, 2002; Yin, 2017). I used a directed content analysis approach (Vaismoradi, Turunen \& Bondas, 2013), where I started with initial codes derived from the study's conceptual framework and theoretical foundations.

The interview discussions were used for thematic analysis using pattern recognition which was distinguished as the researcher made sense of the content analysis. The nonrecurring evidence was attributed to individual case compositions. By making 
sense of common relationships across cases, the coding analysis of the interviews enabled the cataloguing of data within various themes across the different cases (Patton, 2014). In addition to combining different data sources, the codes also enabled the bridging of themes across different methodologies including interviews, government labor reports, and online discussion boards (Patton, 2014).

The cross-case data analysis technique enabled me to synthesize important findings of individual case studies, and synthesize themes across and between cases, a pivotal characteristic of the multiple case analysis (Yin, 2017). Because of the comparatively low number of cases associated with the qualitative study, word tables helped me to search for patterns across cases as opposed to the meta-analysis associated with large numbers of case studies. Because the causal links in real life experiences are complex and patterns may not be readily observable, in using cross-case synthesis I managed to strengthen the validity of my results and assess the logic which links the data to the propositions. I, therefore, enhanced the trustworthiness of data by consolidating, reducing, and interpreting the data to establish a coherent argument based on evidence (Cooper \& White, 2012; Yin, 2017).

\section{Issues of Trustworthiness}

It is argued that the issue of quality in qualitative research can never be addressed by a single method but may be judged through multiple perspectives that fuel the selection of an adequate methodology with a solid research design that oversees trustworthiness from the perspective of credibility, transferability, dependability, conformability, and ethics (Chowdhury, 2015; Richardson, 2018). The philosophical 
orientation to research as well as methodological integrity to qualitative inquiry requires that qualitative researchers intersect the issues of quality and credibility with the intended research goals (Patton, 1999). Researchers therefore, argue that the approach to trustworthiness is a vital component and influential criterion in social research that helps maintain research objectivity and reliability (Chowdhury, 2015; Levitt, Motulsky, Wertz, Morrow, \& Ponterotto, 2017).

\section{Credibility}

The concept of credibility in qualitative research studies often refers to the truth of the data that is resulted from participants' views and from the interpretative representation of the researcher (Polit \& Beck, 2012). This study achieved credibility by following a systematic process as identified by seminal methodology scholars (Denzin \& Lincoln, 2011; Patton, 2014; Yin, 2017) and by describing the researcher's experiences so that confidence could be achieved at the verification of research findings with the study participants (Anney, 2014; Cope, 2013). The credibility of the data is reflected on the researcher's personal reflexivity such as looking inwards to see how the researcher himself has informed the research and by looking outward to the members of the community being researched (Cope, 2013; Houghton, Casey, Shaw, \& Murphy, 2013; Treharne \& Riggs, 2015). This was also achieved through the member checking process and by responding to the concerns of outsiders, many of whom who were unfamiliar with or challenged the credibility of the data (Merriam \& Tisdell, 2015; Treharne \& Riggs, 2015). 
The credibility of the research findings reached from the data analysis process was supported through the process of using multiple sources to draw on conclusions. By using triangulation, the researcher had at his disposal multiple methods of data collection to gain a comprehensive view of the phenomenon studied (Casey \& Murphy, 2009; Cope, 2013), and these involved long-term observations, saturation, field notes, an audit trail, cross-case synthesis, and journaling recorded throughout the research process (Cope, 2013; Cooper \& White, 2012; Morse, 2015; Patton, 2014; Yin, 2017). The goal of this qualitative research was to understand the phenomenon investigated from the points of view of the participants, which in the case of this study were Angolan stakeholders' views regarding the rapid diffusion of technological innovations and its implication on labor market challenges within their impoverished regions. The reflexivity exercised over the results represents information that is believable and trustful as a result of the researcher dedicating quality time to understanding and interpret the perspectives and experiences of the research participants along with efforts to avoid researcher bias (Billups, 2014). In the case of this study, the multiple case study design, the voices of these research participants that exhibited characteristics of similarity, dissimilarity, as well as variety and redundancy, were brought together to gain a deeper knowledge of the wider population (Stake, 2013).

\section{Transferability}

Transferability in qualitative research determines the extent to which findings of a particular research are useful to other populations or that they can be applied to other settings (Houghton et al., 2013; Polit \& Beck, 2012). The concept of transferability is 
considered analogous to generalization, yet, it does not carry the same meaning as that of statistical generalization (Connelly, 2016). Transferability in this study was supported by rich data including a detailed description of the context, location, and of the study findings (Anney, 2014) that were derived through purposive sampling and coding of themes that were focused on assumptions that were relevant to the research. A qualitative study meets transferability if the research findings have meaning to individuals outside the scope of the study and readers can associate the research results with their own experiences (Cope, 2013). As the researcher, I provided a detailed description of the study's context, the methodology of inquiry, the findings, and the data samples so that readers could opt to the transferability of this research's results in their particular context (Houghton et al., 2013).

\section{Dependability}

The concept of dependability in qualitative research refers to the constancy and reliability of the data over similar conditions (Polit \& Beck, 2012). This refers to the ability to determine if the study results remain the same if the same research methods are utilized over time under different conditions (Billups, 2014). Dependability in qualitative research can be achieved when researchers concur with decision trails throughout the research process to oversee the degree to which the research procedures are documented, so that someone outside the research process can follow, audit, and critique the research process (Houghton et al., 2013; Polit, Beck, \& Hungler, 2006). Thus, overlapping the methods through which the data are collected enables the researcher to compare intersecting themes using triangulation (Yin, 2017). The study would then be deemed 
dependable if the findings were replicated with similar participants under the similar conditions (Cohen, Manion, \& Morrison, 2011; Koch, 2006)

\section{Confirmability}

Researchers achieve confirmability in qualitative research when they are able to demonstrate that the research findings are a function solely of the research participants and not their own biased motivations, interests, and viewpoints (Polit \& Beck, 2012). By enacting measures, researchers establish the rationale that ensures that the research findings are based on evidence and without any predisposition (Shenton, 2004). In qualitative research, confirmability has implications for studies that provide policy recommendations (Moon, Brewer, Januchowski-Hartley, Adams, \& Blackman, 2016). Thus, the researcher's philosophical and epistemological point of view will be determined by both the problem under investigation and the predisposition of the researcher, in terms of how the truth of the data is categorized. I ensured confirmability of this study by clearly linking the study conclusions in a way it can be followed and replicated from an ontological and epistemological standpoint of the research, to ensure that the results are based on the preferences and experiences of the research participants (Moon et al., 2016).

\section{Ethical Procedures}

Qualitative research methods are typically conducted under an interpretive approach to social sciences, and for such reasons, researchers suggested that it provides enough contextual understanding of research ethics within a pluralistic reality of the research actors themselves (Treviño, Den Nieuwenboer, Kreiner, \& Bishop, 2014). The 
approach to qualitative inquiry raises concerns regarding human subjects. These concerns are mostly associated to the undue burden placed on study participants when the topics under examination address emotive and distressing subjects that cause participants to feel pressured and be unduly intrusive research (Kendall \& Halliday, 2014).

Formal research ethics, outlined in The Belmont Report, dictate three principles and guidelines under which research on humans must be conducted, these are respect for persons, justice, and beneficence (The National Commission, 1978). These principles outline general recommendations regarding obtaining informed consent, the assessment of risk and benefit, and the recruitment of the research participants (Department of Health, 2014; Zucker, 2014), to ensure that participants as human study volunteers are protected and have a voice. By giving voice to participants this approach to research views and establishes ethics from the participant's perspective and own experiences rather than through the lens imposed by the researcher (Reinecke, Arnold, \& Palazzo, 2016).

The first ethical principle outlined in The Belmont Report is about respect for persons, a sentiment shared by Cassell (2000) and Yin (2017) who find that persons are not merely human beings, but are social, moral, and legal entities with rights to a dignified treatment and to whom obligations are due, such considerations are indispensable to a good study. As the researcher, I followed the ethical guidelines set forth in The Belmont Report. The principle of respect for persons oversees the individuality of the research participant that must always be respected, protected and not subject to outside influence in respect to the research questions (Gostin, 1995). 
The second ethical principle which is the principle of beneficence was developed to ensure that no physical and psychological harm comes to research participants and to the society at large because of the research study (Bowie, 2017; Orb, Eisenhauer, \& Wynaden, 2001). This principle considers a moral obligation to maintain research participants' original identities and when not to restrict the circulation of the research study throughout the community where the study was conducted (Orb et al., 2001). The researcher is culpable to ensure the benefits of the study outweigh reasonably anticipated risks which could have occurred during the study and may occur after. The principle of justice refers to equal shares and fairness to all research participants (Orb et al., 2001; Sieber \& Tolich, 2013).

Walden University's IRB requires that all students conducting research with humans obtain research approval. The University's IRB helps to ensure that the ethical guidelines including informed consent, minimal harm, undue burden on participants, privacy, and confidentiality are maintained rather than overlooked (Dziak, 2017; Kendall \& Halliday, 2014). Data collection commenced only after IRB approval was conceived, not before. The research participants were free to ask questions regarding the research (Patton, 2014), and were also reminded of their free will to withdraw from the study at any time they desired without any implications or risk for deciding so.

I followed a specific arrangement in the recording of the data and materials from the interviews that allowed for the examination of my observations and assessments from the research subjects, allowing myself to make sure that the nature of the research was maintained and further approved. All the collected data and interview materials were 
safeguarded against violation in order to maintain confidentiality and stored in a private and secure place which only I as the researcher have access. The data will be kept anonymous for 7 years and, after this period, will be destroyed. All participants for this research signed the Informed Consent Form which they received prior to gathering any data or materials. The researcher strictly informed the participant's engagement in this research through the research methods and the ethical examination and exploration of the research doings ensured that research findings would not be falsified (Walliman, 2017).

\section{Summary}

Chapter 3 provided an in-depth description of this study's chosen research design, highlighting the purpose for its selection. It also provided arguments for the study's rationale, the ethical aspects of the research, the role of the researcher and the measures used to ensure quality control. The nature of this study helped define the selected design; population sampling, participant selection, and corresponding instrumentation have become this study's choice as they align with the purpose of the research study. This chapter also provided a detailed description on the issues of trustworthiness and ethics of qualitative research that need to be adhered to with the Walden University's IRB, covering aspects of research credibility, transferability, dependability, and confirmability.

Chapter 4 oversees a revision of the data collection process, as well as an analysis and presentation of this study's research findings. This involves results obtained from each case and data source, data analysis, data coding, and field management impact of the study. Chapter 4 focuses mainly on answering this study's research question and presenting an evaluation of the findings previously posed in the study. 
Chapter 4: Results

The purpose of this qualitative multiple case study was to gain a deeper understanding on the views of stakeholders residing within impoverished communities in Angola on rapid technology diffusion and its implication on labor market challenges within their regions. I used the central research question to investigate the phenomenon at hand within the context of the empirical setting. By analyzing the daily experiences of Angolan stakeholders with the rapid diffusion of technological innovations, I gained a deeper understanding about the implications of the rapid technology diffusion from the perspectives of stakeholders regarding the labor market challenges within their impoverished regions. The central research question that led as a guide for this study was as follows: How do the views of stakeholders, residing within impoverished communities in Angola, inform innovation policy makers on the implications of rapid technology diffusion on labor market challenges within their regions?

I elaborated the study's central research question after identifying gaps in previous literature regarding the relationship between general ICT diffusion and innovation and socioeconomic growth and development in sub-Saharan African developing countries such as Angola. I identified a literature gap regarding the actual technology initiatives and labor market challenges that can benefit impoverished subSaharan African countries such as Angola and can also cause social harm, resulting in an ambiguous connection between theory, academia, and professional practice.

This study is framed by Rogers's (1995) concept of diffusion of innovations and Danquah and Amankwah-Amoah's (2017) concept of human capital and innovation in 
sub-Saharan Africa. These two concept frameworks are founded in seminal theories that explain the dynamics involved in the process of an innovation spreading among its adopters and the implications on labor market challenges and regional socioeconomic development from the perspectives of sub-Saharan African stakeholders regarding the rapid diffusion of technology within their impoverished regions (Lawson, 2014; Nipo, Bujang, \& Hassan, 2017; Pillania, 2011). A conclusive case study can increase the understanding of the impact of inclusive ICT innovations on labor productivity across low income consumer regions in sub-Saharan African countries.

Research related to the diffusion of innovation and human capital and innovation in sub-Saharan Africa contributes important insights into policy initiatives on the diffusion of innovations in impoverished communities of Angola involving the voices of stakeholders residing in these regions. This offers recommendations for research and policy in support of poverty alleviation, diffusion of innovations, and socioeconomic development in the local populations. With the findings of this empirical investigation, I aim to bring to the research foreground the voices of local populations on technology diffusion in impoverished regions of Angola by shedding a light on effects of human capital on innovation and technology diffusion while contributing original qualitative data to the study's conceptual framework.

In this chapter, I provide a description of the results of this multiple-case study research and will be divided into two main steps. The first is a thematic analysis of the data collected based on the study's multiple sources: (a) a semistructured interview protocol (see Appendix B), the items of which were designed and standardized by a 
previous researcher; (b) archival data in the form of government labor reports; and (c) reflective field notes which I kept throughout the entire data collection process. The second step follows a cross-case analysis in which I synthesize the findings of the initial thematic analysis of data to answer the study's central research question. According to Boyatzis (1998), it is possible to adopt different approaches in the use of a thematic analysis and, yet, obtain the same rigor in the result. All the approaches differ in what they offer to qualitative data analysis; "thematic analysis is flexible and what researchers do with the themes once they uncover them differs based on the intentions of the research and the process of analysis" (Boyatzis, 1998, p. 63).

In a multiple case study, the case itself may be a person, event, entity, or other unit of analysis. When people are the unit of analysis, a single case focuses on one individual, whereas a multiple case study focuses on more than one person (Yin, 2017). Being the case itself is often a person, the interpretation of the multiple case study has often been used in business and management studies in the scholarly literature such as in Brown (2017) with airport managers, Hamlett (2014) with manufacturing managers, Komodromos (2014) with university employees, and Neubert (2016) with tech firm owners. The unit of analysis in this study was the individual stakeholders from impoverished communities in Angola.

The multiple case study approach in this research follows the concept of replication logic discussed by Yin (2017). As in Yin's (2017) approach, I attempt to replicate the same findings across multiple cases as similarities and differences are traced across cases and the study results obtained in this way are deemed robust and reliable. 
Researchers have considered replication logic as a major tool in science results because one single observation cannot be trusted as it may not reflect a regularity that can be found again (Bonett, 2012). Multiple cases tend to be sampled because they can fill theoretical categories, extend emergent theory, exemplify polar types, or even replicate previously selected cases. This study does not only provide replications evidence, but extends the results of previous studies in new and considerable theoretical directions.

The number of cases in a multiple case study is relative to the study's purpose and the research question. Each case study in a multiple-case design is prone to increase the generalizability of research findings past the study's initial sample group. Researchers suggested a limited number of cases ranging from five to 10 , stating that a larger sample size could be a barrier to an in-depth understanding of the phenomena under study (Fusch \& Ness, 2015; Merriam \& Tidsdell, 2015; Schram, 2006).

In this chapter, I portray the recurrent themes and main coding categories in detail with support provided by the voices of the participants. In addition, throughout this chapter are the following: coding categories and themes, tables summarizing demographics of the study's sample population, and a cross-case synthesis of themes across cases following Yin's (2017) recommendations for rigorous multiple case study data analysis process.

\section{Research Setting}

In this multiple case study research, I collected the data by conducting in-person interviews with eight Angolan stakeholders residing within impoverished communities in Angola's province of Cuanza Sul (see Appendix C). I recruited the participants for this 
study via personal contact, approached in public places using purposeful criterion and network sampling. Once the potential participants were identified and approached, I followed up by contacting the participants in person. The scheduling of the interviews was a straightforward process as participants were approached in public buildings. Once consent was acknowledged, participants immediately felt accommodated and comfortable with providing their inputs without any constraints. The criteria for selection required participants were (a) adults over the age of 18, (b) male and female, (c) born and residing in impoverished communities in Angola, and (d) possessing knowledge regarding their experiences with the topic of the study. I conducted the interviews one-on-one in a public setting of the participants' choice in person with minimal interruptions. The semistructured format enabled the participant to become and remain fully engaged during the interview. The participants were aware of the confidentiality agreement and seemed to express themselves very openly and without any incident.

\section{Demographics}

I conducted the interviews in person, face to face. All the interviews were recorded using a voice recording software installed in a Samsung Galaxy A5 mobile/cellphone device. The interviews ranged from 13 minutes up to 20 minutes long. The participants took part in the study and eight stakeholders who are employed in totally different sectors were featured. The participants' ages ranged from21-41. Every participant interacted with technological innovations once in a while, either in their personal or professional lives, from which they were either directly or indirectly responsible for the utilization of it. 
I considered age, gender, residing condition, and understanding of the phenomenon of study since these demographic issues were pertinent variables in the defining conceptual framework. The given pseudonyms are in an $\mathrm{XY}$ format so that $\mathrm{X}$ is presented by the generic letter P symbolizing for "participant" and $\mathrm{Y}$ is the number identifier assigned to each participant. The full demographics follow in Table 1.

Table 1

Participants' Demographics and Characteristics

\begin{tabular}{|c|c|c|c|c|c|c|c|}
\hline Participant & Region & Age & Gender & Occupation & $\begin{array}{l}\text { Earns } \\
\text { Sustainable } \\
\text { Livelihood }\end{array}$ & $\begin{array}{l}\text { Owns a } \\
\text { Mobile } \\
\text { Phone }\end{array}$ & $\begin{array}{l}\text { Owns } \\
\text { another } \\
\text { Mobile } \\
\text { Device }\end{array}$ \\
\hline $\begin{array}{l}\text { Participant } \\
1\end{array}$ & $\begin{array}{l}\text { Cuanza Sul } \\
\text { - Porto } \\
\text { Amboim }\end{array}$ & 28 & $\begin{array}{l}\text { Fem } \\
\text { ale }\end{array}$ & $\begin{array}{l}\text { Supervisor at a Gas } \\
\text { Station }\end{array}$ & Yes & Yes & No \\
\hline $\begin{array}{l}\text { Participant } \\
2\end{array}$ & $\begin{array}{l}\text { Cuanza Sul } \\
\text { - Porto } \\
\text { Amboim }\end{array}$ & 34 & Male & $\begin{array}{l}\text { Manager at a } \\
\text { Cellphone Network } \\
\text { Operator Shop }\end{array}$ & Yes & Yes & Yes \\
\hline $\begin{array}{l}\text { Participant } \\
3\end{array}$ & $\begin{array}{l}\text { Cuanza Sul } \\
\text { - Sumbe }\end{array}$ & 29 & Male & $\begin{array}{l}\text { Sales Manager at a } \\
\text { Car Sales } \\
\text { Establishment }\end{array}$ & Middle & Yes & Yes \\
\hline $\begin{array}{l}\text { Participant } \\
4\end{array}$ & $\begin{array}{l}\text { Cuanza Sul } \\
\text { - Sumbe }\end{array}$ & 41 & Male & $\begin{array}{l}\text { Manager at a } \\
\text { Cellphone Network } \\
\text { Operator Shop }\end{array}$ & Yes & Yes & No \\
\hline $\begin{array}{l}\text { Participant } \\
5\end{array}$ & $\begin{array}{l}\text { Cuanza Sul } \\
- \text { Sumbe }\end{array}$ & 32 & $\begin{array}{l}\text { Fem } \\
\text { ale }\end{array}$ & $\begin{array}{l}\text { Administrative } \\
\text { Operator at a } \\
\text { Supermarket }\end{array}$ & Yes & Yes & No \\
\hline $\begin{array}{l}\text { Participant } \\
6\end{array}$ & $\begin{array}{l}\text { Cuanza Sul } \\
- \text { Sumbe }\end{array}$ & 21 & Male & $\begin{array}{l}\text { Administrative } \\
\text { Assistant at a } \\
\text { Pharmacy } \\
\text { Establishment }\end{array}$ & Yes & Yes & No \\
\hline $\begin{array}{l}\text { Participant } \\
7\end{array}$ & $\begin{array}{l}\text { Cuanza Sul } \\
\text { - Sumbe }\end{array}$ & 38 & Male & School Teacher & Reasonable & Yes & No \\
\hline $\begin{array}{l}\text { Participant } \\
8\end{array}$ & $\begin{array}{l}\text { Cuanza Sul } \\
\text { - Sumbe }\end{array}$ & 30 & Male & $\begin{array}{l}\text { Cook at a Hotel } \\
\text { Establishment }\end{array}$ & Reasonable & Yes & No \\
\hline
\end{tabular}




\section{Data Collection}

The data collection process began on March 1, 2019, following IRB approval from Walden University (Approval Number IRB Approval \#:02-22-19-0514391). The

data collection process concluded on the same day March 1, 2019, when data analysis of interviews and reflective field notes uncovered no new themes, compelling me to conclude the presence of saturation. The participant checking process, however, concluded in the next day March 2, 2019. The evidence of data saturation in themes became clear during the seventh semistructured interview with Participant P6; his responses were familiar to the responses of P4 and P5. In the seventh and eighth interviews with P7 and P8, I did not uncover any new data or themes in the semistructured interview compared to the responses from participants P2, P3, P4, P5, P7, and P8.

The evidence of data saturation within the set of raw data was manifested in themes that included issues of lack of financial resources for technology adoption and lack of public investment to support local digital entrepreneurship. This appeared in the form of challenges of the poor in gaining access to technology in their local communities. The method, scope, and number of interviews for this exploratory study relied on indepth interviews as did other similar studies (Hamlett, 2014; Neubert, 2016). I used data triangulation to assess data points which pointed to similar conclusions, while also using immersion and crystallization in recognition of the potential existence of multiple realities socially constructed. I triangulated the data across individual cases and with observations developed in the literature review and field work, as well as participants' 
and interviewer's post reflections. I structured the emerging patterns from the analysis into general categories and themes to address the purpose of the study and research question to make an original contribution and further extend the theoretical foundation of the study's conceptual framework.

Over a total period of 6 days following IRB approval from Walden University, I correlated two main tasks: (a) recording reflective field notes, and (b) reviewing the seminal literature. However, within a period of 2 days, I was able to correlate three tasks: (a) participant recruitment, (b) scheduling and conducting interviews, (c) transcript review by the participants of the study. I implemented an audit trail within the data collection process to establish rigor. The study's interview guide, which consisted of semistructured questions and probes that explored Angolan stakeholders' views of rapid diffusion of technology and labor market challenges within their regions, was designed and validated by Matthews (2017), whose research is on diffusion of innovation in African underdeveloped countries was also guided by seminal author Rogers's (1995) concept of diffusion of innovations. The interview guide that I utilized was also supported by Danquah and Amankwah-Amoah's (2017) concept of human capital and innovation in sub-Saharan Africa, and Foster and Heeks's (2013) concept of inclusive innovation that defines the link between a new invention and its widespread adoption by low income consumers looking at how innovation impacts individuals belonging to the lowest income groups (Onsongo \& Schot, 2017). The semistructured interview method and protocol was intended to enhance my ability to make meaning from the phenomenon by understanding it from the participant's point of view. 
Data collection consisted of eight in-depth face-to-face in-person interviews. I scheduled the interviews once consent was obtained by the participant and times were set based on participants' preference. I conducted the interviews in public settings, including public buildings.

Reflective field notes were maintained by me one day after IRB approval by Walden University on February 22, 2019, recording my thoughts, travel plans, and reflections throughout the data collection process. I recorded the reactions to formal aspects of the data collection process including the responses of the participants, the recruitment process, and the receipt of the consent forms. I also recorded my reactions to the informal aspects of the data collection process such as respect gained from participants, openness to share experiences as a result of interactions with me throughout this process.

Other than the expected stress of car travel to a different province and having been denied during the recruitment process three times due to people being busy and others feeling afraid to have a first-time participation in an in-depth interview research study, the interviews were conducted as expected. For every interview, participants described their everyday experiences and challenges as participants in technological innovations. The questions addressed some aspects of their daily lives as they are involved or would be involved with the use of technological innovations and how these experiences shape their understanding of the impact on labor market challenges within their regions. 


\section{Initial Contact}

I initiated contact on March 1, 2019, recruiting participants in person using purposeful criterion and network sampling strategies. The recruitment criteria were (a) adults over the age of 18, (b) male and female, (c) born and residing in impoverished communities in Angola, and (d) possessing knowledge regarding their experiences with the topic of the study. As a result of my field approach, several profiles yielded individuals with ages 21 and older, employed in the most diverse sectors that either made use of technological innovations in their personal or professional lives. All potential participants consented to the interview on March 1, 2019 and immediately and comfortably made themselves available on the spot to contribute by sharing their view and experiences about the subject matter. Further search was not necessary beyond that day.

Out of the eight interviews, there was only one delayed response to the recruitment, as the rest of the participants comfortably and immediately agreed to sit down and share views and perceptions regarding the phenomenon of investigation once they got in touch with the recruitment letter. I conducted all the interviews in a conversational partnership style (Rubin \& Rubin, 2012, p. 6), as participants described their daily experiences and perceptions regarding the impact of rapid technology diffusion and its implications on labor market challenges within their regions. There were two individuals who after presented with the recruitment letter felt uncomfortable to participate, and exhibited some sort of fear, and even asked if they were not going to be arrested somehow. From the individuals that agreed to participate only one appointed 
another potential participant who fit the criteria regarding the study. All others were unable to indicate someone they knew would fit the criteria.

\section{Interviews}

Seven of the participants responded immediately after initial contact and I obtained their formal consent a few minutes after. Only one participant that responded to the initial contact provided formal consent after a three-hour period and was immediately ready to be interviewed. The rest of participants felt comfortable to be interviewed immediately after providing the formal consent.

Upon receiving formal consent from seven of the participants, the interviews were scheduled almost immediately. The time difference was only (a) between the time participants received the recruitment letter and took time to read it on the spot, (b) between the time they manifested interest upon reading the recruitment letter and the consent form was given to them to read, and (c) the time they agreed to participate immediately after reading and signing the consent form. During the recruitment process two potential participants approached in public rejected the invitation to participate. One participant rejected on the basis that she felt uncomfortable to provide information that might otherwise jeopardize her and make her go to jail. The other participant, though, she felt that the research study was significant, simply felt that she had no time to participate or even schedule an interview for a later time.

Every participant agreed that the interview conversation would be recorded via a software program installed in a Samsung cellphone device Galaxy A5. There were no interruptions apart from the noise of mostly open public places chosen by the 
participants; as they were approached in public, they felt very comfortable to choose a place within the settings to be interviewed and the interviews were conducted successfully. Though all participants provided information about employment, at the time of first contact they were all approached in public, away from their job locations.

I encouraged all interviewees to respond openly to the questions. The semistructured interview occurred more in a conversational style, allowing me to seize the quality of the daily experience of the participant as well as observe nonverbal cues in a less formal interview setting. In addition, with reflective field notes, this format improved construct validity via triangulation (Guion et al., 2011).

\section{Reflective Field Notes and Journaling}

I began recording reflective field notes one day after IRB approval on February 23, 2019. I recorded my anticipations at the beginning of the data collection process, such as travelling plans, hotel accommodation, the possible disappointments and the achievements of the recruitment search and the difficult task of obtaining formal consent and scheduling interviews in the remote locations I was going to visit. I also recorded the process of selecting the most appropriate tool to use to ensure accurate data collection as well as record my own impressions and views to minimize any personal bias. As the interviewer, my focus with each interviewee was to set my total attention to their day to day experiences as they reported them in detail with an inner desire that their voices be heard. I analyzed attitudes and tones of the participants as well as their nonverbal expressions. Within a confidential setting, as the field notes and review of transcripts 
were shared with participants, it provided them with an opportunity them to reflect on their responses and sentiments (Bolger, Davis, \& Rafaeli, 2003).

Very few observations were noted down during the interview, I on the other hand reflected afterward and followed up with listening to the audio recordings if needed for inference (Patton, 2014). In addition to establishing patterns and themes, this provided some help as the interview process progressed. The mindset of the participant could be understood by their nonverbal expressions such as slumping shoulders, looking off in reflection, making movements with their hands, by taking deep breaths at particular questions, rolling of the eyes, and hand wringing. The handwritten notes provided important information as each interviewee expressed his/her daily experiences and the deep reflection and recollection they experience.

I also observed how some participants presented themselves firmly, whereas others seemed very opinionated and talkative, but all conveyed an awareness of the obstacles they experience daily in their impoverished communities as local stakeholders. Although the study was concerned with the daily experiences and perceptions of stakeholders residing within impoverished communities, I noticed and reflected that there were instances where some stakeholders exhibited frustration as they came in contact with what appeared to be delicate subject matters. In trusting, some participants stated that they were successful with technological innovations usage in their daily usage and activities as their obligations and the current technological market mandates.

The topic of public policy was also pronounced. A few participants were able to recall experiences where the needs of the poor communities regarding the diffusion of 
technologies did not reflect the local government policies; as so, some believed that the government of Angola should revise its public policies to address the needs and demands of local community stakeholders as means to aid in combating poverty and alleviate unemployment. Interestingly, the stakeholders stated that they were compelled to abandon their remote rural communities to move into the cities where minimum conditions appeared to better serve their technological needs.

\section{Transcript Review}

Once interviews were transcribed, each participant received the transcription personally the next day for verification. This back and forth exchange between the researcher and participant assured accuracy and cleared any thoughts the participant felt may not have been adequately expressed during the interview. This exchange process was meant to reduce concerns over the accuracy of data and improvement of credibility (Merriam \& Tisdell, 2015). Overall, there were no changes made in the interview transcriptions. The responses to the request that participants review the transcript and confirm its accuracy or make changes as needed was a very quick process.

All the participants responded immediately, as the exchange process was done in person. I believe that this free schedule of the participants was due to the fact that the exchange day, the next day after the interviews, was a Saturday. Their assurance in the ability of the recording to transpose their words as they were spoken, so transcription was more of a formality. After a kind reminder, participants affirmed the accuracy of the transcriptions and the data were then used for coding. Transcriptions suffered minor edits with no bearing on the topic of interest for this research study. Once transcripts were 
edited and updated, hand coding took place and all the approved files of the participants were stored as per the data collection design in Chapter 3.

\section{Data Analysis}

For raw data analysis a descriptive coding strategy discussed by Saldana (2016) was used in this study. I adopted a descriptive coding strategy to give meanings to raw data segments (Saldana, 2016) in a way to use emerging words and phrases for categorization and thematic analysis. The raw data obtained from the transcripts (collected from the interviews), contained the experiences of all eight participants. The detailed information collected from the data, provided an in-depth contextual understanding of the stakeholders' experiences regarding the diffusion of technological innovations in their impoverished regions.

In qualitative research studies, the process of data collection is driven by the coding. This often causes the researcher to reshape instruments and perspectives as the study progresses. This reshaping of thematic analysis is what occurred during this multiple case study, which in turn led to themes that emerged from stakeholders who resided within impoverished communities in Angola. Considering that qualitative exploratory studies are used to explore real world issues with the purpose of understanding the processes behind an under-researched area, the social phenomenon can be explored as soon as data collection process becomes tangible and continues through the data analysis process (Eisenhardt, 1989; Stake, 2013).

This approach enables the researchers to explore, compare, and contrast research results across cases (Yin, 2017). Comparing and contrasting cases leads to robust results 
when using inductive theory where methods and design are rooted in the methodological literature. An inductive research approach was used as part of the multiple case study strategy, as it allowed themes to emerge from the data, and hence allowed Angolan stakeholders' perspectives within impoverished regions to drive data analysis and make recommendations for further research (Yin, 2017). According to Stake (2013), multiple case study methodology does not quite fit all research purposes, but mainly for those advancing theory generation and theory extension. This multiple case study design carries an immense significance in terms of replication as it supports the exploration of in-depth social phenomena as I compared results between and across eight cases analyzed for this research study.

Thematic analysis is driven by the standardized method of identifying, analyzing, and reporting patterns (coding raw data) typically from conducted interviews (Cruzes, Dybå, Runeson, \& Höst, 2014). This process of examining and providing meaning and provision of a description of the social reality of participants is done through the creation of a theme (Vaismoradi, Jones, Turunen, \& Snelgrove, 2016). Thematic analysis is therefore, classified under the qualitative descriptive research design and follows a set of techniques to analyze textual data to formulate and develop themes. I developed the data for this study with rigor by categorizing and recording thoughts that were similar in the use of views, key words, and sentiments.

I conducted my thematic analysis by hand coding the data through systematically mapping out code in a descriptive approach (Saldana, 2016, p. 102). This descriptive coding method was used to assign meanings to the identified blocks of data forming an 
inventory of words or phrases that are used for indexing and categorization of data (Saldana, 2016). Themes were revealed from the interviews and the description of the daily experiences of the participants (Vaismoradi et al., 2016). As soon as the transcript review checking process was finalized, I hand coded the interview notes and used a Microsoft Excel spreadsheet to record the participants' transcribed responses. The triangulation of data along with word coding also allowed the recognition of number of patterns that also increased dependability by drawing attention to common relationships between cases (Yin, 2017).

As data were entered, I highlighted the key phrases that seemed appropriate to answering the interview questions. The interview discussions served as the base for thematic analysis using pattern recognition. The themes as well as the patterns were set apart as content analysis progressed and those considered nonrecurring evidences were associated to individual case compositions.

The ground up data analysis strategy discussed by Yin (2017) was used to identify codes from raw data. The sentences that were considered relevant to answering the study's research question were extracted from the transcribed interview data for each individual participant. The extracted blocks of data were evaluated and consequently codes were assigned to them. The codes were recorded according to each interview question. More coding analysis of the interviews resulted in the categorization of various themes as the relationships between cases were distinguished (Yin, 2017). Following is a description of the finalized categories and themes as per this multiple case study, illustrating how coding was done for each of the identified categories and themes. 
In total, seven categories enclosing a total of 17 themes were identified for this study. The categories are (a) diffusion of innovations and adoption circumstances, (b) compatibility of technology with social values, (c) trialability within the cultural context, (d) adoption of technology, (e) innovation decision process factors, (f) trust in technology by community stakeholders, (g) inclusive innovation for low-income stakeholders.

The seven coding categories are grounded in the study conceptual framework. This includes the diffusion of innovations conceptual framework (Rogers, 1995) and the human capital and innovation in sub-Saharan Africa (Danquah \& Amankwah-Amoah, 2017). The diffusion of innovations conceptual framework proposed by Rogers (1995) refers to relative advantage, compatibility, complexity, observability, and trialability as important attributes of innovation for its wider acceptance. Acceptance of an innovation in a developing country in turn depends on its compatibility with the existing social norms and trialability within a context of existing cultural practices, which often require a good fit with local needs, local demand, local resources, local skills, and/or local knowledge (Lawson, 2014; Pillania, 2011). The diffusion of innovation incorporates the adoption process of many people over a period (Rogers, 1995), given the risk of innovation and its related cost and accumulative nature. The human capital and innovation in sub-Saharan Africa conceptual framework (Danquah \& Amankwah-Amoah (2017) explains on the significance of stakeholders' views on rapid technology diffusion and its implication on labor market challenges within impoverished communities in subSaharan Africa. It incorporates the role of human capital in production processes and the incentives to invest in skills, including pre-labor market investments. 
With the use of manual descriptive coding, I was able to get much deeper with the data (Cronin, 2014) in such a way that it helped get a more contextual understanding of the data (Finfgeld-Connett, 2013). Being a novice researcher, the descriptive manual coding method was more effective and suitable for me to use than Computer Assisted Qualitative Data Analysis (CAQDAS) software programs for this study's analysis of data. The data analysis considered all data obtained from the study's archival data in the form of government labor reports. Yet, my reflective field notes were kept throughout the data collection process and were used to reflect on participants' responses during the within-case and cross-case data analysis.

Seven coding categories are based on the conceptual framework and 17 themes gleaned from the thematic analysis.

Coding: Diffusion of innovations and adoption circumstances

Themes: 1) Lack of internet access; 2) Low access to electricity; 3) Lack of financial resources for technology adoption;

Coding: Compatibility of technology with social values

Themes: 1) Lack of local role models in diffusion of innovation; 2) Rural dwellers technology acceptance;

Coding: Trialability within the cultural context

Themes: 1) Young, agrarian population not involved with technology; 2) The poor excluded from the mainstream banking system; 
Coding: Adoption of technology

Themes: 1) Low adoption within impoverished communities; 2) Challenges of the poor in gaining access to technology; 3) High rate of illiteracy;

Coding: Innovation-decision process factors

Themes: 1) Lack of ICT education; 2) Lack of financial resources; 3) Limited to no access to Internet;

Coding: Trust in technology by community stakeholders

Themes: 1) Mistrust in information-sharing required by technology;

Coding: Inclusive innovation for low-income stakeholders

Themes: 1) Lack of public investment to support local digital entrepreneurship; 2)

Exclusion factors of local stakeholders in diffusion of innovation; 3) Misalignment of public policy and local economic conditions. 
Table 2

Coding and Theme Examples

\begin{tabular}{|c|c|c|c|}
\hline Participant & Interview Excerpt & Category & Theme \\
\hline Participant 1 & $\begin{array}{l}\text { "Sometimes it is the jobs that do } \\
\text { not show up; For example, here in } \\
\text { Porto Amboim people survive } \\
\text { mainly on fishing; Yes, there are } \\
\text { also people that because of the lack } \\
\text { of financial resources cannot } \\
\text { study; [Signaled with the hand the } \\
\text { lack of cash]" }\end{array}$ & $\begin{array}{l}\text { Diffusion of innovations } \\
\text { and adoption } \\
\text { circumstances. }\end{array}$ & $\begin{array}{l}\text { 1) Lack of internet access; } \\
\text { 2) Low access to } \\
\text { electricity; 3) Lack of } \\
\text { financial resources for } \\
\text { technology adoption; }\end{array}$ \\
\hline Participant 2 & $\begin{array}{l}\text { "So, we have to work a lot in this, } \\
\text { we like very much to import ideas, } \\
\text { import everything (bring from } \\
\text { outside, oversees, what is not from } \\
\text { our culture, we need to create } \\
\text { African models). Even in our local } \\
\text { shop at the service desk, place } \\
\text { people who are more inclined or } \\
\text { has knowledge of the local national } \\
\text { languages, to serve the locals in } \\
\text { their local dialect. When we come } \\
\text { across people speaking a dialect } \\
\text { and the service desk responds in } \\
\text { the same language, you clearly see } \\
\text { that people become more propense } \\
\text { to accept." }\end{array}$ & $\begin{array}{l}\text { Compatibility of } \\
\text { technology with social } \\
\text { values. }\end{array}$ & $\begin{array}{l}\text { 1) lack of local role } \\
\text { models in diffusion of } \\
\text { innovation; 2) Rural } \\
\text { dwellers technology } \\
\text { acceptance; }\end{array}$ \\
\hline Participant 3 & $\begin{array}{l}\text { "Also, the lack of education, } \\
\text { economic conditions, the inability } \\
\text { for people to have access to } \\
\text { technology because they don't } \\
\text { have the economic conditions to } \\
\text { obtain it; also, the excessive price } \\
\text { of technology in third world } \\
\text { countries." }\end{array}$ & Adoption of technology. & $\begin{array}{l}\text { 1) Low adoption within } \\
\text { impoverished } \\
\text { communities; 2) } \\
\text { Challenges of the poor in } \\
\text { gaining access to } \\
\text { technology; 3) High rate } \\
\text { of illiteracy; }\end{array}$ \\
\hline
\end{tabular}




\section{(continued)}

\begin{tabular}{|c|c|c|c|}
\hline Participant & Interview Excerpt & Category & Theme \\
\hline Participant 4 & $\begin{array}{l}\text { "These things I just said are } \\
\text { exactly the problem of } \\
\text { infrastructures, lack of network } \\
\text { access to these communities, and } \\
\text { they are poor communities with } \\
\text { high rate of unemployment, how } \\
\text { are they going to have access to } \\
\text { technology if they don't have the } \\
\text { financial power to buy for example } \\
\text { a cellphone data recharge plan of } \\
\$ 1.5 ? \text { If you go a bit deeper you } \\
\text { will reach places where people } \\
\text { never heard about technology, } \\
\text { never had access to a mobile } \\
\text { device because of the shortage of } \\
\text { the network itself. I can of course } \\
\text { have limitations on what I just said } \\
\text { "access to the network," and there } \\
\text { are areas that have limited access } \\
\text { to telecommunications. }\end{array}$ & $\begin{array}{l}\text { Innovation decision } \\
\text { process factors. }\end{array}$ & $\begin{array}{l}\text { 1) Lack of ICT education; } \\
\text { 2) Lack of financial } \\
\text { resources; 3) Limited to } \\
\text { no access to Internet; }\end{array}$ \\
\hline Participant 5 & $\begin{array}{l}\text { "The problem is not just } \\
\text { financial/economic, but there is } \\
\text { also the factor of mistrust. For } \\
\text { example, at the } 2017 \text { election, at } \\
\text { work people exhibited fear in } \\
\text { providing their personal } \\
\text { information, thinking that they } \\
\text { were going to be watched. I, for } \\
\text { example for a long time I never felt } \\
\text { comfortable in doing online } \\
\text { shopping, fearing that I would } \\
\text { have my pin cards hacked because } \\
\text { I did not know about the secure } \\
\text { sites" }\end{array}$ & $\begin{array}{l}\text { Trust in technology by } \\
\text { community stakeholders. }\end{array}$ & $\begin{array}{l}\text { 1) Mistrust in } \\
\text { information-sharing } \\
\text { required by technology; }\end{array}$ \\
\hline
\end{tabular}




\section{(continued)}

\begin{tabular}{|c|c|c|c|}
\hline Participant & Interview Excerpt & Category & Theme \\
\hline Participant 6 & $\begin{array}{l}\text { "It is the essential. Revision of } \\
\text { public policies. As long as we still } \\
\text { have policies not directed toward } \\
\text { the population, we are doomed. I } \\
\text { believe this problem is } \\
\text { conjunctural because we have } \\
\text { people that have finished their } \\
\text { university degree but have become } \\
\text { roof rack, moto taxis because they } \\
\text { don't have opportunities. Human } \\
\text { capital we have, many good people } \\
\text { that are interested in working, it is } \\
\text { just the lack of opportunities. I } \\
\text { think at first provide opportunities } \\
\text { to entrepreneurs/businessmen. The } \\
\text { government applies a heavy hand } \\
\text { on the entrepreneurs. So, there is a } \\
\text { need to revise the public policies." }\end{array}$ & $\begin{array}{l}\text { Inclusive innovation for } \\
\text { low-income stakeholders. }\end{array}$ & $\begin{array}{l}\text { 1) Lack of public } \\
\text { investment to support } \\
\text { local digital } \\
\text { entrepreneurship; 2) } \\
\text { Exclusion factors of local } \\
\text { stakeholders in diffusion } \\
\text { of innovation; } 3 \text { ) } \\
\text { Misalignment of public } \\
\text { policy and local economic } \\
\text { conditions; }\end{array}$ \\
\hline Participant 7 & $\begin{array}{l}\text { "People who reside in the city and } \\
\text { go there for agricultural products, } \\
\text { usually get in touch with them and } \\
\text { these technologies, but they } \\
\text { basically don't know and don't } \\
\text { have any information about it. } \\
\text { They basically don't use these } \\
\text { technologies; Oh, in this case it has } \\
\text { to do with the financial capacities. } \\
\text { Because of this we don't have } \\
\text { access nor even } 20 \% \text { of it, mainly } \\
\text { us in the rural communities it is } \\
\text { very complicates because we do } \\
\text { not have the purchasing power; We } \\
\text { need to analyze the policies. What } \\
\text { the government must do in the } \\
\text { sector of education to bring } \\
\text { development to the education } \\
\text { itself. We will find a number of } \\
\text { factors that need to be revised by } \\
\text { the government;" }\end{array}$ & $\begin{array}{l}\text { Trialability within the } \\
\text { cultural context. }\end{array}$ & $\begin{array}{l}\text { 1) Young, agrarian } \\
\text { population not involved } \\
\text { with technology; 2) The } \\
\text { poor excluded from the } \\
\text { mainstream banking } \\
\text { system; }\end{array}$ \\
\hline
\end{tabular}


The following is a brief description of each of the 17 themes.

Lack of internet access. This theme refers to the telecommunications infrastructural problems and limitations for rural communities to have access to internet services.

Low access to electricity. This theme refers to a basic and concurrent infrastructure drawback in both rural communities and major cities in Angola.

Lack of financial resources for technology adoption. This theme refers to the lack of financial conditions of stakeholders toward the adoption of ICTs in their rural communities.

Lack of local role models in diffusion of innovation. This theme refers to a common practice among Angolan entrepreneurs to value foreign knowledge and practices instead of local in the diffusion of innovations.

Rural dwellers technology acceptance. This theme refers to rural stakeholders' resistance to technology innovations acceptance as it presents itself nowadays.

Low adoption within impoverished communities. This theme refers to the low rate at which technological innovations are adopted within rural communities due to its various social conditions.

Challenges of the poor in gaining access to technology. This theme refers to the different challenges stakeholders in poor rural communities go through to gain access to basic internet services, and this include the lack of financial conditions and basic technological education. 
High rate of illiteracy. This theme refers to the high rate of illiteracy encountered in the rural communities of Angola that often contributes to the major issues of low adoption rate of technological innovations in these communities.

Lack of ICT education. This theme refers to the lack of technological education in Angola impoverished communities that often culminates to the lack of ICT investment and interest from local stakeholders.

Lack of financial resources. This theme refers to the financial difficulties stakeholders have in rural communities that will not allow them to adopt or get more involved with the technological innovations in their regions.

Limited to no access to Internet. This theme refers to those regions that are both limited in telecommunications infrastructure and are unable to access internet services due to the excessive price of technology.

Mistrust in information-sharing required by technology. This theme refers to rural stakeholders' fears that technological innovation as it presents itself today, are used for manipulative propaganda as means of controlling the poor and that technology will displace unskilled workers and cause further joblessness.

Lack of public investment to support local digital entrepreneurship. This theme refers to the lack of government investments in these poor communities to promote entrepreneurship and combat unemployment.

Exclusion factors of local stakeholders in diffusion of innovation. This theme refers to those factors that are part of everyday stakeholders' lives that will not allow them to have active participation in events of technological innovations. 
Misalignment of public policy and local economic conditions. This theme refers to the lack of government policies aligned with the local people's needs and demands that culminates to a conjunctural problem that devalues the local human capital in these impoverished regions.

Young, agrarian population not involved with technology. This theme refers to the agrarian people within the impoverished regions of Angola that have no access to any technology unless people from the city take the technological means to them as they go for agricultural products in the farm.

The poor excluded from the mainstream banking system. This theme refers to the lack of financial assistance and purchasing power stakeholders have in the access and acquisition of technological innovations.

\section{Evidence of Trustworthiness}

Strategies for rigor in qualitative research must be put in place by the researcher to ensure the trustworthiness of the study and its outcomes (Houghton et al., 2013). To enhance the trustworthiness of this multiple-case study, my data analysis followed a ground-up strategy, which ensured that findings unfolded naturally and reflected the true lived experiences of the participants. I have taken the following steps to ensure that the rigor and trustworthiness of the processes used for conducting this study: (a) I provided detailed description of the strategies and procedures for recruiting study participants, (b) I provided detailed description of my interactions with the participants during and after data collection, and (c) I provided a detailed description of how the interviews were audio recorded, transcribed, and member-checked. 


\section{Credibility}

I ensured the credibility of this study by following a systematic process as identified by seminal methodology scholars (Denzin \& Lincoln, 2011; Patton, 2014; Yin, 2017) and by describing my experiences so that confidence could be achieved at the verification of research findings with the study participants (Anney, 2014; Cope, 2013). The credibility of the data is reflected by a researcher's, personal reflexivity such as looking inwards to see how the researcher himself has informed the research and by looking outward to the members of the communities being researched (Cope, 2013; Houghton, Casey, Shaw, \& Murphy, 2013; Treharne \& Riggs, 2015).

The credibility criteria provide assurances that the responses given by the participants during the interviews reflected their lived experiences regarding the study phenomenon (Baillie, 2015). I ensured the credibility of this study by taking the following steps: (a) by using purposeful sampling technique, I ensured that the selected participants meet the study's inclusion criteria; (b) the interviews were held in the participants' natural environments making them more amenable to volunteer in-depth information; (c) I used data from multiple sources including the interview responses, archival data reviews, and in my observations/reflections (Vissak, 2010); (d) I carried out member checking (Houghton et al., 2013) by the participants' review of the interview transcripts to ensure experiences and descriptions are correctly reflected in my interview transcription; and (e) my prolonged engagement with the participants before, during, and after the interviews provided further reflective notes for triangulation of data (Houghton et al., 2013). In the case of this study, the multiple case study design, the voices of these 
research participants that exhibited characteristics of similarity, dissimilarity, as well as variety and redundancy, were brought together to gain a deeper knowledge of the wider population (Stake, 2013).

\section{Transferability}

To ensure the transferability of a qualitative study, the researcher must provide assurances that the procedures adopted for the study and its findings can be applied in other settings (Houghton et al., 2013; Lincoln \& Guba, 1985). To address the issue of transferability in this study, I provided a detailed and transparent description of all the strategies adopted in the process of recruiting participants, interactions with participants, data collection, data recording, and data analysis (Lincoln \& Guba, 1985). I provided detailed description of each participant such that the contexts under which data for this study were obtained will be helpful to readers in understanding or possibly applying the outcomes of this study in other settings. My personal experiences of my country's impoverished populations as an Angolan myself, ensured robust scrutiny of data to provide reliable answers to the research question. I supported transferability in this study by providing thick, rich descriptions of the context, location, and of the study findings (Anney, 2014) that were derived through purposive sampling and coding of themes.

Given my actions as a researcher, I worked with the goal of my findings having relevance to individuals outside the scope of the study (Cope, 2013).

\section{Dependability}

The concept of dependability in qualitative research refers to the constancy and reliability of the data over similar conditions (Polit \& Beck, 2012), that is, for the study 
results to remain the same if the same research methods are utilized over time under different conditions (Billups, 2014). My Dissertation Committee scrutinized my decision trails throughout the research study so as to assure that my research procedure processes were well-detailed and documented (Houghton et al., 2013; Polit, Beck, \& Hungler, 2006). I ensured detailed documentation of all the procedures for participants' selection, contacting of participants, interview recording, interview transcription, and data analysis. With my Dissertation Committee serving as external auditors, the dependability of the findings was such that one might predict they could be replicated with similar participants under the similar conditions (Cohen, Manion, \& Morrison, 2011; Koch, 2006). I further ensured that for the dependability of this study the conceptual framework was rooted on a strong and widely accepted theoretical foundation (Rogers's diffusion of innovation model) for investigating technology adoption and acceptance in developing countries. This ensured that there is an alignment between the outcomes of the study and other existing knowledge in the literature regarding rapid technology diffusion and its implication on labor market challenges within impoverished communities of developing countries. All data used or obtained during this study were properly and securely preserved.

\section{Confirmability}

Researchers achieve confirmability in qualitative research when they are able to demonstrate that the research findings are a function solely of the research participants and not their own biased motivations, interests, and viewpoints (Polit \& Beck, 2012). By enacting measures, I established the rationale that ensures that the research findings are 
based on evidence and without predisposition (Shenton, 2004). Confirmability has implications for studies such as this one that provides policy recommendations (Moon, Brewer, Januchowski-Hartley, Adams, \& Blackman, 2016), so I ensured that I did not ask leading questions or inadvertently "feed" participants certain answers by strictly adhering to the interview protocol script. Where a participant omitted specific areas that were relevant to the research question, I drew their attention to elucidate on those areas without making any assertions or inferences as to what answer they should provide. I ensured confirmability of this study's results by clearly describing the study conclusions in a way that could be replicated by future researchers (Merriam \& Grenier, 2019).

\section{Study Results}

In this theory-generating multiple case research the central research question was developed after an extensive review of the literature so as to provide answers within the context of the empirical setting (Eisenhardt \& Graebner, 2007; Yin, 2017). By recording the views of stakeholders on rapid technology diffusion within impoverished communities in Angola, a deeper understanding was provided on the implication on rapid technology diffusion for the labor market challenges participants faced within their regions. The research question guiding this study was as follows: How do the views of stakeholders, residing within impoverished communities in Angola, inform innovation policy makers on the implications of rapid technology diffusion on labor market challenges within their regions? This multiple-case study revealed experiences and viewpoints of the participants which emerged from the data analysis and can be attributed to the related themes and patterns presented in the results of the study. The data analysis 
techniques to produce the study's results is presented in this section in a two-step procedure: (a) thematic analysis of the textual data and (b) cross-case synthesis analysis. An analysis which examines the similarities, differences, and themes across cases is referred to as a cross-case synthesis analysis. The cross-case analysis is utilized when the unit of analysis is a case, which is a bounded unit just as an individual, artifact, place, or event or a group (Yin, 2017). A constant comparative approach was used as the analysis of data throughout so that the new group of data was compared to the existing data throughout the entire study to contrast and compare the thematic patterns across cases (Yin, 2017). The goal in this phase of the analysis was to create rich, thick commentaries from every participant, which would reveal their personal experiences and perceptions of the phenomenon under exploration (Stake, 2006).

The primary intention behind the two-step process in the data analysis phase was centered on development of thick, rich, relevant descriptions emerging from each interview participant that could further unveil their experiences, and views on the central topic of study. The data analysis takes into regard the overall data that include interviews, archival data, reflective journal notes, member verified transcriptions, and the findings of seminal research articles. The analysis continued with procedure of cross-case synthesis for familiarity, unfamiliarity, and redundancy as well as crystallization of the data compiled (Stake, 2013). The themes that emerged were classified, and the findings were cross referenced for graphic representation. This established the groundwork for crosscase analysis, where each case is managed separately yet analyzed collectively with other cases in the study, strengthening generalizing the findings (Eisenhardt, 1989; Yin, 2017). 
I followed the same procedure for the collection of data for all the eight participants. I adopted a consistent process for manual coding, categorization, and identification of emergent themes across the eight cases (Yin, 2017).

\section{First Phase: Thematic Analysis of the Textual Data}

There are step by step processes in the literature that suggest how to conduct a relevant and rigorous thematic analysis (Nowell, Norris, White, \& Moules, 2017). The written narrative of the thematic analysis provides "a concise, coherent, logical, nonrepetitive, and interesting account of the data within and across themes" (Nowell et al., 2017, p. 1). A thematic analysis must also include a clear presentation of the logical processes that depicts how the findings were developed overall so that the implications that are made in relation to the data set are considered dependable and credible. The thematic analysis that I conducted for this study followed King's (2004) suggestion to include direct quotes from participants as a foundational element of the final report. Supported by key insights from the eight in-depth interviews, this section presents the 17 themes that emerged and are analyzed and presented in relation to the central research question.

Lack of internet access. This theme refers to the telecommunication's infrastructural problems and limitations for rural communities to have access to internet services. Diffusion of innovation and technology is thwarted in impoverished regions of Angola for many reasons, with pivotal ones being the country's high poverty rate and poor infrastructure in rural areas. Diffusion of technology cannot happen without stable access to the World Wide Web through the Internet. Participant 4 succinctly summed up 
the daily challenges and limitations in impoverished regions of Angola, some of which lack the infrastructure most urban residents take for granted:

"These things I just said are exactly the problem of infrastructures, lack of network access to these communities, and they are poor communities with high rate of unemployment, how are they going to have access to technology if they don't have the financial power to buy for example a cellphone data recharge plan of $\$ 1.5$ ? If you go a bit deeper (in the rural areas) you will reach places where people never heard about technology, never had access to a mobile device because of the shortage of the network itself."

Even those rural communities that have Internet access, the financial cost is prohibitive to many residents. Reflecting on these barriers, Participant 7 stated: "The price of the internet itself. Sometimes when looking to download an article on the internet which just to download could take a Gigabyte...It is very expensive, very expensive. It is with great sacrifice that we access the internet".

Low access to electricity. This theme refers to a basic and concurrent infrastructure drawback in both rural communities and major cities in Angola. All participants recognized that the slowness of rural electrification in Angola causes impoverished communities to feel a lack of social inclusion compared to the urban dwellers of the country. This sense of "social exclusion" appears to lead rural dwellers to fear technology and what to them is the unknown. Most participants do use the Internet at their work, yet even this usage comes with disruption due to the rural areas' low access to electricity. Participant 3 summarized the situation in the rural areas as follows: 
"Because, being them so poor and low, they don't even have access to the basic stuff, such as television, access to electricity... which in turn causes a total disinterest of the people toward technology, because of the lack of knowledge, infrastructure, the lack of means that would enable them to connect to the rest of the world."

The issue of low access to electricity in the rural communities in Angola also becomes an impediment to local stakeholders that return to their communities with an education or professional and technical training, as Participant 7 says: "You use the internet if you have conditions to do so. We have here various educated people that because of the lack of opportunities and (infrastructure) we spoke about, (have) their diplomas and are doing nothing”.

Lack of financial resources for technology adoption. This theme refers to the lack of financial conditions of stakeholders toward the adoption of ICTs in their rural communities. The Angolan population lives mainly on agricultural and fishing. The agricultural sector alone covers about $70 \%$ of the Angolan population's main activity for subsistence, nevertheless, it accounts for only 12\% of Angola's GDP (OECD, 2017b). Despite the importance of this sector, researchers noticed a decline in the importance of this sector in the rural areas, due to the expansion of non-farm activities as processes of economic development (Davis, Di Giuseppe, \& Zezza, 2017). Participant 1 mentioned:

"for example, here in Porto Amboim people survive mainly on fishing; those people who have more possibilities to open a canteen (this is common small 
business in Angola that sell all sort of everyday consumable products), a pharmacy, a shop to provide employment".

In other words, "there isn't much possibilities and diversity of jobs", people are poor in this side of the country without much choice. Therefore, unemployment tends to be high in rural regions of Angola, and for this reasons, financial resources to acquire technology becomes almost impossible for these populations since all they earn is directed toward their livelihood.

Lack of local role models in diffusion of innovation. This theme refers to a common practice among Angolan entrepreneurs to value foreign knowledge and practices instead of local in the diffusion of innovations. Researchers believe that if institutions in a developing country such as that of Angola devalue and undervalue local knowledge, acceptance of an innovation in that country becomes difficult (Amavilah, 2016). For technology diffusion to succeed at the local level, its compatibility with the existing social norms and trialability within a context of existing cultural practices is imperative. As mentioned by Participant 2:

"We came to realize that "CompanyA" (the company he works for) doesn't communicate as good as it should. For example, we want to make a publicity in Porto Amboim or Sumbe and are placing "Actress A" (Angolan female 2011 miss universe) in the advertising poster! ActressA doesn't say (mean) anything to the people of those regions in the outdoor, and place in their local and consensual figures, like a famous "soba" (traditional rural authorities). This will transfer sort of more security for the product being advertised. So, we 
have to work a lot in this, we like very much to import ideas, import everything (bring from outside, oversees, what is not from our culture, we need to create African models)".

Therefore, technology diffusion to succeed in Angola, must prove to a local community that it will be a good fit with local needs, local demand, local resources, local skills, and/or local knowledge (Lawson, 2014; Pillania, 2011).

Rural dwellers technology acceptance. This theme refers to rural stakeholders' resistance to technology innovations acceptance as it presents itself nowadays. Scholars in sub-Saharan African countries reported challenges of rapid technology diffusion such as people's resistance to rapid changes and fear of the Internet being used for manipulation and propaganda (Pierskalla \& Hollenbach, 2013). Participant 2 specifically commented on some aspects of his everyday life experiences within his job activities not just as a manager but as a sales representative, saying:

"We defended the fact that Company should implement in our Call Center the learning of national languages (dialects). When we come across people speaking a dialect and the service desk responds in the same language, you clearly see that people become more propense to accept, so, we also have this difficulty, the language, we came to realize that CompanyA doesn't communicate as good as it should".

Participant 3 specifically argued that rural dwellers tend to avoid technology because of its excessive price: 
"the excessive price of technology in third world countries. Because sometimes you have the technology but it is too expensive to maintain it, for example to top up (charge) your cellphone with data (for internet usage); Even to have access to information to use the technology itself is difficult. The means to have technology going (working) is also very expensive."

According to Participant 3, rural dwellers also find themselves unable to accept technology because: "the lack of education, economic conditions, the inability for people to have access to technology because they don't have the economic conditions to obtain it".

Low adoption within impoverished communities. This theme refers to the low rate at which technological innovations are adopted within rural communities due to various social conditions. Because the populations within the impoverished rural communities of Angola live mainly on traditional agriculture, their purchasing power is low, financial resources for technology acquisition are extremely limited, and knowledge to interact with technology, in general, is almost none. There is also the problem of infrastructures, road access, lack of electricity, and the lack of contact to technology itself.

Researchers found that the strong adoption of mobile data services by regional standards is now due to concentrated usage of mobile services among Angola's wealthier consumers in urban areas, while many rural communities are still excluded from network coverage or unable to afford the very high cost of traditional voice services (BMI, 2017b). Participant 8 summed up his daily experiences as a rural dweller, stating that: 
"Oh, in this case it has to do with the financial capacities. Because of this, we don't have access not even $20 \%$ of it, mainly us in the rural communities it is very complicated because we do not have the purchasing power. If we look at these rural communities, for them to have access to technologies it is usually related to the people who go in there to work with the populations. Perhaps for them to see a cellphone, a computer or these technologies it has to be someone who goes there. People who reside in the city and go there for agricultural products, usually get in touch with them and these technologies, but they basically don't know and don't have any information about it. They basically don't use these technologies."

Challenges of the poor in gaining access to technology. This theme refers to the different challenges stakeholders in poor rural communities go through to gain access to basic internet services, and this include the lack of financial conditions and basic technological education. Economic activity in the rural communities of Angola is weak, therefore, their financial abilities to acquire better education is limited. Basic sanitation is a problem, access to electricity a complex issue, and access to information itself tends to be one way from urban to rural and not the other way around. Participant 8 for example, mentioned that

"if you go to the rural communities you will find that family farming is the subsistence of many families and the means they use are elementary means that have nothing to do with technologies, our reality, mainly us in the province of 
Cuanza Sul, also known a type "B" province, the rate of impoverishment is too elevated."

For such reasons of poverty, lack of infrastructure, and poor education participant 8 states: "we see that people are abandoning the rural communities to be in the cities and the situation (in rural communities) gets more complicated. It is, therefore, also necessary to qualify to train the people, in this case education."

High rate of illiteracy. This theme refers to the high rate of illiteracy encountered in the rural communities of Angola that often contributes to the major issues of low adoption rate of technological innovations in these communities. Apart from poor or total lack of infrastructure, the lack of proper education in these rural communities constitutes one of the challenges of why the adoption of technology is low in rural communities and why it concerns stakeholders. Participant 2 suggests that it is the high rate of illiteracy that is most likely one of the causes of the limited participation of individuals in events of technology, by saying: "Ok, I feel this every day. Firstly, is due to the lack of training, the low level of education, and I would say academic education." Participant 8 mentioned that "people that are abandoning the rural communities to stay in the cities have a little more knowledge, the rest remains illiterate. So, these illiterates don't have means to take on the new technologies."

Lack of ICT education. This theme refers to the lack of technological education in Angola impoverished communities that often culminates to the lack of ICT investment and interest from local stakeholders. The lack of directive ICT education also culminates to stakeholders not wanting to adopt technological innovations, since they do not 
understand it. Participant 8 suggests that "professional training, also the times forces us to get updated. It has to do with the dominion, training itself. Generally speaking, in Angola, we that use ICTs, didn't have proper training and this makes things complicated." Participant 7 on the other hand mentions that "human capital we have, many good people that are interested in working, it is just the lack of opportunities." Participant 6 agrees that "if there were points were the educational system worked. not every person has the money to pay for professional training, I say the general educational system. Also, if the technological means were a bit cheaper.” Participant 3 states that “yes, because people (companies, institutions) need educated people, but people cannot get an education due to expensive rate of school attendance. People, therefore, become, illiterate."

Lack of financial resources. This theme refers to the financial difficulties stakeholders have in rural communities that won't allow them to adopt or get more involved with the technological innovations in their regions. The financial resources available to stakeholders in the rural regions of Angola are tied to their economic activities within the regions which is mainly family farming and fishing. On one side the continuous decline in the importance of this sector in the rural areas as a result of the expansion of non-farming activities (Davis, Di Giuseppe, \& Zezza, 2017), leads stakeholders to lack financially. On the other side, agriculture intensification implies a production system that is characterized by either high inputs of capital and labor or heavy usage of technologies which are heavily reliant on the availability of banking credit (Abdallah, 2016; Kolade et al., 2014; Sheahan \& Barrett, 2014). But stakeholders' 
financial resources in these regions tend to be limited and so is their capacity for technology acquisition, for knowledge acquisition, and education acquisition. Participant 5 for example, mentioned that:

"Perhaps it also has to do with the financial means because sometimes we need to buy a cellphone that might cost around $\$ 160$ and I do not have the financial means to buy such a cellphone. So, I will have technology according to my financial capacity".

Limited to no access to Internet. This theme refers to those regions that are not just limited in telecommunications infrastructure but consequently in access to internet information and are unable to access such services due to the excessive price of accessing it. Despite the lack and mostly poor telecommunications infrastructure, for those who can access internet services, the drawbacks in accessing information lies first, in the quality of the services; second in the cost to maintain such services. Participant 8 mentioned the following:

"Only that the disadvantage there is with this online system is when the system is down, in this case my work gets more complicated. If we compare in a $100 \%$ perspective, we use the online system at about $30 \%$ and $70 \%$ is the manual system. These are the disadvantages. In my point of view that is due to the internet itself, which is not enough advanced and that would facilitate our day to day work. I think it is the service itself, because we feel that the internet is very slow, the quality of the service". 
Mistrust in information-sharing required by technology. This theme refers to rural stakeholders' fears regarding technological innovation as it presents itself today. Despite the fact that technology has been regarded as the economy's backbone for many African countries, many of these country's rural regions perceive technology differently. Fears have been reported regarding potential negative impact of ICTs disclosure on the poor when modern ICTs such as communications systems are controlled by powerful groups and rapid integration into the global economy could result in exploitation (Diga et al., 2013; Njoh, 2018). Participant 2 shared his experiences regarding this aspect when dealing with stakeholders from poor communities who lack access to information and have fear when faced with the opportunity to share it:

"Well, I think it is a conjunctural and not just an isolated factor. Mostly it is a cultural and economic factor. But sometimes you'll find that it is not just about money. Some people do have money but they lack access to information because they have no contact with technology. The problem is not just financial/economic, but there is also the factor of mistrust. For example, at the 2017 election, at work people exhibited fear in providing their personal information, thinking that they were going to be watched. I for example, for a long time I never felt comfortable in doing online shopping, fearing that I would have my pin cards hacked".

\section{Lack of public investment to support local digital entrepreneurship. This}

theme refers to the lack of government investments in these poor communities to promote entrepreneurship and combat unemployment. The entrepreneurial activities in Angola 
stand low at $21.5 \%$ hindered by heavy infrastructure deficiencies (OECD, 2017b). In poor regions of Africa, entrepreneurship can foster inclusive development, combat poverty and unemployment through technology (Amankwah-Amoah, 2014). Participant 6's opinion is that "the government should have more promotional events to captivate more entrepreneurs to promote more investment in our localities".

Researchers believe that the promotion of knowledge-based entrepreneurship holds high potential for the improvement and development of sectors such as agriculture, water and energy, and technology (Tchamyou, 2016). When asked about a viable solution to combat unemployment, Participant 5 suggested that investing in entrepreneurship would create more jobs, and explained the following:

"This would be the first solution. Provide more opportunities to the young people (unemployed). In our province there are very few companies (entrepreneurship is low), so, the rate of unemployment is high. If there were more private companies, more people would be employed".

Participant 3 mentioned the following: "Today the major problem is the lack of infrastructure, the lack of commerce, entrepreneurs".

Participant 2 when asked about a possible solution to combat unemployment mentioned that "the government has to begin here by implementing industries; This place needs industries, factories that at once employ for example a thousand people". To the same question participant 1 answered: “implement factories”. But stakeholders feel that the government should be a major player in supporting local entrepreneurship. Participant 6 shared his views by commenting the following: 
"I think at first provide opportunities to entrepreneurs/businessmen. The government applies a heavy hand on the entrepreneurs. The government gives many laws. The government should have more promotional events to captivate more entrepreneurs to promote more investment in our localities; Yes, it doesn't facilitate. At least if they moderated it a little for the small entrepreneurs".

Exclusion factors of local stakeholders in diffusion of innovation. This theme refers to those factors that are part of everyday stakeholders' lives that will not allow them to have active participation in events of technological innovations. Researchers highlighted the fact that African governments should combine elements that oversee the successful implementation of technological platforms through institutions and the industry (Biseswar, Mthembu, \& Ogembo-Kachienga, 2012; Grabowski, 2017). Yet, for stakeholders in impoverished regions of Angola, technology can cause exclusion and depress local development (Kianian, Tavassoli, \& Larsson, 2015) due to various factors such as lack of infrastructure, lack of unskilled labor, lack of access to information, problems with sanitation, lack of electricity, lack of involvement in local policy formulations, lack of financial resources, difficulties in affording education, and lack of connection from urban regions to rural regions and because the rate of poverty is too elevated in rural regions.

Participant 3 mentioned that there is no active participation of the government among the population by saying that:

"the government should participate in this type of activities by creating syndicates with more active participations among the population, to know them 
(the people) because one cannot solve someone else's problem without having an exact knowledge where the problem comes from, where the source of the problem is".

The participant also explained that what causes a total disinterest of the rural dwellers toward technology is:

"because of the lack of knowledge, infrastructure, the lack of means that would enable them to connect to the rest of the world or from urban connection initiative to their rural communities, it also fails; Even to have access to information to use the technology itself is difficult. The means to have technology going (to use) is also very expensive. So, many people decide to not even acquire technology because they will not have the means or condition to maintain it". Participant 8 mentioned that "policies that oversee impoverishment is a serious case and that the rate of impoverishment is too elevated". Participant 6 argues that "financial means, it has been one of the major difficulties. I feel that if a great part of the population had a small capital, I think that the desire to participate exists, but there is no financial capacity". Participant 5 also shared the same views: "No, it is just about the financial conditions; I will have technology according to my financial capacity; Financial means to be able to support themselves".

Misalignment of public policy and local economic conditions. This theme refers to the lack of government policies aligned with the local people's needs and demands that culminates to a conjunctural problem that devalues the local human capital in these impoverished regions. Researchers believe that the promising potential of 
development should be leveraged and implemented in combination with community stakeholders and policy makers to ensure formulated policies address the challenges that hinder local development (Amankwah-Amoah, 2016b; Asongu, Le Roux, \& Biekpe, 2018). Participant 3 suggests that:

"that the government should participate in this type of activities by creating syndicates with more active participations among the population, to know them (the people) because one cannot solve someone else's problem without having an exact knowledge where the problem comes from, where the source of the problem is".

Participant 7 believes that a revision of policies would be a viable solution to combat unemployment in these impoverished communities by saying:

"It is of knowledge that most of the population is young and most is unemployed. This major limitation makes them not to be actively involved in new technologies. It is the essential, revision of public policies. As long as we don't have policies directed toward the population, we are doomed. You just look at how our Sumbe is. We are not sure if it is lack of will to do things or lack of financial means. This is the Sumbe we have. So, there is the need to revive the public policies".

The participant also adds the following comments:

"If that is not so, we'll continue to see people poor, poor, and poor, but we have many intelligent people. We need to analyze the policies. What the government must do in the sector of education to bring development to the 
education itself. We will find a number of factors that need to be revised by the government. For example, you will find schools located further than 15 kilometers and the student that goes to this school doesn't have means of transportation. There are no buses, there is nothing that takes the student to his school. No, you analyze with me; the person leaves home 7 o'clock to go to school and walks 15 kilometers on foot, arrives at the classroom at 11 o'clock and is there in the classroom, how is this student going to pay attention to what the teacher is saying? Or think how is he/she going to return home or what is going to eat. I suggest that the government should have school located inside the localities instead of outside to minimize the situation. Also, the lack of library inside the schools also influence that which the Brazilians say "the unlearning" of the people".

In the same line of rationality, participant 8 explains the following: "So, policies need to be created for these rural communities so that an exchange between rural and urban communities may coexist".

Young, agrarian population not involved with technology. This theme refers to the agrarian people within the impoverished regions of Angola that have no access to any technology unless people from the city take the technological means to them as they go for agricultural products in the farm. Smallholder farmers' concerns fall under a few major factors namely, (a) on the rate at which technological innovations shape their local communities because innovations tend to replace traditional labor practices which can cause exclusion because it inhibits opportunities; (b) on the potential socioeconomic 
benefits and constraints it might bring to them; (c) on the lack of skilled labor or cost associated with the availability of skilled labor; (d) on the limited access to cash resources such as bank credit; and (e) on lack or limited access to proper infrastructure (Abdallah, 2016; Kolade, Harpham, \& Kibreab, 2014; Langyintuo \& Mungoma, 2008; Moser \& Barrett, 2003; White, Labarta, \& Leguía, 2005).

Unfortunately, traditional agricultural practices in sub-Saharan Africa still rely in human power (Sheahan \& Barrett, 2014). The technological interventions in the farming business emphasize the introduction of new methods of production such as biotechnological agricultural innovation and services (Stewart et al., 2015) that according to Ton et al. (2013) may lead to the conceptions of new industries which rural dwellers do not want. Concerns therefore fall under the need for training interventions, building capacities for technical skills and understanding, acquiring new managerial practices with emphasis on facilitating knowledge transfers on topics of technology and innovation in agriculture that may benefit farmers and create linkages with other firms and institutions (Stewart et al., 2015).

Participant 8 thinks that policies should be created to promote the agricultural sector by mentioning the following: "Firstly, create policies that promote the agricultural sector". It is believed that these young agrarians often lack investment projects that have the capacity to generate jobs. Participant 4 suggested that:

"to have the conditions (banking institutions to support investment credits) it might even have, but what about the projects originating from these locations? After implementation there are many situations that might come 
against it or have a direct interference so that the business, I have invested on will not yield results; and also, the projects have to be able to generate jobs. If a network like this is able to work, then, it is wonderful. Give you an example: the farmers, they produce in their land etc. How are they going to distribute/sell their products? Do they have conditions for transportation? For example, someone wants to open a shop to sell cellphones. Is the market favorable, are the people capable to adhere to this type of business? So, the market itself is not favorable. I myself see this small businesses (startups) opening, six to three month later they are closing down".

The poor excluded from the mainstream banking system. This theme refers to the lack of financial assistance and purchasing power stakeholders have in the access and acquisition of technological innovations. Researchers argued that it is unfortunate that sub-Saharan African countries lag behind in supplying financial aid to poor and vulnerable farmers (Abdallah, 2016; Kasirye, 2013). Africa has been characterized as a fundamental source of inefficiency in credit with collateral impact in the form of valuable assets like land, farms, cattle, and so on (Abdallah, 2016). Participant 3 argues that "banking institutions should provide more financial loans/credit for those companies that have investment projects that are solid and focused on providing social solutions". Participant 4's perspectives on the subject matter were the following:

"There are a lot of talks about entrepreneurship, but in order for me to wage on some endeavor who's going to provide me with the financial means? The 
banking sector is in conditions to respond to possible number of requests that might come from these rural locations?"

Participant 3 explained that "banking institutions should provide more financial loans/credit for those companies that have investment projects that are solid and focused on providing social solutions."

\section{Second Phase: Cross-Case Synthesis and Analysis}

I utilized the cross-case synthesis analysis technique to incorporate critical findings of individual cases studies and arrange themes across the seven cases in this study (Yin, 2017). Because of the small sample size inherent within a qualitative study, word tables offered an alternative method to seek for patterns across cases instead of the meta-analysis associated with large numbers of case studies (Yin, 2017). Because real life experiences are complex and patterns may not be readily observable through just a thematic analysis of the study's textual data, the cross-case synthesis method strengthened the trustworthiness of the data and allowed generalization to the analysis process (Eisenhardt, 1989; Yin, 2017). By consolidating and interpreting the data, trustworthiness of the data is strengthened, and I was able to establish an evidence-based argument to be analyzed through the study's conceptual framework (Cooper \& White, 2012; Yin, 2017).

Cross-case analysis was a continuous process as each of the seven cases was analyzed separately. This helped to identify recurrent themes emerging from the data to meet the study purpose of exploring views of stakeholders, residing within impoverished communities in Angola, on rapid technology diffusion and its implication on labor 
market challenges within their regions. By using cross-case synthesis I systemically identified the convergent and divergent data across cases and removed any minor data unrelated to the purpose of the study (Yin, 2017).

The cumulative theme frequencies of occurrence by participant are illustrated in Figure 1, in which I combined the thematic analysis results from each case to graphically provide the reader with an idea of how many themes converged across cases based on the findings of this multiple-case study.

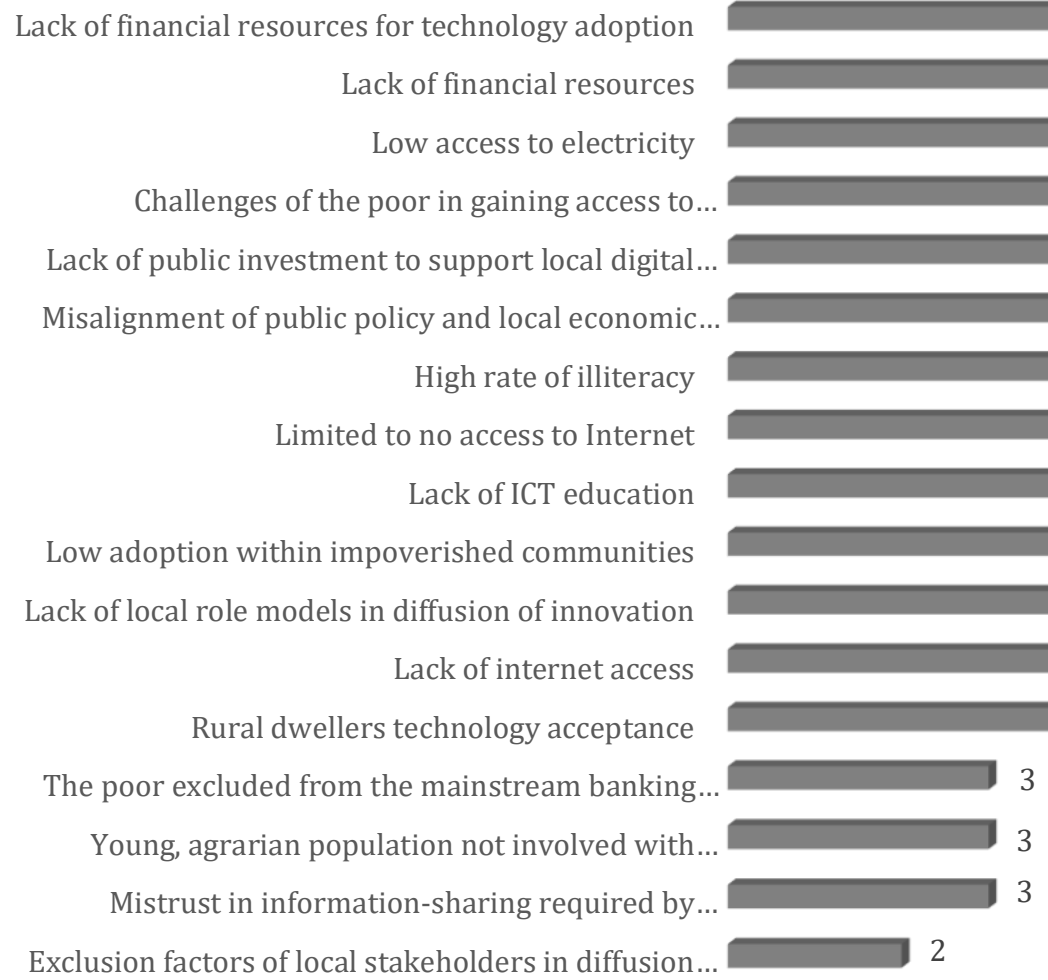

3

2

Figure 1. Multiple case analysis (theme frequency of occurrence by participant). 
The cross-case analysis was an iterative process and I first analyzed each of the eight cases separately. Recurrent themes were identified across the data to meet the purpose of the study of gaining a deeper understanding of views of stakeholders, residing within impoverished communities in Angola, on rapid technology diffusion and its implication on labor market challenges within their regions. The cumulative frequencies of occurrence for each theme are illustrated in Figure 1, in which I combined the data analysis from each case while analyzing the convergent and divergent data across the eight cases. In Figure 1, I present a multiple case study cross-case synthesis graph as a visual representation of the participants' views on rapid technology diffusion within their impoverished communities in Angola.

Two categories that figured prominently across the data collected from all eight cases was lack of financial resources for technology adoptions and a lack of financial resources in general. In general, poverty and financial difficulties keep stakeholders in the rural communities from affording and getting more involved with technological innovations that are available in their regions. These factors, including lack of access to the Internet and poor infrastructure, are part of local stakeholders' daily lives, barriers will not allow them to have active participation in events of technological innovations. Such conditions lead to usually low rates of technology adoption in rural, impoverished communities in Angola. These low rates of technology adoption in turn leave impoverished Angolans dependent on the urban supply chain that can leverage technology to bring agricultural products into the farming communities and pushing local farmers out of the marketplace. Such a dependency has left rural Angolans valuing 
foreign knowledge and practices instead of local ones in the diffusion of innovations, resulting in a lack of local role models in the diffusion of innovation process. Once local stakeholders feel so devalued and marginalized within their country's technological advent, the cycle of social exclusion, despondency, poverty, and unemployment continues to fester in rural, impoverished communities.

Five themes figured prominent across six out of the eight cases: low access to electricity, challenges of the poor in gaining technology, lack of public investment to support local digital entrepreneurship, a misalignment of public policy and local economic conditions, and high rate of illiteracy. Six out of eight participants mentioned that the lack of technological education in Angola's impoverished communities often leads to indifference in public and private stakeholders to invest in bringing technology to impoverished communities. The younger population wants to become involved in local entrepreneurship, yet the lack of education leads many in these impoverished communities to enter adulthood being functionally illiterate, resulting in a massive younger, agrarian population isolated from local diffusion of technology.

Because of high rates of illiteracy public investors shy away from supporting digital entrepreneurship in rural Angolan communities. Additionally, without proper access to electricity even microentrepreneurs, often excluded from the mainstream banking system, who attempt to leverage technology through their mobile phones, often lose any competitive advantage in their local markets to larger organizations coming in from the urban areas for commerce purposes. The result is a vicious cycle of poverty often seen in rural areas of developing countries, and public and private sector 
indifference reinforcing the desperation and marginalization of a significant population of rural Angola.

Across five out of eight cases, the prominent themes of rural stakeholders' resistance to technology innovations acceptance are linked to the perpetuation of social challenges faced by Angola's impoverished communes. Local stakeholders' resistance is stoked by their fears that technological innovation lacks proper security to protect their citizen's rights. The poor cannot become mainstreamed into a country's diffusion of innovation unless their government shows indigenous knowledge and local stakeholders the respect of offering solutions for their cyclical economic and social challenges, such as lack of education, proper infrastructure, rampant unemployment due to a lack of private business investments and a lack of support for local entrepreneurial initiatives. At least half the study participants argued that there can be no solutions for themselves and their families unless government policies aligned with the local people's needs and so as to thwart a conjunctural problem that devalues the local human capital and stokes mistrust in technology in these impoverished regions of Angola.

\section{Triangulation}

Collecting data from specific populations requires that the researcher acquires community knowledge that will make the process culturally sensitive and appropriate (O'Hegarty et al., 2010). Thus, it became of paramount importance to choose the appropriate instruments that would produce themes to support the insights that would result from studying Angolan stakeholders' experiences on their views of rapid diffusion of technology and labor market challenges within their regions. This study used three 
sources of data: (a) a semistructured interview protocol (see Appendix B) whose items were designed and standardized by a previous researcher; (b) ICT policy documents in the form of government labor reports; and (c) reflective field notes (Merriam \& Tisdell, 2015) that were kept by the researcher throughout the data collection process.

In addition to binding data sources, the codes bridged themes across a variety of methodologies including interviews, field notes, historical literature, and archival data (Stake, 2013). This data source triangulation boosted the quality of the study and promoted a more aggregate consideration of the data (Yin, 2017). Handwritten notes were a valuable component of the data collection process. The handwritten notes supplemented the audible data recorded in the interview tape which were translated literally; notes provided a contextual report of nonverbal behaviors such as fears, uncertainty, for a more comprehensive documentation of participant interactions. I provided each study participant with a copy of the transcript and requested they read and verify the accuracy of their responses; the transcripts were also useful to review researcher reflexivity (Merriam \& Tisdell, 2015).

I used an interview protocol for the semistructured interviews to standardize the data collection process (see Appendix B). An audit trail of the research record is a synthesis of reports for member checking, coding structure, and memos on the progress of a research study. I used an audit trail and methodological triangulation to attain dependability of the study results (Guion, Diehl, \& McDonald, 2011). For the process of methods triangulation during the data analysis, I referenced data from my reflective 
journal notes and analyzed archival data such as Angolan government reports and United Nations and World Bank repots.

After I conducted semistructured interviews with the participants I continued in the method triangulation process to answer the research question. I read and annotated peer-reviewed scholarly papers from approximately 200 scientific journals. I discovered approximately 100 articles that included government, business, company, and media reports, white papers and popular media (newspaper, a magazine) relevant to the study. These reports were not substantive for the literature review but were a source to complement the overall data collection process. This reading helped me question the meaning of recurring concepts and ideas to generate themes that were complete, accurate, and credible. This type of triangulation can ensure the data are rich (Fusch \& Ness, 2015). In conclusion, methodological triangulation of three data sources provided enough thick, rich information to replicate the study design (Guion, Diehl, \& McDonald, 2011; Yin, 2017). I analyzed and interpreted study results within the conceptual framework and illustrated how findings of the study added to the body of knowledge related to views of stakeholders, residing within impoverished communities in Angola, on rapid technology diffusion and its implication on labor market challenges within their regions.

\section{Summary}

A case by case analysis was conducted and presented in the chapter with a total of eight separate cases, leading to a cross-case analysis and synthesis process to provide answers for the central research question of this multiple case study: How do the views of stakeholders, residing within impoverished communities in Angola, inform innovation 
policy makers on the implications of rapid technology diffusion on labor market

challenges within their regions? Based on the findings of this multiple-case study, a total of seven coding categories that enclose a total of 17 themes were identified for this study leading to thick, rich data on the experiences of the study participants. The seven coding categories are grounded in the study conceptual framework. This includes the diffusion of innovations conceptual framework (Rogers, 1995) and the human capital and innovation in sub-Saharan Africa concept (Danquah \& Amankwah-Amoah, 2017). The coding categories were (a) diffusion of innovations and adoption circumstances, (b) compatibility of technology with social values, (c) trialability within the cultural context, (d) adoption of technology, (e) innovation decision process factors, (f) trust in technology by community stakeholders, (g) inclusive innovation for low-income stakeholders.

I used cross-case synthesis as the data analysis technique to incorporate critical findings of individual cases studies. Once themes were arranged across the multiple cases in this study, the 17 themes gleaned from the raw data include the following: low access to electricity, lack of financial resources for technology adoption, lack of local role models in diffusion of innovation, rural dwellers technology acceptance, low adoption within impoverished communities, lack of internet access, challenges of the poor in gaining access to technology, high rate of illiteracy, lack of ICT education, lack of financial resources, limited to no access to Internet, mistrust in information-sharing required by technology, lack of public investment to support local digital entrepreneurship, exclusion factors of local stakeholders in diffusion of innovation, misalignment of public policy and local economic conditions, young agrarian population 
not involved with technology, and the poor excluded from the mainstream banking system. In addition to binding data sources, I enhanced the trustworthiness of the study's data by employing methodological triangulation of three data sources: interviews, journaling/reflective field notes, and archival data (Guion, et al., 2011). I analyzed and interpreted the multiple case study results through the lens of the conceptual framework.

In Chapter 5, I will further interpret the study findings in terms of how they compare and contrast to the literature described in Chapter 2. I will demonstrate the significance of the research for theory, practice, and social change and how my study results extend the body of knowledge on diffusion of innovation in developing countries challenged by high poverty, poor infrastructure, and significant labor challenges. I will also describe how future scholarly research can extend the findings of this study. 
Chapter 5: Discussion, Conclusions, and Recommendations

The purpose of this qualitative multiple case study was to gain a deeper understanding of the views of stakeholders residing within impoverished communities in Angola on rapid technology diffusion and its implication on labor market challenges within their regions. To address this gap, and consistent with the qualitative paradigm and to provide a strong basis for theory extension, I utilized a multiple case study methodology to answer the study's central research question through multisource data collection, including semistructured interviews and archival data in the form of government labor reports and reflective field notes.

Qualitative research methodologies used within the constructivist paradigm help to give a voice to victims of social oppression and to their experiences with dominant cultural and social groups, such as those of local stakeholders living in impoverished communities in Angola. This study is framed by two key concepts, Rogers's (1995) concept of diffusion of innovations and Danquah and Amankwah-Amoah's (2017) concept of human capital and innovation in sub-Saharan Africa, which focus on the significance of stakeholders' views on rapid technology diffusion and its implication on labor market challenges within impoverished communities in sub-Saharan Africa.

A multiple-case analysis of eight interviews and thematic analysis, cross-case synthesis, and analysis revealed 17 themes gleaned from the raw data: (a) low access to electricity, (b) lack of financial resources for technology adoption, (c) lack of local role models in diffusion of innovation, (d) rural dwellers technology acceptance, (e) low adoption within impoverished communities, (f) lack of internet access, (g) challenges of 
the poor in gaining access to technology, (h) high rate of illiteracy, (i) lack of ICT education, (j) lack of financial resources, (k) limited to no access to Internet, (1) mistrust in information-sharing required by technology, (m) lack of public investment to support local digital entrepreneurship, (n) exclusion factors of local stakeholders in diffusion of innovation, (o) misalignment of public policy and local economic conditions, (p) young, agrarian population not involved with technology, and (q) the poor excluded from the mainstream banking system.

\section{Interpretation of Findings}

The findings of this multiple case study confirm or extend current knowledge in the discipline, with each case presenting examples of issues discussed in the literature review in Chapter 2. In this section, I present the study's findings and review them in the context of the coding categories that emerged from the data analysis. I compare each of these seven categories with relevant concepts from the conceptual framework and the extant literature reviewed presented in Chapter 2. I provide evidence from the eight semistructured interviews to support how the study's findings either confirm or disconfirm existing knowledge, or extend it. Extension studies, such as this multiple case study, provide not only replication evidence but also support extending prior research results with offering new and important theoretical directions (Bonett, 2012).

Diffusion of innovations and adoption circumstances. In his concept of diffusion of innovations, Rogers (1995) proposed that relative advantage, compatibility, complexity, observability, and trialability are important attributes of innovation for its wider acceptance. My results confirm that Rogers's (1995) five contributing factors to the 
diffusion of innovation are pivotal for the process to take its course and that if any one of these issues is derailed this can halt the diffusion of technology in developing regions. Data that I gathered from my sample residing within the impoverished communities in Angola confirmed Matthews's (2017) results from 10 years of ethnographic research in rural villages of sub-Saharan Africa: local stakeholders resented any diffusion of innovation originating outside of their community that was not a good fit with local needs and resources, and did not respect local skills, and/or local knowledge (Matthews, 2017; Pillania 2011). My study results confirmed that the human capital and innovation in subSaharan Africa conceptual framework (Danquah \& Amankwah-Amoah, 2017) does explain the significance of stakeholders' views on rapid technology diffusion and its implication on labor market challenges within impoverished communities and extends this framework with original qualitative data from rural Angola.

Compatibility of technology with social values. On one of the specific topics of acceptance of an innovation in a developing country, my results extend Lawson's (2014) argument that its compatibility depends on stakeholders' willingness to embed technology side by side with the existing social norms. My research findings confirmed that the diffusion of innovations must be supported by social values to propel regional economic development in impoverished regions of sub-Saharan Africa and that local stakeholders drive such changes. The findings of the study are also consistent with Amavilah's (2016) research on the obstacles to technological progress and economic growth in some African countries that cannot be properly explained without a profound understanding of the interplay between relevant authoritative elements of religion (that 
being stakeholders of impoverished communities in Angola) and their role in the economic growth of civilizations and the undervalued local knowledge in favor of foreign knowledge.

Trialability within the cultural context. Social values, culture, and norms compose the dynamic constructs for labor productivity and represent the fundamental source of economic development (Li, Park, \& Selover, 2017). My study results were consistent with scholars' viewpoints that local stakeholders in impoverished communities were open to a new technology's trialability if such a device did not interrupt existing cultural practices and respected indigenous knowledge. Generally, stakeholders' concerns, like those of smallholder farmers within impoverished rural communities, fall under a few factors such as: (a) on the rate at which technological innovations shape their local communities because innovations tend to replace traditional labor practices which they feel can cause exclusion; (b) on the potential socioeconomic benefits and constraints; (c) on the lack of skilled labor or cost associated with the availability of skilled labor; (d) on the limited access to cash resources such as bank credit; and (e) on lack or limited access to proper infrastructure (Abdallah, 2016; Kolade, Harpham, \& Kibreab, 2014; Langyintuo \& Mungoma, 2008; Moser \& Barrett, 2003; White, Labarta, \& Leguía, 2005). The study results confirmed Saidi and Douglas's (2017) perceptions on the relationship between technology, innovations, and the society that it should be contextualized, strengthened, and driven in the notion of solving the very problems and challenges faced by these immediate local populations. 
Adoption of technology. The underlying assumption was that technology acceptance in a particular society and its effects on socioeconomic development is dependent on the economic conditions, government regulations, societal openness, and attributes of the country that facilitate the basic conditions for technology uptake (Pick \& Nishida, 2015). Mwangi and Kariuki (2015) suggested that in order to enhance technology adoption among farmers in impoverished regions, it is important that policy makers and investors of new technology understand local farmers' needs as well as their ability to adopt technology that will suit them. On his theoretical foundation Becker (1964) defended the fact that in order to adopt technological innovations it is important to understand the role of individuals in its accelerating process, an axion confirmed by my study results. My research results confirmed Danquah and Amankwah-Amoah's (2017) conceptualization and operationalization of the term human capital and innovation in subSaharan Africa that is founded in Becker's (1964) theoretical foundation.

The issues confirmed by my study pertained to high rate of poverty, rural stakeholder's competencies, lack of education, knowledge management, lack of access to information and the price of technology acquisition which in turn has led these local populations to fear that technology might displace unskilled workers and cause further joblessness (Amavilah, 2016). The study was consistent with previous research conducted by Kolade et al. (2014), confirming the role and lack of cohesion between government investments directly affecting ICT initiatives and policies on access to micro-credit institutions to support technology adoption. 
Innovation decision process factors. Some scholars argued that employment opportunities in sub-Saharan Africa are somewhat limited because of the fixed human capital stock, because only a small number of migrated technology-educated laborers can find jobs (Chattopadhyay \& Mondal, 2016). My study results align with previous research studies that investigated obstacles behind different innovation decision processes that are reinforced by the devaluation of local knowledge and overvaluing of foreign knowledge. In part, the study is consistent with research that oversaw the possibility of technology being biased to the point of displacing unskilled workers and is far less likely to be linked to job creation in the long run. These perspectives often indicated that in certain impoverished sub-Saharan African countries, technology may constitute the downside of economic productivity, which most likely increases the rate of unemployment in the long-term and possibly worsens many other economic factors.

Trust in technology by community stakeholders. Scholars concur that religion and economic sciences in general do mobilize knowledge, while technology, as a multidimensional agent of social change, applies knowledge in a manner that allows it to be diffused through any social system. The diffusion of innovations model is concerned with how innovation, defined as new knowledge or practices, is spread through a population (Lawson, 2014; Pillania, 2011; Rogers, 2004).

For technology to be diffused within impoverished African communities, it must be understood and accepted from the perspective of local human networks (Sirine, 2017; Stier, 2017). Across cases in my study, fears and mistrust were voiced about the abuse of technology by more powerful others for manipulative propaganda to control the poor and 
to bring technology to replace unskilled workers and cause further joblessness, perspectives confirmed in the extant literature.

The study also confirmed stakeholders' concerns regarding the mistrust of technology diffusion among impoverished populations across sub-Saharan Africa due to a belief that the government investments in technology may be for propaganda and to control the poor. Researchers have agreed that this has remained the bane of African countries as political elite make use of national policies for private gains instead of public interest. In this case, my research is consistent with the fact that impoverished populations become skeptical about adopting a technology and in cases where they must adopt, hence remaining quite cautious in making the decision to adopt (Fosu, 2017).

Inclusive innovation for low-income stakeholders. Most rural regions in subSaharan Africa are composed by old and unsuitable institutional structures, lack of law and regulations, scarce capital, lack of technological education, inappropriate supply behavior of economic agents, and a huge disparity between the livelihood of the rich and poor (Chattopadhyay \& Mondal, 2016; Danquah \& Amankwah-Amoah, 2017), all factors confirmed by study participants. Instead of inclusive access to ICT infrastructures and services, access is rather inequitable (Cruz-Jesus et al., 2016; Salla, 2016). Today's economists expected development in low-income countries to be modern, contemporary, and inclusive in nature, without preferences to any specific group or stakeholder (Altenburg, Lundvall, Joseph, Chaminade, \& Vang, 2009). Yet, a study conducted by Lingelbach et al. (2015) on the economic development and diffusion of innovation in impoverished sub-Saharan African countries revealed political preferences to certain 
groups as well as human capital differences, resulting into some kind of digital divide.

Noninclusive economic and technological development ignites conflicts between rich and poor, rural and urban, educated and uneducated, upper and lower social classes, indigenous and modern societies in these low-income African countries (Danquah \& Amankwah-Amoah, 2017).

\section{Limitations of the Study}

In this qualitative multiple case study, I considered a key limitation to be those participants who did not have the time to contribute their views on the phenomenon being investigated. To address this issue, I did my best to manage and accommodate the time limitations of participants when scheduling the interviews. I mitigated the issue of limited experiences regarding the study's central phenomenon by carefully using the purposeful criterion and network sampling strategies to identify those hard to locate participants meeting the inclusion criteria of the study. Prior to each interview, I asked pre-interview questions to ensure as much as possible that participants possessed in-depth knowledge of the topic under study.

Another limitation was related to the sample size, which may not have been representative of the entire population, leading to issues of generalizability. Qualitative research is not about analyzing inferential statistics but assuring transferability of the results. This type of limitation was mitigated through careful interpretation of the data and strong conclusion of results. As with all qualitative case studies, one limitation is the transferability of results to the general population. To determine transferability, I described in detail the original context of the research so sound judgments can be made 
about the results. I developed detailed descriptions so I could make an informed decision regarding the transferability of the findings to their specific contexts. Further, I diligently created 'thick' descriptions, including accounts of the context, research methods, and examples of raw data.

This multiple case study was about gaining a deeper understanding of each individual participant as a unit of analysis within a specific context. To address the issue of transferability in this study, I provided a detailed and transparent description of all the strategies adopted in the process of recruiting participants, interactions with participants, data collection, data recording, and data analysis. I provided detailed descriptions of each participant such that the contexts under which the data for this study were obtained will be helpful to readers in understanding or possibly applying the outcomes of this study in different contexts.

\section{Recommendations}

Rogers (2003) defined diffusion within his seminal theory as "the process by which an innovation is communicated through certain channels over time among the members of a social system" (p. 5). The role of local human capital in technological progress and knowledge generation was well recognized in growth literature (Atiqur Rahman \& Zaman, 2016). According to Danquah and Amankwah-Amoah (2017) and Van Uden, Knoben, and Vermeulen (2016), human capital plays a major role in promoting productivity in local impoverished communities and foster knowledge to determine the economic capacity to adopt innovation. For such reason, researchers believed that the measures for ICT policy should not be constrained to outcomes from 
infrastructure and macro-economic indicators alone, but should combine the relevant micro-level factors that underpin the betterment of the lives of impoverished populations to address gaps in the literature on these topics. (Diga, Nwaiwu, \& Plantinga, 2013). This study aimed to fill these gaps by gathering data in the field from stakeholders in impoverished communities in Angola on rapid technology diffusion and its implication on labor market challenges within their regions.

The significance of a study addresses the need to fill a gap in theoretical knowledge and make recommendations for future studies (Merriam \& Tisdell, 2015). Governments in the developing countries of sub-Saharan Africa often ignore the voices of impoverished populations on hesitancy to accept technology diffusion within their local communities (Dutz et al., 2014; Gudmundsdottir, 2010). This study is significant in that it may lead to a better understanding of the phenomena being studied and provide information-rich data and recommendations for future studies and policy initiatives (Yin, 2017). The study's findings may also provide public and private sector of stakeholders and governing institutions with information that can help improve diffusion of innovation in impoverished areas of developing nations.

\section{Recommendation 1: Quantitative Validation}

On the basis of the study's strengths and limitations as previously detailed, future researchers are encouraged to replicate this study utilizing qualitative research paradigms that address this topic in various contexts or to validate my research findings through appropriate quantitative research methods. Employing a quantitative research method such as a survey could offer important insights into the transferability of my investigation 
on a larger sample population and extended geographic location. While certain sections of my study evidence near unanimity among the participants, the views of a wider sample of local stakeholders in impoverished communities on diffusion of innovation may differ based on location (Coenen et al., 2016). A larger, quantitative study could confirm or highlight geographic similarities and discrepancies and reveal more or less prominent aspects of various components of my study in relation to such characteristics as age, gender, level of education, and specific variables that highlight the significance of certain policy initiatives for greater diffusion of innovation in impoverished communities of developing countries.

\section{Recommendation 2: Qualitative Replication}

Rogers (2003) based his work on studying and observing the diffusion of innovations in developed countries. Outdated or resource-constrained national innovation systems in developing countries do not meet the original objectives for which they were designed. Diffusion and creation of innovation in developing countries is also restricted by weak institutional relationship between private and public sectors (Adanu, 2017). Further qualitative research utilizing the multiple-case study method, as I have done, is also encouraged. This could prove useful for determining how research findings differ across regions, including areas that have marked cultural differences and/or are characterized by different socioeconomic and political burdens (Coenen et al., 2017; Cozza et al., 2012; Landabaso, 1997; Noman et al., 2011; OECD, 2012; Wang et al., 2017; Whitfield et al., 2015). Additionally, future researchers could conduct a similar study with a sample that is equally represented by both genders; this could deliver 
valuable insights into the gendered aspect of diffusion of innovation in impoverished communities of developing countries.

\section{Recommendations for Future Research}

Themes that emanated from my study may provide opportunities for future research that will allow for a more contextual examination of the diffusion of innovation in impoverished communities of developing countries.

Lack of financial resources and infrastructure. The growing level of poverty in sub-Saharan Africa and the role of innovation in reduction of poverty and the power of the quality of governance institutions in improvement of innovative capacity of states should become a focused area of future research (Amavilah, 2016; Asongu \& Biekpe, 2017; Beilock \& Dimitrova, 2003; Biseswar et al., 2012; Grabowski, 2017; Nakabashi et al., 2013). Gaps and arguments continue in the literature on the diffusion of innovation that focuses the quality of government institutions in sub-Saharan Africa (Bennett et al., 2017; Chattopadhyay \& Mondal, 2016; Lovrić, 2012; Nguimkeu, 2014). The development of new paradigms in the conceptualization and the measurement of quality of governance institutions is a recommended area of future research to gain a better understanding of the direct and indirect effects of quality of governance institutions on identified themes within this study. My results situate both the public and the private sector in sub-Saharan Africa mostly in the role of diffusion of knowledge and technology transfer, or as conveners of innovation (Asheim et al., 2017; Biseswar et al., 2012). More research is needed on developing pathways of action for intermediators of innovation which have not been properly addressed or built. This is mostly due to weak capabilities 
and scarce financial resources to perform the tasks involved in these roles (BMI, 2018a; BMI, 2018b; Ngunga, 2018). This leads to a recommendation for research on policy initiatives to address the access to Internet, weak infrastructure, and Internet access problems at the grassroots level.

Barriers for adoption of technology at the grassroots level. The issue of mistrust of technology diffusion in most impoverished populations across sub-Saharan Africa is due to a belief that the government certification of the technology is based on rent seeking and private gains and this has remained the bane of African countries as political elite make national policies for private gains instead of public interest. In this case, impoverished populations become skeptical about adopting a technology and wonder if it will replace their jobs, manipulate the poor or use their private information for political and financial gain, and continue the exclusion of the formal banking system (Fosu, 2017). To ensure the success of technology transfer, it is necessary to understand the barriers of the adopter country to new technologies and/or knowledge, especially in the case of countries with sharp regional differences (Wang, Bai, \& Cheng, 2017). Although there are dozens of idiosyncratic factors that may affect a country's economic development (Noman, Botchwey, Stein, \& Stiglitz, 2011), regions are vital and crucial for the long sustainability planning of growth or productivity (Wheeler, 2009). I would recommend that my study be replicated with key stakeholders at the grassroots level in other developing countries of Africa.

Education and development of innovation by empowering local populations. One cannot diffuse modern information or innovation if one is dealing with a mistrustful, 
poor and mostly illiterate people that have been marginalized within their own mainstream national economy. Researchers should focus on developing recommendations for how public and private governing centers with financial resources can bring training, education, and better infrastructure to rural, impoverished areas in sub-Saharan Africa (Economist Intelligence Unit, 2016; Chattopadhyay \& Mondal, 2016; Lovrić, 2012; Nguimkeu, 2014). As well, outsiders from centers of governing power need to find ways to bring rural populations out of marginalization and into a national inclusive development scheme. The need for a knowledge-oriented culture, promotion of linkages between the existing industry and the rest of the actors in the innovation system, and the internationalization of knowledge promoting local ownership are some of the aspects that need to be addressed by researchers if they are to be key influencers of technology and innovation policies in their countries. Such research initiatives must include the respect and inclusion of local and indigenous knowledge in innovation practices (Matthews, 2017).

\section{Implications}

Positive social change. This study is important because it addresses an underresearched area on why innovation policy initiatives calling for technology diffusion in Angola continue to stall rather than combating labor market challenges in impoverished communities (Danquah \& Amankwah-Amoah, 2017; Ramani et al., 2017). Political parties, businesses, families, universities, non-governmental organizations (NGOs), and civil organizations are key institutional players that contribute to the developmental potential of any social change initiative. This study brought the voices of local 
populations on technology diffusion in impoverished regions of Angola to the extant literature, launching the development of a body of knowledge that may point the way to a promising avenue of social change through innovation and technology diffusion.

Technology, and specifically the appearance of new forms of innovations, can affect social change in as much as it allows existing products and practices to be transformed (Andrés et al., 2016). My sample reported unanimously the obstacles to social change through the diffusion of innovation in sub-Saharan Africa countries due to the exclusion of local knowledge in favor of foreign knowledge. The results of my study may begin a national dialogue among all social actors in Angola on ways and means to promote social change, by addressing issues of citizen inequality and the legitimate causes of slow growth and change in African countries beyond quantifiable measures (Sirine, 2017). Such a national dialogue must include the critical voices of agents/stakeholders/potential technology users now be accounted for through this qualitative research to gain a deeper understanding of the issues (Amavilah, 2016; Ojo, 2015).

Policy implications. The adoption of well-established knowledge management strategies and policies among industry and knowledge intermediaries for inclusive development of impoverished populations in Africa could potentially increase performance and improve the efficient use of available resources. A fundamental awareness of the shift in policy paradigms is needed for policymakers to target social issues as defined by the UN's Sustainability Development Goals if countries in subSaharan Africa are to reframe their development strategies toward an innovative 
economic agenda. Such an inclusive development agenda needs policies developed to empower the millions now living in marginalized populations. The results of this study have implications for policymakers in the government to include the tens of millions of local and indigenous populations in innovation practices. A country cannot proceed to bring all its people into the modern scope of the 21 st century if national policy excludes millions as valued actors in the innovation performance.

Institutional implications. The extant literature highlights that Angola's economic progress continues to be impeded due to persistent structural challenges, weak institutions, weak agricultural productivity, inadequate infrastructure, limited qualified human resources in respect to science and technology that still hinder inclusive growth and economic diversification (Ngunga, 2019). When institutions in a developing country devalue and undervalue local knowledge, acceptance of an innovation in that country becomes difficult and institutions remain weakened (Amavilah, 2016). For the diffusion of innovation to succeed in any context, social norms and trialability within a context of existing cultural practices cannot be ignored. To incite social change, governing institutions must engage the millions of disenfranchised populations within their countries, and find ways to include local needs, local demand, local resources, local skills, and/or local knowledge (Lawson, 2014). If governing powers include marginalized, rural civilians in policy decisions, there is a vibrant civil society in Angola ready to participate and the outlook for positive social change can be deemed hopeful (Amankwah-Amoah, 2016b). 
The diffusion of technology and innovation in a society will, therefore, depend on the benefit, cost, risk, and uncertainty, as well as environmental and institutional framework prevalent in the society because formal institutions matter in the technology utilization process (Asongu \& Biekpe, 2017; Beilock \& Dimitrova, 2003). Governments in the developing countries of sub-Saharan Africa may achieve the results that have eluded them in the technology innovation area by exploring research outcomes tied to local stakeholders and not formal policy makers, allowing impoverished populations to be heard on their fears and resistance to technology diffusion of innovations (Dutz et al., 2014; Gudmundsdottir, 2010).

Theoretical implications. The lack of exploratory research on innovation policy initiatives in Angola to combat labor market challenges through technology diffusion that continue to stall among impoverished communities is a critical knowledge gap in the extant literature (Danquah \& Amankwah-Amoah, 2017; Ramani, Thutupalli, \& Urias, 2017). My study confirms the importance of anchoring local stakeholders' views on rapid technology diffusion and the need for more multi-level analysis to capture the complex interplay of micro-level individual, meso-level organizational and macro-level national influences on diffusion of innovation in developing countries. These are all pathways of future theoretical investigations to better inform academics, policy-makers, technology innovators and influencers in sub-Saharan Africa. By filling the gap of missing knowledge in the theoretical foundations of the conceptual framework through my study's results, this study contributes original, qualitative data to the theory of diffusion of innovation and human capital theory that may prove useful in future related research. 
Recommendations for practice. The disproportionate innovative efforts by the public and especially by the private sector in regions of sub-Saharan Africa reinforce the technology gap between regions enhancing a cohesion gap (Landabaso, 1997). A cohesion gap between regions are regional disparities resulted of differences in productivity and competitiveness aggravated by distinct innovation efforts in regional structures of production (Landabaso, 1997). The diffusion of technology is critical for the sectoral and regional growth patterns (Castaldi \& Sapio, 2009; OECD, 2012). While the theoretical literature on technology diffusion has produced contributions to seminal theories such as that of Rogers's (1995) technology-related studies on the diffusion of innovations, it excluded offering recommendations to practitioners on the factors that inform technology diffusion in impoverished regions of sub-Saharan Africa (Andrés, Amavilah, \& Asongu, 2016).

Several interesting findings from my study can be targeted to practitioners. Specifically, my results are informative for practitioners attempting the diffusion of innovation in underdeveloped countries that continue to face enormous developmental challenges from unemployment to inequality in the living conditions, and across a large segment of its population (Angola Press Agency [ANGOP], 2013; Da Rocha, 2011; The World Bank, 2017b). In such an unpredictable state of everyday life for Angolans, the rapid diffusion of technology by public and private partnerships was met with fear of information and communication technologies being used to manipulate the poor (Lawson, 2015) and raise the level of unemployment by displacing unskilled workers (Amavilah, 2016). This study is significant for practice because the research results may 
be used to inform innovation policy makers in Angola and other African countries characterized by poor institutional quality (Efobi \& Osabuohien, 2015). Governments in sub-Saharan Africa may achieve the results that have eluded them in the technology innovation area by practicing inclusive development strategies and not leave local stakeholders on the periphery of a national strategy for diffusion of innovation.

Any recommendations for practice emerging from my study rest on the need for systematic changes in order to bring about the diffusion of innovation within impoverished communities in Angola and that of sub-Saharan Africa. Such systemic changes in economically and socially challenged regions cannot just be based on isolated policies or innovation breaks, but must become part of a systemic solution that targets the United National's global sustainability challenges, which can be used by local authorities as a structured launching pad to begin the inclusive development processes among the poor (Amankwah-Amoah, 2014; Danquah, 2012; Page, 2012). The results of my study can be viewed by practitioners as a call to draw attention to the need for transformative, systemic innovation to align the economic and social aspects of inclusive development at the local and global levels, among the poor in sub-Saharan Africa (Asongu \& Nwachukwu, 2018a; Saidi \& Douglas, 2017). This implies the formulation of innovation policies and the reformulation of growth strategies in sub-Saharan Africa away from traditional industry centers and infrastructures and toward work on global societal goals, within an international agenda, and grounded in the local context. 


\section{Conclusions}

The individuals in this study played a pivotal role in gaining a deeper understanding about stakeholders' views regarding the rapid diffusion of innovation and its implications on labor market challenges within their regions. They provided in-depth insight into why innovation policy initiatives to combat labor market challenges in Angola through technology diffusion continue to stall among impoverished communities, where local stakeholders' views on rapid technology diffusion remain absent and unaddressed by innovation policymakers. Although technology can greatly benefit impoverished sub-Saharan Africans in the form of social change, rapidly diffused initiatives in the form of technology may also cause harm, spread fear, cause inequality, promote exclusion, and depress economic growth among impoverished populations.

While governments in the developing countries of sub-Saharan Africa often ignore the voices of impoverished populations on hesitancy to accept technology diffusion within their local communities (Dutz et al., 2014; Gudmundsdottir, 2010), these local stakeholders' views offer recommendations for future research and policy in support of poverty alleviation, diffusion of innovations, and socioeconomic development in the local populations (Munyoka \& Maharaj, 2017). Furthermore, future research should promote alternative views and pathways of theoretical investigations to better inform academics, policy makers, technology innovators, and influencers in sub-Saharan Africa, particularly in Angola, on the issue of diffusion of innovations in rural, impoverished communities. 


\section{References}

Abdallah, A. H. (2016). Does credit market inefficiency affect technology adoption? Evidence from Sub-Saharan Africa. Agricultural Finance Review, 76(4), 494511. doi:10.1108/afr-05-2016-0052

Abrams, L. S. (2010). Sampling "hard to reach" populations in qualitative research. Qualitative Social Work: Research and Practice, 9(4), 536-550. doi:10.1177/1473325010367821

Adanu, K. (2017). Institutional change and economic development: A conceptual analysis of the African case. International Journal of Social Economics, 44(4), 547-559. doi:10.1108/ijse-02-2014-0022

Adera, E. O., Waema, T. M., \& May, J. D. (Eds.). (2014). ICT pathways to poverty reduction: Empirical evidence from East and Southern Africa. Ottwa, ON: IDRC.

Adesida, O., \& Karuri-Sebina, M. G. (2013). Building innovation driven economies in Africa. African Journal of Science, Technology, Innovation and Development, 5(1), 1-3. doi:10.1080/20421338.2013.798094

Adeyeye, D., Egbetokun, A., Opele, J., Oluwatope, O., \& Sanni, M. (2018). How barriers influence firms' search strategies and innovative performance. International Journal of Innovation Management, 22(02), 1850011. doi:10.1142/s1363919618500111

African Development Bank (2018a). African economic outlook 2018: Chapter 2 Growth, jobs, and poverty in Africa. Abidjan, C.te d'Ivoire: African Development Bank Group. 
African Development Bank (2018b). African economic outlook 2018: Chapter 3 Africa's infrastructure: Great potential but little impact. Abidjan, C.te d'Ivoire: African Development Bank Group.

Afutu-Kotey, R. L., Gough, K. V., \& Owusu, G. (2017). Young entrepreneurs in the mobile telephony sector in Ghana: From necessities to aspirations. Journal of African Business, 18(4), 476-491. doi:10.1080/15228916.2017.1339252

Africa News Service (2014). U.S. falters, corruption represses Angola, Zimbabwe [analysis]. Opposing Viewpoints in Context. Retrieved from http://link.galegroup.com/apps/doc/A355742714/OVIC?u=minn4020\&xid=d2113 $03 \mathrm{e}$

Aissaoui, N. (2017). Is inequality harmful for broadband diffusion and economic growth? Asian Economic and Financial Review, 7(8), 799-808. doi:10.18488/journal.aefr.2017.78.799.808

Akudugu, M., Guo, E., Dadzie, S. (2012). Adoption of modern agricultural production technologies by farm households in Ghana: What Factors Influence their Decisions? Journal of Biology, Agriculture and Healthcare 2(3). Retrieved from https://www.researchgate.net/profile/Samuel_Dadzie/publication/235751741_Ado ption_of_modern_agricultural_production_technologies_by_farm_households_in _Ghana_What_factors_influence_their_decisions/links/00463533b1249ebdf1000 000.pdf

Albiman, M. M., \& Sulong, Z. (2016). The role of ICT use to the economic growth in Sub Saharan African region (SSA). Journal of Science and Technology Policy 
Management, 7(3), 306-329. doi:10.1108/jstpm-06-2016-0010

Alden, C., \& Large, D. (2015). On becoming a norms maker: Chinese foreign policy, norms evolution and the challenges of security in Africa. The China Quarterly, 221, 123-142. doi:10.1017/s0305741015000028

Aljohani, M., \& Blustein, J. (2018). A study using the in-depth interview approach to understand current practices in the management of personal health information and privacy compliance. 2018 IEEE International Conference on Healthcare Informatics (ICHI). doi:10.1109/ichi.2018.00016

Altenburg, T., Lundvall, B., Joseph, K., Chaminade, C., \& Vang, J. (2009). Building inclusive innovation systems in developing countries: Challenges for IS research. In B. Lundvall, J. Vang, K. Joseph, \& C. Chaminade (Eds.), Handbook of innovation systems and developing countries: Building domestic capabilities in a global setting. Cheltenham, UK: Elgar Publishing.

Alvarez, I., \& Marin, R. (2013). FDI and technology as levering factors of competitiveness in developing countries. Journal of International Management, 19(3), 232-246. doi:10.1016/j.intman.2013.02.005

Alvesson, M., \& Sköldberg, K. (2017). Reflexive methodology: New vistas for qualitative research. Sage Publications.

Amankwah-Amoah, J. (2014). Solar energy in sub-Saharan Africa: The challenges and opportunities of technological leapfrogging. Thunderbird International Business Review, 57(1), 15-31. doi:10.1002/tie.21677

Amankwah-Amoah, J. (2016a). Global business and emerging economies: Towards a 
new perspective on the effects of e-waste. Technological Forecasting and Social Change, 105, 20-26. doi:10.1016/j.techfore.2016.01.026

Amankwah-Amoah, J. (2016b). The evolution of science, technology and innovation policies: A review of the Ghanaian experience. Technological Forecasting and Social Change, 110, 134-142. doi:10.1016/j.techfore.2015.11.022

Amankwah-Amoah, J., Osabutey, E. L. C., \& Egbetokun, A. (2018). Contemporary challenges and opportunities of doing business in Africa: The emerging roles and effects of technologies. Technological Forecasting and Social Change, 131, 171174. doi:10.1016/j.techfore.2018.01.003

Amavilah, V. H. (2016). Social obstacles to technology, technological change, and the economic growth of African countries: Some anecdotal evidence from economic history. Turkish Economic Review, 3(2), 320. Retrieved from http://www.kspjournals.org/index.php/TER/article/download/820/890

Andrés, A. R., Amavilah, V., Asongu, S. (2016) Linkages between formal institutions, ICT adoption, and inclusive human development in sub-Saharan Africa. In H. Kaur, E. Lechman, \& A. Marszk (Eds.), Catalyzing Development through ICT Adoption. Switzerland, ZG: Springer

Ang, J. B., Madsen, J. B., \& Islam, M. R. (2011). The effects of human capital composition on technological convergence. Journal of Macroeconomics, 33(3), 465-476. doi:10.1016/j.jmacro.2011.03.001

Angola Press Agency. (2013, July). Baixa taxa de sucesso do empreendedorismo tem a ver com constrangimentos económicos. [Low success rate of entrepreneurship has 
to do with economic constraints]. Retrieved from http://www.angop.ao/angola/pt_pt/noticias/economia/2013/6/29/Baixa-taxasucesso-empreendedorismo-tem-ver-com-constrangimentoseconomicos,30a296c4-9adc-45d3-9918-e125cdd4d365.html

Angonotícias.com (2015). Mais de 15 milhões de angolanos vivem em meio urbano. Retrieved from http://www.angonoticias.com/Artigos/item/47795/mais-de-15milhoes-de-angolanos-vivem-em-meio-urbano

Anney, V. N. (2014). Ensuring the quality of the findings of qualitative research: Looking at trustworthiness criteria. Journal of Emerging Trends in Educational Research and Policy Studies (JETERAPS) 5(2), 272-281. Retrieved from http://repository.udsm.ac.tz:8080/xmlui/bitstream/handle/123456789/256/Ensurin g\%20the \%20Quality\%20of\%20the\%20Findings\%20of\%20Qualitative\%20Resear $\operatorname{ch} \% 20 \mathrm{NEW}$. pdf?sequence $=1 \&$ is Allowed $=\mathrm{y}$

Asheim, B., Bugge, M. M., Coenen, L, \& Herstad, S. J. (2017). Advancing regional innovation systems: What does evolutionary economic geography bring to the policy table? Environment and Planning C: Politics and Space, 35(4), 600-620. doi: $10.1177 / 0263774 \times 16646583$

Asongu, S. A. (2013). How has mobile phone penetration stimulated financial development in Africa? Journal of African Business, 14(1), 7-18. doi:10.1080/15228916.2013.765309

Asongu, S. A. (2015). Conditional determinants of mobile phones penetration and mobile banking in sub-Saharan Africa. Journal of the Knowledge Economy, 9(1), 81-135. 
doi:10.1007/s13132-015-0322-z

Asongu, S. A., \& Biekpe, N. (2017). Government quality determinants of ICT adoption in sub-Saharan Africa. SSRN Electronic Journal, 1-24. doi:10.2139/ssrn.3002189

Asongu, S. A., Boateng, A., \& Akamavi, R. K. (2016, March). Mobile phone innovation and inclusive human development: Evidence from sub-Saharan Africa (Working Paper No. 16/27). doi:10.2139/ssrn.2822103

Asongu, S. A., \& Kodila-Tedika, O. (2017). Institutions and poverty: A critical comment based on evolving currents and debates. Social Indicators Research, 139(1), 99117. doi:10.1007/s11205-017-1709-y

Asongu, S. A., \& Le Roux, S. (2017). Enhancing ICT for inclusive human development in sub-Saharan Africa. Technological Forecasting and Social Change, 118, 4454. doi:10.1016/j.techfore.2017.01.026

Asongu, S. A., \& Nwachukwu, J. C. (2018a). Educational quality thresholds in the diffusion of knowledge with mobile phones for inclusive human development in sub-Saharan Africa. Technological Forecasting and Social Change, 129, 164172. doi:10.1016/j.techfore.2018.01.004

Asongu, S. A., \& Nwachukwu, J. C. (2018b). Openness, ICT and entrepreneurship in sub-Saharan Africa. Information Technology \& People, 31(1), 278-303. doi:10.1108/itp-02-2017-0033

Assefa, S., Alemneh, D. G., \& Rorissa, A. (2015). Diffusion of scientific knowledge in agriculture: The case for Africa. Agricultural Information Worldwide, 6, 34-47. 
Retrieved from

http://journals.sfu.ca/iaald/index.php/aginfo/article/download/652/578

AtiqurRahman, A. K. M., \& Zaman, M. (2016). Human capital and technological catchup of developing countries: In search of a technological leader. The Journal of Developing Areas, 50(1), 157-174. doi:10.1353/jda.2016.0006v

Attwood, H., Diga, K., \& May, J. (2014). The complexities of establishing causality between an ICT intervention and changes in quality of life: CLIQ in South Africa. In E. O., Adera, M. T., Waema, J. D., May (Eds.), ICT Pathways to Poverty Reduction, 179-204. International Development Research Centre, Ottwa, ON: IDRC

Augusto Felício, J., Couto, E., \& Caiado, J. (2014). Human capital, social capital and organizational performance. Management Decision, 52(2), 350-364. doi:10.1108/md-04-2013-0260

Ball, J. (2017). The history of Angola. Oxford Research Encyclopedia of African History. doi:10.1093/acrefore/9780190277734.013.180

Barros, C. P. (2012). The resource curse and rent-seeking in Angola. Centro de Estudos sobre Africa e do Desenvolvimento [Center for African Studies and Development] (Working Paper No 102/2012). Retrieved from http://pascal.iseg.utl.pt/ cesa/RePEc/cav/cavwpp/wp102.pdf

Bazerman, C. (1997). Discursively structured activities. Mind, Culture, and Activity, 4(4), 296-308. doi:10.1207/s15327884mca0404_6 
Bhattacharya, M. (2015). A conceptual framework of RFID adoption in retail using Rogers stage model. Business Process Management Journal, 21(3), 517-540. doi:10.1108/bpmj-06-2014-0047

Baumgartner, B. (2016a). Angola - an oil dependent country in sub-Saharan Africa. Studia Commercialia Bratislavensia, 9(35). doi:10.1515/stcb-2016-0023

Baumgartner, B. (2016b). The position of sub-Saharan countries in the world economy. Studia Commercialia Bratislavensia, 9(33). doi:10.1515/stcb-2016-0001

Baxter, P., \& Jack, S. (2008). Qualitative case study methodology: Study design and implementation for novice researchers. The Qualitative Report, 13(4), 544-559. Retrieved from http://nsuworks.nova.edu/tqr/vol13/iss4/2/

Becker, G. S. (1964). Human capital. The University of Chicago Press.

Becker, G. S. (1994). Human capital revisited. In human capital: A theoretical and empirical analysis with special reference to education (3rd ed., pp. 15-28). The University of Chicago Press.

Beilock, R., \& Dimitrova, D. V. (2003). An exploratory model of inter-country Internet diffusion. Telecommunications Policy, 27(3-4), 237-252. doi:10.1016/s0308-5961(02)00100-3

Bengtsson, P. (1999). Multiple Case Studies-not just more data points. Term paper in graduate course in Research Methodology. Publisher Unknown, 1-9. Retrieved from https://pdfs.semanticscholar.org/a465/f7986f029ab0f38851873e33b01bd42b 5 cde.pdf

Bennett, D. L., Faria, H. J., Gwartney, J. D., \& Morales, D. R. (2017). Economic 
institutions and comparative economic development: A post-colonial perspective. World Development, 96, 503-519. doi:10.1016/j.worlddev.2017.03.032

Bennett, D. L., \& Nikolaev, B. (2016). Factor endowments, the rule of law and structural inequality. Journal of Institutional Economics, 12(4), 773-795. doi:10.1017/s1744137416000084

Berg (2017). Model-based economic evaluations in smoking cessation and their transferability to new contexts: A systematic review. Addiction, 112(6), 946-967. doi:10.1111/add.13748

Berger, R. (2013). Now I see it, now I don't: researcher's position and reflexivity in qualitative research. Qualitative Research, 15(2), 219-234. doi:10.1177/1468794112468475

Bezemer, D., Bolt, J., \& Lensink, R. (2014). Slavery, statehood, and economic development in sub-Saharan Africa. World Development, 57, 148-163. doi:10.1016/j.worlddev.2013.12.004

Bhattacharyya, S., \& Hodler, R. (2010). Natural resources, democracy and corruption. European Economic Review, 54(4), 608-621. doi:10.1016/j.euroecorev.2009.10.004

Bircan, C. \& De Haas, R. (2015, July). The limits of lending: Banks and technology adoption across Russia (Working Paper No. 5461). European Bank for Reconstruction and Development, London, UK: Center for Economic Studies \& Ifo Institute.

Biseswar, S., Mthembu, N. S., \& Ogembo-Kachienga, M. (2012, July). Developing 
technology platforms for an emerging economy: A situational analysis of South Africa. Technology Management for Emerging Technologies, 2012 Proceedings of PICMET'12, 233-240. Vancouver, BC: IEEE

Bolger, N., Davis, A., \& Rafaeli, E. (2003). Diary methods: Capturing life as it is lived. Annual Review of Psychology, 54(1), 579-616. doi:10.1146/annurev.psych.54.101601.145030

Boyatzis, R.E. (1998). Transforming qualitative information: Thematic analysis and code development. Thousand Oaks, CA: Sage

Bree, R. T., \& Gallagher, G. (2016). Using Microsoft Excel to code and thematically analyse qualitative data: A simple, cost-effective approach. AISHE-J: The All Ireland Journal of Teaching and Learning in Higher Education, 8(2). Retrieved from http://ojs.aishe.org/aishe/index.php/aishe-j/article/view/281

Brixiova, Z., Ncube, M. and Bicaba, Z. (2015, May). Skills and Youth Entrepreneurship in Africa: Analysis with Evidence from Swaziland (Working Paper No. 2014/131). WIDER Working Papers, United Nations University.

Brown Jr, W. L. (2017). Airport managers' perspectives on security and safety management systems in aviation operations: A multiple case study. Retrieved from http://adsabs.harvard.edu/abs/2017PhDT.......19B

Browne, M. N., \& Keeley, S. M. (2014). Asking the right questions: A guide to critical thinking (11th ed.). Upper Saddle River, NJ: Pearson

Bonett, D. G. (2012). Replication-extension studies. Current Directions in Psychological Science, 21(6), 409-412. doi:10.1177/0963721412459512 
Burr, V. (2003). Social constructionism. London, UK: Routledge.

Burr, V. (2015). Social constructionism. London, U.K.: Routledge.

Business Monitor International. (2016). Angola infrastructure report. Includes 10-year forecasts to 2024. Part of BMI's industry report \& forecasts series (Research Report N Q1 2016). London, UK: BMI Research.

Business Monitor International. (2017a). Angola infrastructure report. Includes 10-year forecasts to 2024. Part of BMI's industry report \& forecasts series (Research Report N Q4 2017). London, UK: BMI Research.

Business Monitor International. (2017b). Angola telecommunications report. Includes 5year forecasts to 2021. London, UK: BMI Research.

Business Monitor International. (2018a). Angola infrastructure report. Includes 10-year forecasts to 2027 (Research Report N Q2 2016). London, UK: BMI Research.

Business Monitor International. (2018b). Angola labour market risk report. Includes the BMI operational risk index (Research Report $\mathrm{N}^{\circ}$ Q2 2018). London, UK: BMI Research.

Business Monitor International. (2018c). Angola country risk report. Includes the BMI operational risk index (Research Report N Q3 2018). London, UK: BMI Research

Business Monitor International. (2018d). Angola logistic risk report. Includes the BMI operational risk index (Research Report N Q3 2018). London, UK: BMI Research

Business Monitor International. (2018e). Angola power report. Includes 10-year forecast 
(Research Report No Q3 2018). London, UK: BMI Research.

Business Monitor International. (2018f). Angola labour market risk report. Includes the BMI operational risk index (Research Report $N^{\circ}$ Q3 2018). London, UK: BMI Research.

Cain, A. (2017). Alternatives to African commodity-backed urbanization: The case of China in Angola. Oxford Review of Economic Policy, 33(3), 478-495. doi:10.1093/oxrep/grx037

Campa, R. (2014). Technological growth and unemployment: A global scenario analysis. Journal of Evolution \& Technology, 24(1), 86-103. Retrieved from http://jetpress.org/v24/campa2.htm

Casey, D., \& Murphy, K. (2009). Issues in using methodological triangulation in research. Nurse Researcher, 16(4), 40-55. doi:10.7748/nr2009.07.16.4.40.c7160

Cassell, E. J. (2000). The principles of the Belmont Report revisited: How have respect for persons, beneficence, and justice been applied to clinical medicine? The Hastings Center Report, 30(4), 12. doi:10.2307/3527640

Castaldi, C., \& Sapio, S. (2009). Growing like mushrooms? Sectoral evidence from four large European economies. In U. Cantner, J.L. Gaffard, \& L. Nesta (Eds.), Schumpeterian Perspectives on Innovation, Competition and Growth. Berlin, Heidelberg: Springer.

Chaouali, W., Yahia, I. B., Charfeddine, L., \& Triki, A. (2016). Understanding citizens' adoption of e-filing in developing countries: An empirical investigation. The 
Journal of High Technology Management Research, 27(2), 161-176.

doi:10.1016/j.hitech.2016.10.006

Chataway, J., Hanlin, R., \& Kaplinsky, R. (2014). Inclusive innovation: An architecture for policy development. Innovation and Development, 4(1), 33-54. doi:10.1080/2157930x.2013.876800

Chattopadhyay, S., \& Mondal, R. (2016). Characterisation of economic growth in developing economies with informal sector. Economic Papers: A Journal of Applied Economics and Policy, 36(1), 86-101. doi:10.1111/1759-3441.12149

Chen, H., Wakeland, W., \& Yu, J. (2012). A two-stage technology foresight model with system dynamics simulation and its application in the Chinese ICT industry. Technological Forecasting and Social Change, 79(7), 1254-1267. doi:10.1016/j.techfore.2012.02.007

Chen, M. (2014). Informal employment and development: Patterns of inclusion and exclusion. The European Journal of Development Research, 26(4), 397-418. doi:10.1057/ejdr.2014.31

Chinembiri, E. (2010). An empirical assessment of the impact of trade liberalization on employment in South Africa. Trade and Industrial Policy Studies, AUSAID. Retrieved from http://www.tips.org.za/files/Evans_Assessment_of_the_Impact_of_Trade_Liberal ization_on_EmploymentFINAL.pdf 
Chowdhury, I. A. (2015). Issue of quality in a qualitative research: An overview. Innovative Issues and Approaches in Social Sciences, 8(1), 142-162. doi:10.12959/issn.1855-0541.iiass-2015-no1-art09

Christensen, C. M., Ojomo, E., \& Van Bever, D. (2017). Africa's new generation of innovators. How some entrepreneurs have succeeded in creating new markets where many global giants have failed. Harvard Business Review, 95(1), 128-136. Retrieved from https://hbr.org/2017/01/africas-new-generation-of-innovators

Ciarli, T., Savona, M., Thorpe, J., \& Ayele, S. (2018). Innovation for inclusive structural change. A framework and research agenda (Working Paper No. 2018-04). SPRUScience and Technology Policy Research, University of Sussex.

Cirera, X., Lage, F., \& Sabetti, L. (2016). ICT use, innovation, and productivity: Evidence from Sub-Saharan Africa (Working Paper No. 7868). The World Bank. Cirillo, V. (2014). Patterns of innovation and wage distribution. Do "innovative firms" pay higher wages? Evidence from Chile. Eurasian Business Review, 4(2), 181206. doi:10.1007/s40821-014-0010-0

Cleland, J. (2017). Population growth, employment, and livelihoods: the triple challenge. Journal of Demographic Economics, 83(01), 51-61. doi:10.1017/dem.2016.15

Cohen, L., Manion, L., \& Morrison, K. (2011). Research methods in education (7th ed.). New York, NY: Routledge.

Coleman, J. (1988). Social capital in the creation of human capital. Knowledge and Social Capital, 17-41. doi:10.1016/b978-0-7506-7222-1.50005-2 
Connelly, L. M. (2016). Understanding research. Trustworthiness in qualitative research. MEDSURG Nursing, 25(6), 435-436. Retrieved from https://www.researchgate.net/publication/321684950_Trustworthiness_in_Qualita tive_Research/citations

Cope, D. G. (2013). Methods and meanings: Credibility and trustworthiness of qualitative research. Oncology Nursing Forum, 41(1), 89-91. doi:10.1188/14.onf.89-91

Cooper, K., \& White, R. E. (2012). Qualitative research in the post-modern era: Contexts of qualitative research. London, UK: Springer.

Cortes, L. P., Roberto, C. D., \& Dias, L.G.S. (2014). Development of corporate social responsibility projects in Angola. Social Responsibility Journal, 10(2), 268-281. doi:10.1108/srj-01-2012-0004

Cozza, C., Ortega-Argilés, R., Piva, M., \& Baptista, R. (2012). Productivity gaps among European regions. In D. B. Audretsch, E. E. Lehmann, A. N. Link, \& A. Starnecker (Eds.), Technology transfer in a global economy (pp. 205-232). New York, NY: Springer

Cronin, C. (2014). Using case study research as a rigorous form of inquiry. Nurse Researcher, 21(5), 19-27. doi:10.7748/nr.21.5.19.e1240

Cruzes, D. S., Dybå, T., Runeson, P., \& Höst, M. (2014). Case studies synthesis: A thematic, cross-case, and narrative synthesis worked example. Empirical Software Engineering, 20(6), 1634-1665. doi:10.1007/s10664-014-9326-8 
Cruz-Jesus, F., Oliveira, T., Bacao, F., \& Irani, Z. (2016). Assessing the pattern between economic and digital development of countries. Information Systems Frontiers, 19(4), 835-854. doi:10.1007/s10796-016-9634-1

Cumming-Potvin, W. (2013). "New basics" and literacies: Deepening reflexivity in qualitative research. Qualitative Research Journal, 13(2), 214-230. doi:10.1108/QRJ-04-2013-0024

Daher, M., Carré, D., Jaramillo, A., Olivares, H., \& Tomicic, A. (2017). Experience and meaning in qualitative research: A conceptual review and a methodological device proposal. Forum: Qualitative Social Research, 18(3), 62-85. doi:10.17169/fqs-18.3.2696

Danquah, M. (2012). Efficiency and productivity growth in sub-Saharan Africa (Doctoral thesis, Swansea University, UK). Retrieved from http://ethos.bl.uk/OrderDetails.do?uin=uk.bl.ethos.643555

Danquah, M. (2018). Technology transfer, adoption of technology and the efficiency of nations: Empirical evidence from sub Saharan Africa. Technological Forecasting and Social Change, 131, 175-182. doi:10.1016/j.techfore.2017.12.007

Danquah, M., \& Amankwah-Amoah, J. (2017). Assessing the relationships between human capital, innovation and technology adoption: Evidence from sub-Saharan Africa. Technological Forecasting and Social Change, 122, 24-33. doi:10.1016/j.techfore.2017.04.021

Danquah, M., \& Ouattara, B. (2014). Productivity growth, human capital and distance to frontier in sub-Saharan Africa. Journal of Economic Development, 39(4), 27-48. 
Retrieved from

https://www.researchgate.net/profile/Michael_Danquah2/publication/303287041_ PRODUCTIVITY_GROWTH_HUMAN_CAPITAL_AND_DISTANCE_TO_FR ONTIER_IN_SUB-

SAHARAN_AFRICA/links/573b102e08aea45ee84054d3/PRODUCTIVITYGROWTH-HUMAN-CAPITAL-AND-DISTANCE-TO-FRONTIER-IN-SUBSAHARAN-AFRICA.pdf

Da Rocha, M. J. A. (2011). Estabilização, reforma e desenvolvimento em Angola (2nd ed) [Stabilization, reform and development in Angola]. Luanda: Mayamba

Davis, B., Di Giuseppe, S., \& Zezza, A. (2017). Are African households (not) leaving agriculture? Patterns of households' income sources in rural Sub-Saharan Africa. Food Policy, 67, 153-174. doi:10.1016/j.foodpol.2016.09.018

Davis, D. R. (2016). The journey to the top: Stories on the intersection of race and gender for African American women in academia and business. Journal of Research Initiatives, 2(1), 1-12. Retrieved from http://digitalcommons.uncfsu.edu/jri/vol2/iss $1 / 4$

Dean, E., Caspar, R., McAvinchey, G., Reed, L., \& Quiroz, R. (2007). Developing a lowcost technique for parallel cross-cultural instrument development: The question appraisal system (QAS-04). International Journal of Social Research Methodology, 10(3), 227-241. doi:10.1080/13645570701401032 
Denzin, N. K. (2009). The elephant in the living room: Or extending the conversation about the politics of evidence. Qualitative Research, 9(2), 139-160. doi:10.1177/1468794108098034

Denzin, N. K. (2009). The research act: A theoretical introduction to sociological methods. New York, NY: Aldine Transaction.

Denzin, N. K., \& Lincoln, Y. S. (Eds.). (2011). The Sage handbook of qualitative research. Thousand Oaks, CA: Sage.

Department for International Development (2005). Autumn performance report. An outline of progress against the 2003-06 and 2005-2008 Public Service Agreements and the Efficiency Programme. Retrieved from https://www.gov.uk/government/publications/department-for-internationaldevelopment-2005-autumn-performance-report

Department of Health, E. (2014). The Belmont Report. Ethical principles and guidelines for the protection of human subjects of research. The Journal of the American College of Dentists, 81(3), 4. Retrieved from https://www.ncbi.nlm.nih.gov/pubmed/25951677

Díaz-josé, J., Rendón-medel, R., Govaerts, B., Aguilar-Ávila, J., \& Muñoz-rodriguez, M. (2016). Innovation diffusion in conservation agriculture: A network approach. The European Journal of Development Research, 28(2), 314-329. doi:10.1057/ejdr.2015.9 
Diga, K., Nwaiwu, F., \& Plantinga, P. (2013). ICT policy and poverty reduction in Africa. Info, 15(5), 114-127. doi:10.1108/info-05-2013-0032

Dodgson, M. (2000). Policies for science, technology and innovation in Asian newly industrializing economies. In L. Kim, R.R. Nelson,(Eds.), Technology, Learning and Innovation. Cambridge University Press, Cambridge.

Duflo, E., Galiani, S., \& Mobarak, M.A. (2012). Improving access to urban services for the poor: Open issues and a framework for future research agenda. J-PAL Urban Services Review Paper. Retrieved from https://www.povertyactionlab.org/sites/default/files/publications/USI\%20Review \%20Paper.pdf

Dutz, M., Yevgeny, K., Esperanza, L., \& Dirk, P. (Eds.). (2014). Making innovation policy work: Learning from Experimentation. France, Paris: OECD Publishing.

Duygun, M., Isaksson, A., \& Kaulich, F. (2016). Did the global financial crisis hit Africa? Insights from a multi-country firm level survey. Economic Modelling, 58, 308-316. doi:10.1016/j.econmod.2016.06.008

Dziak, M. (2017). Institutional Review Board (IRB). Salem Press Encyclopedia, EBSCOhost.

Economist Intelligence Unit. (2016). Analysis by country. Retrieved from http://country.eiu.com/angola

Effangola.org (2016). Resultados definitivos do recenseamento geral da população e da habitação de Angola 2014. Retrieved from http://www.effaangola.org AngolaCensus2014_ResultadosDefinitivos_Mar2016.pdf 
Efobi U.R., Osabuohien E.S. (2015). Technological utilization in Africa: How do institutions matter?. In S. Majumdar, S. Guha, \& N. Marakkath, (Eds.), Technology and Innovation for Social Change. Mumbai, India: Springer

Egbetokun, A., Atta-Ankomah, R., Jegede, O., \& Lorenz, E. (2016). Firm-level innovation in Africa: Overcoming limits and constraints. Innovation and Development, 6(2), 161-174. doi:10.1080/2157930x.2016.1224619

Eisenhardt, K. M. (1989). Building theories from case study research. Academy of Management Review, 14(4), 532-550. doi:10.2307/258557

Eisenhardt, K., \& Graebner, M. (2007). Theory building from cases: Opportunities and challenges. Academy of Management Journal, 50(1), 25-32. doi:10.5465/amj.2007.24160888

Emmel, N. (2013). Sampling and choosing cases in qualitative research: A realist approach. doi:10.4135/9781473913882

Eriksson, P., \& Kovalainen, A. (2015). Qualitative methods in business research: A practical guide to social research. London, UK: Sage Publications.

Evans, O. (2019). Digital politics: Internet and democracy in Africa. Journal of Economic Studies, 46(1), 169-191. doi:10.1108/jes-08-2017-0234

Finfgeld-Connett, D. (2013). Use of content analysis to conduct knowledge-building and theory-generating qualitative systematic reviews. Qualitative Research, 14(3), 341-352. doi:10.1177/1468794113481790 
Flick, U. (2014). An introduction to qualitative research (5th ed.). Thousand Oaks, CA: Sage Publications.

Foster, C., \& Heeks, R. (2013). Conceptualizing inclusive innovation: Modifying systems of innovation frameworks to understand diffusion of new technology to lowincome consumers. The European Journal of Development Research, 25(3), 333355. doi:10.1057/ejdr.2013.7

Fosu, A. K. (2013). Institutions and African Economies: An Overview. Journal of African Economies, 22(4), 491-498. doi:10.1093/jae/ejt016

Fosu, A. K. (2017). Growth, inequality, and poverty reduction in developing countries: Recent global evidence. Research in Economics, 71(2), 306-336. doi:10.1016/j.rie.2016.05.005

Fosu, A. K. (2017). The recent growth resurgence in africa and poverty reduction: the context and evidence. Journal of African Economies, 27(1), 92-107. doi:10.1093/jae/ejx016

Fosu, A. K., \& O’Connell, S.A. (2006, January). Explaining African economic growth: The role of anti-growth syndromes. In F. Bourguignon \& B. Pleskovic (Eds.), Annual World Bank conference on development economics [ABCDE]. Washington, DC: The World Bank.

Fusch, P. I., \& Ness, L. R. (2015). Are we there yet? data saturation in qualitative research. The Qualitative Report, 20(9), 1408-1416. Retrieved from https://nsuw orks.nova.edu/tqr/vol20/iss9/3 
Freiman, V., Martinovic, D., \& Robichaud, X. (2018). New faces of digital divide and how to bridge it. In M. Khosrow-Pour, D.B.A. (Ed.), Encyclopedia of Information Science and Technology (4th ed., pp. 7248-7258). Hershey, PA: IGI Global.

Galbin, A. (2014). An introduction to social constructionism. Social Research Reports, 26, 82-92. Retrieved from https://researchreports.ro/images/researchreports/social/srr_2014_vol026_004.pdf

Galperin, H., \& Fernanda Viecens, M. (2017). Connected for development? Theory and evidence about the impact of Internet technologies on poverty alleviation.

Development Policy Review, 35(3), 315-336. doi:10.1111/dpr.12210

Gaus, N. (2017). Selecting research approaches and research designs: A reflective essay. Qualitative Research Journal, 17(2), 99-112. doi:10.1108/qrj-07-2016-0041

Gebreegziabher, Z., Mekonnen, A., Kassie, M., \& Köhlin, G. (2012). Urban energy transition and technology adoption: The case of Tigrai, northern Ethiopia. Energy Economics, 34(2), 410-418. doi:10.1016/j.eneco.2011.07.017

Geddes, A., Parker, C., \& Scott, S. (2018). When the snowball fails to roll and the use of 'horizontal'networking in qualitative social research. International Journal of Social Research Methodology, 21(3), 347-358.

doi.org/10.1080/13645579.2017.1406219

Gentzoglanis, A. (2013). Regulation of the electricity industry in Africa: In search of an optimal model - Where and when the next model. African Journal of Economic and Management Studies, 4(1), 34-57. doi:10.1108/20400701311303140 
Gergen, K. J. (1973). Social psychology as history. Journal of Personality and Social Psychology, 26(2), 309-320. doi:10.1037/h0034436

GhaffarianHoseini, A., Tookey, J., GhaffarianHoseini, A., Naismith, N., \& Rotimi, B. J. O. (2016). Integrating alternative technologies to improve built environment sustainability in Africa. Smart and Sustainable Built Environment, 5(3), 193-211. doi:10.1108/sasbe-07-2015-0015

Gildersleeve, R. E., \& Kuntz, A. M. (2010). A Dialogue on space and method in qualitative research on education. Qualitative Inquiry, 17(1), 15-22. doi:10.1177/1077800410389440

Glover, D., Sumberg, J., \& Andersson, J. A. (2016). The adoption problem; Or why we still understand so little about technological change in African agriculture. Outlook on Agriculture, 45(1), 3-6. doi:10.5367/oa.2016.0235

Golub, S., \& Prasad, V. (2016). Promoting economic diversification and international competitiveness in Angola. Retrieved from https://www.swarthmore.edu/sites/default/files/assets/documents/user_profiles/sg olub1/AngolaStudyTrade2016.rev2_.pdf

Gomez, R., \& Pather, S. (2012). ICT evaluation: Are we asking the right questions? The Electronic Journal of Information Systems in Developing Countries, 50(1), 1-14. doi:10.1002/j.1681-4835.2012.tb00355.x

Goncalves, G., Oliveira, T., \& Cruz-Jesus, F. (2018). Understanding individual-level digital divide: Evidence of an African country. Computers in Human Behavior, 87, 276-291. doi:10.1016/j.chb.2018.05.039 
Gostin, L. O. (1995). Informed consent, cultural sensitivity, and respect for persons. JAMA, 274(10), 844-845. doi:10.1001/jama.1995.03530100084039

Grabowski, R. (2017). Premature deindustrialization and inequality. International Journal of Social Economics, 44(2), 154-168. doi:10.1108/ijse-07-2015-0197

Green, J., \& Thorogood, N. (2018). Qualitative methods for health research. Sage Publications.

Gudmundsdottir, G. B. (2010). From digital divide to digital equity: Learners' ICT competence in four primary schools in Cape Town, South Africa. International Journal of Education and Development using Information and Communication Technology, 6(2), 1H. Retrieved from https://files.eric.ed.gov/fulltext/EJ1084980.pdf

Guest, G., Bunce, A., \& Johnson, L. (2006). How many interviews are enough? Field Methods, 18(1), 59-82. doi:10.1177/1525822x05279903

Guillemin, M., Gillam, L., Barnard, E., Stewart, P., Walker, H., \& Rosenthal, D. (2016). "We're checking them out": Indigenous and non-Indigenous research participants' accounts of deciding to be involved in research. International Journal for Equity in Health, 15(1). doi:10.1186/s12939-016-0301-4

Guion, L. A., Diehl, D. C., \& McDonald, D. (2011). Triangulation: Establishing the validity of qualitative studies. Retrieved from http://documentslide.com/documents/guion-et-al-triangulation-establishing-thevalidity-of-qualitative-studies.html

Gurumurthy, A. (2010). From social enterprises to mobiles-seeking a peg to hang a 
premeditated ICTD theory. Information Technologies \& International

Development, 6(SE), 57. Retrieved from

https://scholar.google.com/scholar_url?url=http://dev.itidjournal.org/index.php/iti

d/article/download/624/264\&hl=en\&sa=T\&oi=gsb-

gga\&ct=res\&cd=0\&ei=pjgqW9bwKonYmgHvpbbIAw\&scisig=AAGBfm12E1_s k2V8ErZi6vHHWBF7qgC4RA

Guetterman, T. C., (2015). Descriptions of sampling practices within five approaches to qualitative research in education and the health sciences. Forum: Qualitative Social Research, 16(2). doi:10.17169/fqs-16.2.2290

Habiyaremye, A. (2013). "Angola-mode" trade deals and the awakening of African lion economies. African Development Review, 25(4), 636-647. doi:10.1111/14678268.12057

Hackshaw, A. (2008). Small studies: Strengths and limitations. European Respiratory Journal, 32(5), 1141-1143. doi:10.1183/09031936.00136408

Hall, B. H. (2004). Innovation and diffusion. National Bureau of Economic Research (Working Paper No. 10212). Cambridge, MA.

Hall, J. \& Martin, M. J. C. (2005). Disruptive technologies stakeholders and the innovation value chain: A framework for evaluating radical technology development, R\&D Management, 35(3), 273-284. doi:10.1111/j.14679310.2005.00389.x 
Hamlett, J. (2014). Managers' perceptions of turnover intention using an organizational justice framework in a large-sized manufacturing company. International Journal of Teaching and Case Studies, 5(3-4), 289-302. doi:10.1504/IJTCS.2014.067821

Harkiolakis, N. (2017). Quantitative research methods: From theory to publication. Create Space.

Hatch, A. J. (2002). Doing qualitative research in education settings. Albany, NY: SUNY Press.

Haynes, K. (2012). Reflexivity in qualitative research. Qualitative Organizational Research: Core Methods and Current Challenges, 72-89. doi:10.4135/9781526435620.n5

Herrington, M. \& Kelly, D. (2014). GEM 2012. Sub-Saharan Africa regional reportpolicy. Retrieved from http://www.gemconsortium.org/country-profile/35

Houghton, C., Casey, D., Shaw, D., \& Murphy, K. (2013). Rigour in qualitative casestudy research. Nurse Researcher, 20(4), 12-17. doi:10.7748/nr2013.03.20.4.12.e326

Howells, J. (2005). Innovation and regional economic development: A matter of perspective? Research Policy, 34(8), 1220-1234. doi:10.1016/j.respol.2005.03.014

Human Capital Research Platform (2015). Human capital and labour report Angola. Retrieved from https://www.hcresearchportal.com/reports/angola Hunting, G. (2014). Intersectionality-informed qualitative research: A primer. Criminology, 4(1), 32-56. Retrieved from 
https://www.ifsee.ulaval.ca/sites/ifsee.ulaval.ca/files/b95277db179219c5ee8080a 99b0b91276941.pdf

Ine.gov.ao (2018). Indicadores estatísticos [Statistics indicators]. Retrieved from http://ine.gov.ao/indicadores-estatisticos/populacao

Ine.gov.ao (2013). Inquerito sobre o bem estar da população | IBEP. Relatório de tabelas - Vol II [Survey on the welfare of the population | IBEP. Report tables].

Retrieved from

http://www.ine.gov.ao/xportal/xmain?xpid=ine\&xpgid=publications_detail\&publi cations_detail_qry=BOUI=10418998

Ine.gov.ao (2013). Publicação: Inquérito integrado sobre o bem estar da população Vol.

III - perfil da pobreza. Retrieved from http://www.ine.gov.ao/xportal/xmain?xpid=ine\&xpgid=publications_detail\&publi cations_detail_qry=BOUI=10418998

Info-Angola.com. (2018). Resultados defenitivos do censo 2014 [Final results of the 2014 census]. Retrieved from http://www.infoangola.com/attachments/article/4654/Publicação-Resultados-Definitivos-CensoGeral-2014.pdf

International Labour Organization. (2012). Africa's response to the youth unemployment crisis. Geneva, Switzerland: ILO.

Jack, E. P., \& Raturi, A. S. (2006). Lessons learned from methodological triangulation in management research. Management Research News, 29(6), 345-357. doi:10.1108/01409170610683833 
Kabanda, G. (2014). The impact of ICTs on customer service excellence in Zimbabwe. International Journal of Emerging Technology and Advanced Engineering, 4(5). Retrieved from https://www.researchgate.net/profile/Professor_Gabriel_Kabanda/publication/262 535595_The_Impact_of_ICTs_on_Customer_Service_Excellence_in_Zimbabwe/ links/0a85e537f2e966d5cc000000/The-Impact-of-ICTs-on-Customer-ServiceExcellence-in-Zimbabwe.pdf

Kasirye, I. (2013). Constraints to agricultural technology adoption in Uganda: Evidence from the 2005/06-2009/10 Uganda national panel survey. Economic Policy Research (Research Series No. 102). Kampala, Uganda.

Katz, J. (2014). Situational evidence. Sociological Methods \& Research, 44(1), 108-144. doi:10.1177/0049124114554870

Kendall, S., \& Halliday, L. E. (2014). Undertaking ethical qualitative research in public health: Are current ethical processes sufficient? Australian and New Zealand Journal of Public Health, 38, 306-310. doi:10.1111/1753-6405.12250

Ketokivi, M., \& Choi, T. (2014). Renaissance of case research as a scientific method. Journal of Operations Management, 32(5), 232-240. doi:10.1016/j.jom.2014.03.004

Khan, S., \& VanWynsberghe, R. (2008). Cultivating the under-mined: Cross-case analysis as knowledge mobilization. Forum Qualitative Sozialforschung/Forum: Qualitative Social Research 9(1). doi: 10.17169/fqs-9.1.334 
Kianian, B., Tavassoli, S., \& Larsson, T. C. (2015). The role of additive manufacturing technology in job creation: An exploratory case study of suppliers of additive manufacturing in Sweden. Procedia CIRP, 26, 93-98.

doi:10.1016/j.procir.2014.07.109

King, N. (2004). Using templates in the thematic analysis of text. In C. Cassell \& G. Symon (Eds.), Essential guide to qualitative methods in organizational research (pp. 257-270). London, UK: Sage

Klenke, K. (Ed.). (2016). Qualitative research in the study of leadership (2nd ed.). Bingley, UK: Emerald Group Publishing Limited. http://dx.doi.org/10.1108/978$1-78560-651-920152019$

Koch, T. (2006). Establishing rigour in qualitative research: The decision trail. Journal of Advanced Nursing, 53(1), 91-100. doi:10.1111/j.1365-2648.2006.03681.x

Kolade, O., Harpham, T., \& Kibreab, G. (2014). Institutional barriers to successful innovations: Perceptions of rural farmers and key stakeholders in southwest Nigeria. African Journal of Science, Technology, Innovation and Development, 6(4), 339-353. doi:10.1080/20421338.2014.966039

Kolstad, I., Wiig, A., \& Chivunda, V. (2017). Making money in Angola is about connections, not hard work. CMI Brief, 12. Retrieved from https://www.cmi.no/publications/6387-making-money-in-angola-is-aboutconnections 
Komodromos, M. (2014). Employees' perceptions of trust, fairness, and the management of change in three private universities in Cyprus. Journal of Human Resources, 2(2), 35-54. doi:10.1504/ijtcs.2014.065625

Kozinets, R. (2017). Netnography: Radical participative understanding for a networked communications society. In C. Willig \& W. Stainton Rogers (Eds.), The SAGE Handbook of Qualitative Research in Psychology (p. 374). London, UK: Sage Publications.

Kreindler, G. E., \& Young, H. P. (2014). Rapid innovation diffusion in social networks. Proceedings of the National Academy of Sciences, 111 (Supplement 3), 1088110888. doi:10.1073/pnas. 1400842111

Krüger, J. J. (2016). Revisiting the world technology frontier: A directional distance function approach. Journal of Economic Growth, 22(1), 67-95. doi:10.1007/s10887-016-9136-5

Kshetri, N. (2016). Creation, deployment, diffusion and export of sub-Saharan Africaoriginated information technology-related innovations. International Journal of Information Management, 36(6), 1274-1287. doi:10.1016/j.ijinfomgt.2016.09.003

Kurronen, S. (2015). Financial sector in resource-dependent economies. Emerging Markets Review, 23, 208-229. doi:10.1016/j.ememar.2015.04.010

Kus, B. (2014). The informal road to markets. International Journal of Social Economics, 4l(4), 278-293. doi:10.1108/ijse-11-2012-0209 
Kwan, L. Y., \& Chiu, C. (2015). Country variations in different innovation outputs: The interactive effect of institutional support and human capital. Journal of Organizational Behavior, 36(7). doi:1050-1070. doi:10.1002/job.2017

Lam, S. K. K., Kwong, E. W. Y., Hung, M. S. Y., Pang, S. M. C., \& Chiang, V. C. L. (2018). Nurses' preparedness for infectious disease outbreaks: A literature review and narrative synthesis of qualitative evidence. Journal of Clinical Nursing, 27(78), e1244-e1255. doi:10.1111/jocn.14210

Landabaso, M. (1997). The promotion of innovation in regional policy: Proposals for a regional innovation strategy1. Entrepreneurship \& Regional Development, 9(1), 1-24. doi:10.1080/08985629700000001

Langyintuo, A. S., \& Mungoma, C. (2008). The effect of household wealth on the adoption of improved maize varieties in Zambia. Food Policy, 33(6), 550-559. doi:10.1016/j.foodpol.2008.04.002

Lawson T. (2014). A speeding up of the rate of social change? Power, technology, resistance, globalisation and the good society. In: M. Archer (Ed.) Late Modernity. Social Morphogenesis. Lausanne, Switzerland: Springer.

Lawson T. (2015) The modern corporation: The site of a mechanism (of global social change) that Is out-of-control? In M. S. Archer (Ed.), Generative mechanisms transforming the social order. Social Morphogenesis. Switzerland: Springer.

Lee, L. Y.-S. (2013). Hospitality industry web-based self-service technology adoption model. Journal of Hospitality \& Tourism Research, 40(2), 162-197. doi:10.1177/1096348013495695 
Levitt, H. M., Motulsky, S. L., Wertz, F. J., Morrow, S. L., \& Ponterotto, J. G. (2017). Recommendations for designing and reviewing qualitative research in psychology: Promoting methodological integrity. Qualitative Psychology, 4(1), 222. doi:10.1037/qup0000082

Lewis, W.A. (2013). Theory of economic growth (Vol. 7). Routledge.

Leydesdorff, L., Cooke, P., \& Olazaran, M. (2002). Technology transfer in European regions: Introduction to the special issue. Journal of Technology Transfer, 27(1), 5-13. Retrieved from https://www.leydesdorff.net/eu-regions/

Li, D., Lin, J., Cui, W., \& Qian, Y. (2018). The trade-off between knowledge exploration and exploitation in technological innovation. Journal of Knowledge Management. doi:10.1108/jkm-09-2016-0401

Lincoln, Y. S., \& Guba, E. G. (1985). Naturalistic inquiry. Newbury Park, CA: Sage Publications.

Lingelbach, D., Sriram, V., Mersha, T., \& Saffu, K. (2015). The innovation process in emerging economies: An effectuation perspective. The International Journal of Entrepreneurship and Innovation, 16(1), 5-17. doi:10.5367/ijei.2015.0172

Litwiński, M. (2017). The evolution of idea of socio-economic development. Ekonomia $i$ Prawo. Ecomomics and Law, 16(4): 449-458. doi:10.12775/EiP.2017.031

Maharaj, N. (2016). Using field notes to facilitate critical reflection. Reflective Practice, 17(2), 114-124. doi:10.1080/14623943.2015.1134472

McWilliams, S. A. (2010). The varieties of meaning-making experience. Journal of Constructivist Psychology, 23(3), 261-266. doi:10.1080/10720531003799642 
Masud, M. (2018). An examination of case studies in management research: a paradigmatic bridge. International Journal of Social Science Studies, 6(3), 9. doi:10.11114/ijsss.v6i3.2971

Matthews, J. R. (2017). Understanding indigenous innovation in rural West Africa: Challenges to diffusion of innovations theory and current social innovation practice. Journal of Human Development and Capabilities, 18(2), 223-238. doi:10.1080/19452829.2016.1270917

May, J., Dutton, V., \& Munyakazi, L. (2014). Information and communication technologies as a pathway from poverty: Evidence from East Africa. In E. O., Adera, M. T., Waema, J. D., May (Eds.), ICT Pathways to Poverty Reduction. International Development Research Centre, Ottwa, ON: IDRC

May, J., Karugia, J., \& Ndokweni, M. (2007). Information and communication technologies and agricultural development in sub-Saharan Africa: Transformation and employment generation. Retrieved from https://www.africaportal.org/search/?query=Information+and+communication+te chnologies+and+agricultural+development+in+sub-Saharan+Africa

McCall, L. (2005). The complexity of intersectionality. Signs: Journal of Women in Culture and Society, 30(3), 1771-1800. doi:10.1086/426800

McGrath, S. K., \& Whitty, S. J. (2017). Stakeholder defined. International Journal of Managing Projects in Business, 10(4), 721-748. doi:10.1108/ijmpb-12-20160097 
McKinlay, E. M., Morgan, S. J., Gray, B. V., Macdonald, L. M., \& Pullon, S. R. (2017). Exploring interprofessional, interagency multimorbidity care: Case study based observational research. Journal of Comorbidity, 7(1), 64-78. doi:10.15256/joc.2017.7.103

McKinsey \& Company. (2016). Bridging global infrastructure gaps. Retrieved from http://www.mckinsey.com/industries/infrastructure/our-insights/bridgingglobalinfrastructure-gaps.

Medina, L., Jonelis, M. A. W., \& Cangul, M. (2017). The informal economy in subSaharan Africa: Size and determinants (Working Paper No. 17/156). International Monetary Fund.

Melkote, S. R. (2006). Everett M. Rogers and his contributions to the field of communication and social change in developing countries. Journal of Creative Communications, 1(1), 111-121. doi:10.1177/097325860500100109

Merriam, S. B., \& Grenier, R. S. (Eds.). (2019). Qualitative research in practice: Examples for discussion and analysis. Jossey-Bass.

Merriam, S. B., \& Tisdell, E. J. (2015). Qualitative research: A guide to design and implementation. San Francisco, CA: Wiley \& Sons.

Minde, I., Terblanche, S., Bashaasha, B., Madakadze, I. C., Snyder, J., \& Mugisha, A. (2015). Challenges for agricultural education and training (AET) institutions in preparing growing student populations for productive careers in the agri-food system. Journal of Agribusiness in Developing and Emerging Economies, 5(2), 137-169. doi:10.1108/jadee-02-2015-0011 
Moon, K., Brewer, T. D., Januchowski-Hartley, S. R., Adams, V. M., \& Blackman, D. A. (2016). A guideline to improve qualitative social science publishing in ecology and conservation journals. Ecology and Society, 21(3). doi:10.5751/es-08663210317

Moser, C. M., \& Barrett, C. B. (2003). The disappointing adoption dynamics of a yieldincreasing, low external-input technology: the case of SRI in Madagascar. Agricultural Systems, 76(3), 1085-1100. doi:10.1016/s0308-521x(02)00041-0

Mothobi, O., \& Grzybowski, L. (2017). Infrastructure deficiencies and adoption of mobile money in sub-Saharan Africa. Information Economics and Policy, 40, 7179. doi:10.1016/j.infoecopol.2017.05.003

Mokyr, J., Vickers, C., \& Ziebarth, N. L. (2015). The history of technological anxiety and the future of economic growth: is this time different? Journal of Economic Perspectives, 29(3), 31-50. doi:10.1257/jep.29.3.31

Mramba, N., Rumanyika, J., Apiola, M., \& Suhonen, J. (2017). ICT for informal workers in Sub-Saharan Africa: Systematic review and analysis. 2017 IEEE AFRICON. doi:10.1109/afrcon.2017.8095530

Mudombi, S., \& Muchie, M. (2014). An institutional perspective to challenges undermining innovation activities in Africa. Innovation and Development, 4(2), 313-326. doi:10.1080/2157930x.2014.921272

Mulhall, A. (2003). In the field: Notes on observation in qualitative research. Journal of Advanced Nursing, 41(3), 306-313. doi:10.1046/j.1365-2648.2003.02514.x 
Mumporeze, N., \& Prieler, M. (2017). Gender digital divide in Rwanda: A qualitative analysis of socioeconomic factors. Telematics and Informatics, 34(7), 1285-1293. doi:10.1016/j.tele.2017.05.014

Munro, L. (2011). A Literature review on trade and informal labour markets in developing countries. OECD Trade Policy (Working Paper No. 132). Paris, France: OECD Publishing.

Munyoka, W., \& Maharaj, M. (2017). Towards the harmonisation of information and communication technology policy frameworks in the Southern African Development Community. Paper presented at the 2017 International Conference on Information Technology Systems and Innovation (ICITSI), Bandung, Indonesia.

Mutula, S. M. (2008). Digital divide and economic development: Case study of subSaharan Africa. The Electronic Library, 26(4), 468-489. doi:10.1108/02640470810893738

Mwangi, M., \& Kariuki, S. (2015). Factors determining adoption of new agricultural technology by smallholder farmers in developing countries. Journal of Economics and Sustainable Development, 6(5). Retrieved from https://pdfs.semanticscholar.org/8e9b/28e14286f65a9168738a97c74a256bc8e4c3. pdf

Nakabashi, L., Pereira, A. E.G., \& Sachsida, A. (2013). Institutions and growth: A developing country case study. Journal of Economic Studies, 40(5), 614-634. doi:10.1108/jes-09-2011-0111 
Nakano, Y., Tsusaka, T. W., Aida, T., \& Pede, V. O. (2018). Is farmer-to-farmer extension effective? The impact of training on technology adoption and rice farming productivity in Tanzania. World Development, 105, 336-351. doi:10.1016/j.worlddev.2017.12.013

Nath, R., \& Murthy, V. N. (2018). What accounts for the differences in internet diffusion rates around the world?. In M. Khosrow-Pour, D.B.A. (Ed.), Encyclopedia of Information Science and Technology, Fourth Edition (pp. 8095-8104). Hershey, PA: IGI Global.

Ncube, M., Shimeles, A., \& Verdier-Chouchane, A. (2013). South Africa's quest for inclusive development. International Development, 697-713. doi: 10.1093/acprof:oso/9780199671656.003.0042

Ndichu, J., Blohmke, J., Kemp, R., Adeoti, J., \& Obayelu, A. E. (2015). The adoption of energy efficiency measures by firms in Africa: Case studies of cassava processing in Nigeria and maize milling in Kenya. Innovation and Development, 5(2), 189206. doi:10.1080/2157930x.2015.1057980

Neubert, M. (2016). Significance of the speed of internationalisation for born global firms-a multiple case study approach. International Journal of Teaching and Case Studies, 7(1), 66-81. doi:10.1504/IJTCS.2016.076067

Nguimkeu, P. (2014). A structural econometric analysis of the informal sector heterogeneity. Journal of Development Economics, 107, 175-191. doi:10.1016/j.jdeveco.2013.12.001 
Ngunga, E. J. (2018). Higher education, R\&D, and challenges in national innovation system building of Angola. Innovation, Regional Integration, and Development in Africa, 191-210. doi:10.1007/978-3-319-92180-8_13

Nicolina, A., Gabriela, E.A., Ghosh, B.S., Mikul, B., Irina, B., Gustavo, I.J.,... Goldenberg, J. (2013). Global tracking framework: Overview. Sustainable energy for all (Working Oaoer No. 77889 Vol.2). Washington, DC: World Bank.

Nicotra, M., Romano, M., \& Del Giudice, M. (2014). The evolution dynamic of a cluster knowledge network: The role of firms' absorptive capacity. Journal of the Knowledge Economy, 5(2), 240-264. doi:10.1007/s13132-013-0147-6

Niebel, T. (2018). ICT and economic growth - Comparing developing, emerging and developed countries. World Development, 104, 197-211. doi:10.1016/j.worlddev.2017.11.024

Nipo, D. T., Bujang, I., \& Hassan, H. (2017). Global digital divide: Inter-regional study on the impact of ICT diffusion on economic growth. In F. Noording, A. K. Othman, \& E. S. Kassim (Eds.), Proceedings of the 2nd Advances in Business Research International Conference. Singapore: Springer

Nistor, N., Schworm, S., \& Werner, M. (2012). Online help-seeking in communities of practice: Modeling the acceptance of conceptual artifacts. Computers \& Education, 59(2), 774-784. doi:10.1016/j.compedu.2012.03.017

Njoh, A. J. (2018). The relationship between modern information and communications technologies (ICTs) and development in Africa. Utilities Policy, 50, 83-90. doi:10.1016/j.jup.2017.10.005 
Noman, A., Botchwey, K., Stein, H., \& Stiglitz, J. E. (Eds.). (2012). Good growth and governance in Africa: Rethinking development strategies. Oxford University Press.

Norman, A., \& Stiglitz, J. (2012). African development prospects and possibilities. The Oxford Companion to the Economics of Africa. Oxford University Press.

Nowell, L. S., Norris, J. M., White, D. E., \& Moules, N. J. (2017). Thematic analysis. International Journal of Qualitative Methods, 16(1), 160940691773384. doi:10.1177/1609406917733847

Ogbuabor, J. E., \& Malaolu, V. A. (2013). Size and causes of the informal sector of the Nigerian economy: evidence from error correction Mimic model. Journal of Economics and Sustainable Development, 4(1), 85-103. Retrieved from http://iiste.org/Journals/index.php/JEDS/article/viewFile/4100/4128

O'Hegarty, M., Pederson, L. L., Thome, S. L., Caraballo, R. S., Evans, B., Athey, L., \& McMichael, J. (2010). Customizing survey instruments and data collection to reach Hispanic/Latino adults in border communities in Texas. American Journal of Public Health, 100(S1), S159-S164. doi:10.2105/AJPH.2009.167338

Ojo, E. O. (2015). The Atlantic slave trade and colonialism: Reasons for Africa's underdevelopment? European Scientific Journal, ESJ, 11(17). Retrieved from http://www.eujournal.org/index.php/esj/article/download/5796/5669\&hl=en\&sa= T\&oi=gsb-gga\&ct=res\&cd=0\&ei=x9k2Wq2gJM0mAGz_6DQCw\&scisig=AAGBfm0zqmLdBDi-G5g0t6iuwOfs-kqVfw

Okunola, O. M., Rowley, J., \& Johnson, F. (2017). The multi-dimensional digital divide: 
Perspectives from an e-government portal in Nigeria. Government Information Quarterly, 34(2), 329-339. doi:10.1016/j.giq.2017.02.002

Oloruntoba, S. O., \& Muchie, M. (Eds.). (2019). Innovation, Regional Integration, and Development in Africa. Advances in African Economic, Social and Political Development. doi:10.1007/978-3-319-92180-8

Oluwatayo, I. B., \& Ojo, A. O. (2018). Walking through a tightrope: The challenge of economic growth and poverty in Africa. The Journal of Developing Areas, 52(1), 59-69. doi:10.1353/jda.2018.0004

Oluwatobi, S., Efobi, U., Olurinola, I., \& Alege, P. (2014). Innovation in Africa: Why institutions matter. South African Journal of Economics, 83(3), 390-410. doi:10.1111/saje.12071

Oluwatobi, S., Ola-David, O., Olurinola, I. O., Alege, P., \& Ogundipe, A. (2016). Human capital, institutions and innovation in sub-Saharan Africa. International Journal of Economics and Financial Issues, 6(4). Retrieved from http://dergipark.gov.tr/download/article-file/366210

Omwenga, B. G. (2016). Designing the ultimate tech-hub. Proceedings of the 7th Annual Symposium on Computing for Development - ACM DEV'16. doi:10.1145/3001913.3006648

Onsongo, E. K., \& Schot, J. (2017). Inclusive innovation and rapid sociotechnical transitions: The case of mobile money in Kenya (Working Paper No. 2017/07). Falmer Brighton, UK: SSRN Electronic Journal.

Orb, A., Eisenhauer, L., \& Wynaden, D. (2001). Ethics in qualitative research. Journal of 
Nursing Scholarship, 33(1), 93-96. doi:10.1111/j.1547-5069.2001.00093.x

Organization for Economic Co-operation and Development. (2012). Promoting growth in all regions. France, Paris: OECD Publishing.

Organization for Economic Co-operation and Development. (2014). African economic outlook 2014: Global value chains and Africa's industrialisation. France, Paris: OECD Publishing.

Organization for Economic Co-operation and Development. (2015). African economic outlook 2015: Regional Development and spatial inclusion. France, Paris: OECD Publishing.

Organization for Economic Co-operation and Development. (2017a). African economic outlook 2017: Entrepreneurship and industrialisation. France, Paris: OECD Publishing.

Organization for Economic Co-operation and Development. (2017b). "Angola", African economic outlook 2017: Entrepreneurship and industrialisation. France, Paris: OECD Publishing.

Osabutey, E. L. C., Williams, K., \& Debrah, Y. A. (2014). The potential for technology and knowledge transfers between foreign and local firms: A study of the construction industry in Ghana. Journal of World Business, 49(4), 560-571. doi:10.1016/j.jwb.2013.12.009

Osakwe, P., \& Moussa, N. (2017, July). Innovation, diversification and inclusive development in Africa. United Nations Conference on Trade and Development (Working Paper No. SER.RP/2017/2). UNCTAD Publications. 
Ovadia, J. S. (2014). Local content and natural resource governance: The cases of Angola and Nigeria. The Extractive Industries and Society, 1(2), 137-146. doi:10.1016/j.exis.2014.08.002

Oxford Poverty \& Human Development Initiative. (2018). Oxford department of international development. University of Oxford, UK. Retrieved from: https://ophi.org.uk/multidimensional-poverty-index/mpi-resources/

Oyedemi, T. D. (2012). Digital inequalities and implications for social inequalities: A study of Internet penetration amongst university students in South Africa. Telematics and Informatics, 29(3), 302-313. doi:10.1016/j.tele.2011.12.001

Page, J. (2012). Can Africa industrialize? Journal of African Economies, 21(2), ii86ii124. doi:10.1093/jae/ejr045

Pannucci, C. J., \& Wilkins, E. G. (2010). Identifying and avoiding bias in research. Plastic and Reconstructive Surgery, 126(2), 619-625. doi:10.1097/prs.0b013e3181de24bc

Papyrakis, E. (2014). A development curse: Formal vs informal activities in resourcedependent economies. International Journal of Social Economics, 41(3), 244264. doi:10.1108/ijse-01-2013-0141

Parienté, W. (2017). Urbanization in sub-Saharan Africa and the challenge of access to basic services. Journal of Demographic Economics, 83(01), 31-39. doi:10.1017/dem.2017.3 
Park, S. R., Choi, D. Y., \& Hong, P. (2015). Club convergence and factors of digital divide across countries. Technological Forecasting and Social Change, 96, 92100. doi:10.1016/j.techfore.2015.02.011

Patton, M. Q. (1999). Enhancing the quality and credibility of qualitative analysis. Health Services Research, 34(5/2), 1189. Retrieved from https://www.ncbi.nlm.nih.gov/pmc/articles/PMC1089059/pdf/hsresearch000220112.pdf

Patton, M. Q. (2014). Qualitative research \& evaluation methods. Thousand Oaks, CA: Sage Publications.

Peck, B., \& Mummery, J. (2017). Hermeneutic Constructivism: An ontology for qualitative research. Qualitative Health Research, 28(3), 389-407. doi:10.1177/1049732317706931

Penard, T., Poussing, N., Mukoko, B., \& Tamokwe Piaptie, G. B. (2015). Internet adoption and usage patterns in Africa: Evidence from Cameroon. Technology in Society, 42, 71-80. doi:10.1016/j.techsoc.2015.03.004

Phillippi, J., \& Lauderdale, J. (2017). A guide to field notes for qualitative research: context and conversation. Qualitative Health Research, 28(3), 381-388. doi:10.1177/1049732317697102

Pick, J. B., \& Nishida, T. (2015). Digital divides in the world and its regions: A spatial and multivariate analysis of technological utilization. Technological Forecasting and Social Change, 91, 1-17. doi:10.1016/j.techfore.2013.12.026 
Pick, J., \& Sarkar, A. (2016). Theories of the digital divide: Critical comparison. 2016 49th Hawaii International Conference on System Sciences (HICSS). doi:10.1109/hicss.2016.484

Pierskalla, J. H., \& Hollenbach, F. M. (2013). Technology and collective action: The effect of cell phone coverage on political violence in Africa. American Political Science Review, 107(02), 207-224. doi:10.1017/s0003055413000075

Pillania, R. K. (2011). The state of research on technological uncertainties, social uncertainties and emerging markets: A multidisciplinary literature review. Technological Forecasting and Social Change, 78(7), 1158-1163. doi:10.1016/j.techfore.2011.02.006

Política Nacional de Ciência, Tecnologia e Inovação. ( 2011). Decreto Presidencial. Nº 2011/11, de 20 de Julho. Retrieved from http://ciencia.ao/legislacao_angola/PNCTI_DP201_2011.pdf

Polit, D., F., Beck, C.T., \& Hungler, B. P. (2006). Essentials of nursing research: Methods, appraisal, and utilization. Lippincott, NY.

Polit, D.F., \& Beck, C.T. (2012). Nursing research: Generating and assessing evidence for nursing practice. Philadelphia, PA: Lippincott Williams and Wilkins.

Pope, C., Mays, N., \& Popay, J. (2007). Synthesising qualitative and quantitative health evidence: A guide to methods. McGraw-Hill Education (UK).

Porta, R.L. \& Shleifer, A. (2014, June). Informality and development. National Bureau of Economic Research (Working Paper No. 20205). Cambridge, MA. 
Porter, G. (2014). Transport services and their impact on poverty and growth in rural subSaharan Africa: A review of recent research and future research needs. Transport Reviews, 34(1), 25-45. doi:10.1080/01441647.2013.865148

Power, M. (2011). Angola 2025: The future of the "world's richest poor country" as seen through a Chinese rear-view mirror. Antipode, 44(3), 993-1014. doi:10.1111/j.1467 8330.2011.00896.x

PR, N. (2013, October 24). IBM provides advice for Angola's energy, tourism and education sectors. PR Newswire US.

Ramani, S. V., Thutupalli, A., \& Urias, E. (2017). High-value hi-tech product introduction in emerging countries: The role and construction of legitimacy. Qualitative Market Research: An International Journal, 20(2), 208225. doi:10.1108/qmr-01-2017-0034

Ravitch, S.M., \& Carl, N.M. (2016). Qualitative research: Bridging the conceptual, theoretical, and methodological. Thousand Oaks, CA: Sage Publications

Reed, M. (2016). Africa to reach landmark 1 billion mobile subscriptions by end of 2016 . Retrieved from https://www.ovum.com/press_releases/africa-reach-landmark-1billion-mobilesubscriptions-end-2016/

Reiff, M. R. (2015). Technological innovation and structural unemployment. In $O n$ Unemployment, 65-92. Palgrave Macmillan, New York.

Reinecke, J., Arnold, D. G., \& Palazzo, G. (2016). Qualitative methods in business ethics, corporate responsibility, and sustainability research. Business Ethics Quarterly, 26(04), xiii-xxii. doi:10.1017/beq.2016.67 
Reiter, S., Stewart, G., \& Bruce, C. (2011). A strategy for delayed research method selection: Deciding between grounded theory and phenomenology. The Electronic Journal of Business Research Methods, 9(1), 35-46. Retrieved from http://eprints.qut.edu.au/48527/1/Reiter\%2C_S.\%2C_et_al._\%282011\%29._A_St rategy_for_Delayed_Research_Method_Selection_Deciding_Between_Grounded_Theory_and_Phenomenology._The_Electronic\% C2\%A0Journal_of_Business_Research_Methods\%2C_9\%281\%29\%2C_3546..pdf

Richardson, A.J. (2018). The discovery of cumulative knowledge. Accounting, Auditing \& Accountability Journal, 31(2), 563-585. doi:10.1108/aaaj-08-2014-1808

Rivers, P. A., Rivers, J. K., \& Hazell, V. (2015). Africa and technology in higher education: Trends, challenges, and promise. International Journal for Innovation Education and Research, 3(5). Retrieved from http://ijier.net/index.php/ijier/article/download/354/273

Ritchie, J., Lewis, J., Nicholls, C. M., \& Ormston, R. (Eds.). (2013). Qualitative research practice: A guide for social science students and researchers. Thousand Oaks, CA: Sage.

Rogers, E. M. (1995). Diffusion of innovations (4th ed.). New York, NY: Free Press Rogers, E. M. (2003). Diffusion of innovations (5th ed.). New York, NY: Free Press Rogers, E. M. (2004). A prospective and retrospective look at the diffusion model. Journal of Health Communication, 9(1), 13-19. doi:10.1080/10810730490271449 Rogers, E. M. (2010). Diffusion of innovations. New York, NY: Simon and Schuster. 
Rogers, E. M., Medina, U. E., Rivera, M. A., \& Wiley, C. J. (2005). Complex adaptive systems and the diffusion of innovations. The Innovation Journal: The Public Sector Innovation Journal, 10(3), 1-26. Retrieved from https://www.innovation.cc/peer-reviewed/rogersadaptivesystem7finalv10i3a3.pdf

Rogers, E. M., Takegami, S., \& Yin, J. (2001). Lessons learned about technology transfer. Technovation, 21(4), 253-261. doi:10.1016/s0166-4972(00)00039-0

Rohracher, H., B. Truffer, and J. Markard. (2009, June). The analysis of institutions in technological innovation systems - A conceptual framework applied to biogas development in Austria. Paper presented at the DRUID Conference, Frederiksberg, Denmark.

Romer, P. M. (1990). Endogenous technological change. Journal of Political Economy, 98(5/2), 71-102. doi:10.1086/261725

Roque, P. C. (2011). Angola: Parallel governments, oil and neopatrimonial system reproduction. Retrieved from https://www.africaportal.org/documents/6376/6June2011Angola.pdf Rowley, J. (2002). Using case studies in research. Management Research News, (1), 1627. doi:10.1108/01409170210782990

Rubin, H. J., \& Rubin, I. S. (2012). Qualitative interviewing: The art of hearing data 3rd ed.). Thousand Oaks, CA: Sage Publications.

Saidi, T., \& Douglas, T. S. (2017). Towards the socialization of science, technology and innovation for African development. African Journal of Science, Technology, 
Innovation and Development, 10(1), 110-113.

doi:10.1080/20421338.2017.1399534

Salami, A., A. B. Kamara, and Z. Brixiova. (2010, April). Smallholder agriculture in east africa: trends, constraints and opportunities (Working Paper $\left.\mathrm{N}^{\circ} 105\right)$. Tunis: African Development Bank. Retrieved from https://pdfs.semanticscholar.org/cfa3/09d7c77c5922291155296df2f4721d442829. pdf

Sallah, A. (2016). Re-reading the narrative of the informal economy in the context of economic development in sub-Saharan Africa. International Journal of Social Economics, 43(10), 1063-1078. doi:10.1108/ijse-04-2015-0091

Saunders, B., Sim, J., Kingstone, T., Baker, S., Waterfield, J., Bartlam, B., ... Jinks, C. (2017). Saturation in qualitative research: Exploring its conceptualization and operationalization. Quality \& Quantity, 52(4), 1893-1907. doi:10.1007/s11135017-0574-8

Schillo, R. S., \& Robinson, R. M. (2017). Inclusive innovation in developed countries: The who, what, why, and how. Technology Innovation Management Review, 7(7). Retrieved from http://www.timreview.ca/sites/default/files/article_PDF/SchilloRobinson_TIMRe view_July2017.pdf

Sheahan, M. \& Barrett, C.B. (2014). Understanding the agricultural input landscape in sub-Saharan Africa: Recent plot, household, and community-level evidence. 
Policy Research (Working Paper No. WPS 7014). Washington, DC: World Bank Group.

Shiferaw, A., \& Hailu, D. (2016). Job creation and trade in manufactures: Industry-level analysis across countries. IZA Journal of Labor \& Development, 5(1). doi:10.1186/s40175-016-0052-Z

Schmidt, T. S., \& Huenteler, J. (2016). Anticipating industry localization effects of clean technology deployment policies in developing countries. Global Environmental Change, 38, 8-20. doi:10.1016/j.gloenvcha.2016.02.005

Schmidt, S. (2017). Replication. In M. C. Makel, J. A. Plucker, M. C. Makel, J. A. Plucker (Eds.), Toward a more perfect psychology: Improving trust, accuracy, and transparency in research (pp. 233-253). Washington, DC, US: American Psychological Association. doi:10.1037/0000033-015

Schram, T. H. (2006). Conceptualizing and proposing qualitative research ( $2 \mathrm{nd} \mathrm{ed}$.$) .$ Lewiston, NY: Pearson.

Schultz, T. (1961). Investment in human capital. The American Economic Review, 51(1), 1-17. Retrieved from https://www.jstor.org/stable/1818907

Shen, W., Yang, S.-C. S., \& Zanna, L.-F. (2018). Government spending effects in lowincome countries. Journal of Development Economics. doi:10.1016/j.jdeveco.2018.02.005

Shenton, A. K. (2004). Strategies for ensuring trustworthiness in qualitative research projects. Education for Information, 22, 63-75. doi:10.12691/education-3-7-4 
Silk, K. J., Hurley, A., Pace, K., Maloney, E. K., \& Lapinski, M. (2014). A Diffusion of Innovations Approach to Understand Stakeholder Perceptions of Renewable Energy Initiatives. Science Communication, 36(5), 646-669. doi:10.1177/1075547014549891

Silva, K. N. N., \& Broekel, T. (2016). Factors constraining farmers' adoption of new agricultural technology programme in Hambantota district in Sri Lanka:

Perceptions of agriculture extension officers. Paper presented at 13th International Conference on Business Management (ICBM) 2016. University of Sri Jayewardenepura, Sri Lanka.

Silva, M. R., Roque, H. C., \& Caetano, A. (2015). Culture in Angola: Insights for human resources management. Cross Cultural Management: An International Journal, 22(2), 166-186. doi:10.1108/ccm-02-2013-0036

Silva, S., Badasyan, N., \& Busby, M. (2018). Diversity and digital divide: Using the National Broadband Map to identify the non-adopters of broadband. Telecommunications Policy. doi:10.1016/j.telpol.2018.02.008

Simon, M. K., \& Goes, J. (2013). Scope, limitations, and delimitations. Dissertation and. Scholarly Research: Recipes for Success. Retrieved from http://dissertationrecipes.com/wpcontent/uploads/2011/04/limitationscopedelimitation1.pdf

Sirine, M. N. I. F. (2017). The impact of inequality on growth driven by technological changes: A panel of developing countries. Journal of the Knowledge Economy, 8(1), 127-140. doi:10.1007/s13132-016-0363-y 
Smith, R.A., Kim, Y., Zhu, X., Doudou, D. T., Sternberg, E.D., \& Thomas, M.B. (2018). Integrating models of diffusion and behavior to predict innovation adoption, maintenance, and social diffusion. Journal of Health Communication, 1-8. doi:10.1080/10810730.2018.1434259

Sobratee, N., \& Bodhanya, S. (2017). How can we envision smallholder positioning in African agribusiness? Harnessing innovation and capabilities. Journal of Business $\&$ Retail Management Research, 12(01). doi:10.24052/jbrmr/v12is01/hcwespiaahiac

Stake, R. E. (2010). Qualitative research: Studying how things work. Guilford Press. Stake, R. E. (2013). Multiple case study analysis. New York, NY: Guilford Press.

Stambouli, A., Khiat, Z., Flazi, S., Tanemoto, H., Nakajima, M., Isoda, H., ... Yassaa, N. (2014). Trends and challenges of sustainable energy and water research in north Africa: Sahara solar breeder concerns at the intersection of energy/water. Renewable and Sustainable Energy Reviews, 30, 912-922. doi:10.1016/j.rser.2013.11.042

Stewart, R., Langer, L., Natalie Rebelo, D. S., Muchiri, E., Zaranyika, H., Erasmus, Y., . . . de Wet, T. (2015). The effects of training, innovation and new technology on African smallholder farmers' wealth and food security: A systematic review. Campbell Systematic Reviews, 11(16). doi:10.4073/csr.2015.16

Stier, S. (2017). Internet diffusion and regime type: Temporal patterns in technology adoption. Telecommunications Policy, 41(1), 25-34. doi:10.1016/j.telpol.2016.10.005 
Schwarzenegger, C. (2017). Triangulation. The International Encyclopedia of Communication Research Methods, 1-5. doi:10.1002/9781118901731.iecrm0255

Taylor, I. (2014). Book review: Uncovering African agency: Angola's management of china's credit lines. The China Quarterly, 217, 285-287. doi10.1017/S0305741014000162

Tayo, O., Thompson, R., \& Thompson, E. (2015). Impact of the digital divide on computer use and internet access on the poor in Nigeria. Journal of Education and Learning, 5(1), 1. doi:10.5539/jel.v5n1p1

Tchamyou, V. S. (2016). The role of knowledge economy in african business. Journal of the Knowledge Economy, 8(4), 1189-1228. doi:10.1007/s13132-016-0417-1

The World Bank. (2012). Etransform Africa: ICTs for financial services in Africa. Retrieved from http://siteresources.worldbank.org/EXTINFORMATIONANDCOMMUNICATI ONANDTECHNOLOGIES/Resources/2828221346223280837/FinancialServices.pdf

The World Bank. (2016a). Addressing labor market challenges and unlocking private sector growth are key to gainful and quality employment for all. Retrieved from http://www.worldbank.org/en/news/press-release/2016/11/17/addressing-labormarket-challenges-unlocking-private-sector-growth

The World Bank (2016b). World development report 2016: Digital dividends. Washington, DC: Author. 
The World Bank. (2017a). Angola: Aspectos gerais [Angola: General aspects]. Retrieved from http://www.worldbank.org/pt/country/angola/overview

The World Bank. (2017b). Labor force, total. Retrieved from https://data.worldbank.org/indicator/SL.TLF.TOTL.IN?end=2017\&locations=AO $\&$ start=2017 \&view=map

The World Bank (2018). The World Bank in Angola. Retrieved from: http://www.worldbank.org/en/country/angola

Tigabu, A. D. (2017). Analysing the diffusion and adoption of renewable energy technologies in Africa: The functions of innovation systems perspective. African Journal of Science, Technology, Innovation and Development, 1-10. doi:10.1080/20421338.2017.1366130

Ton, G., de Grip, K., Klerkx, L., Rau, M.L., Douma, M., Friis-Hansen, E., ... Wongtschowski, M., (2013). Effectiveness of innovation grants to smallholder agricultural rroducers: An explorative systematic review. EPPI- Centre, Social Science Research Unit, Institute of Education, University of London. Retrieved from http://eppi.ioe.ac.uk/cms/LinkClick.aspx?fileticket=4soRhylhV4A\%3D\&tabid=3 401

Tordo, S., Warner, M., Manzano, O.E., \& Anouti, Y., (2013). Local content policies in the oil and gas sector. Washington, DC: The World Bank.

Tracy, S. J. (2010). Qualitative quality: Eight "Big-Tent" criteria for excellent qualitative research. Qualitative Inquiry, 16(10), 837-851. doi:10.1177/1077800410383121 
Trading Economics (2018). Angola unemployment rate. Retrieved from https://tradingeconomics.com/angola/unemployment-rate

Transparency.org. (2014). Corruption perceptions index: Results. Retrieved from https://www.transparency.org/cpi2014/results

Traoré, B., Markley, S., \& Zebdi, I. (2017). Electricity for all in Africa: Possible? OECD Development Centre. Retrieved from https://medium.com/@OECD/electricityfor-all-in-africa-possible-f142ee $33 \mathrm{e} 83 \mathrm{~b}$

Treharne, G. J., \& Riggs, D. W. (2015). Ensuring quality in qualitative research. Qualitative Research in Clinical and Health Psychology, 57-73. doi:10.1007/9781-137-29105-9_5

Treviño, L. K., Den Nieuwenboer, N. A., Kreiner, G. E., \& Bishop, D. G. (2014). Legitimating the legitimate: A grounded theory study of legitimacy work among Ethics and Compliance Officers. Organizational Behavior and Human Decision Processes, 123(2), 186-205. doi:10.1016/j.obhdp.2013.10.009

Trino, C. A. P. (2016). International technology transfer performance: The case of organizations located in Angolan province (Unpublished master's thesis). Universidade do Porto [University of Porto], Portugal.

Tshempo, N. S. \& Ishihara, Y. (2016). Buthan's labor market. Toward gainful quality employment for all. Washington, DC: World Bank Publications.

UCLA (2012). Guidance and procedure: Recruitment and screening methods and Materials. Retrieved from http://ora.research.ucla.edu/OHRPP/Documents/Policy/5/Recruitment.pdf 
Udelsmann, R. U. C. (2017). Changes to urban society in Angola: From limited to multicriteria stratification. African Studies Review, 60(02), 161-181. doi:10.1017/asr.2017.48

Ugur, M., \& Mitra, A. (2017). Technology adoption and employment in less developed countries: A mixed-method systematic review. World Development, 96, 1-18. doi:10.1016/j.worlddev.2017.03.015

United Nations Habitat. (2016). Urbanization and development: Emerging futures. World Cities Report 2016. Retrieved from http://wcr.unhabitat.org/wpcontent/uploads/2017/03/Chapter1-WCR-2016.pdf

United Nations Development Programme (2013). Angola HDI values and rank changes in the 2013 report. New York, NY: UN.

United Nations Development Programme. (2014). Human development report 2014: Sustaining Human Progress: Reducing Vulnerabilities and Building Resilience. New York, NY: UN.

United Nations Development Programme. (2016). Human development report 2016: Human Development for Everyone. New York, NY: UN.

United Nations Economic Commission for Africa. (2016). Transformative industrial policy for Africa. Addis Ababa, Ethiopia: Author.

Unruh, J. D. (2012). Eviction policy in postwar Angola. Land Use Policy, 29(3), 661663. doi:10.1016/j.landusepol.2011.11.001

Vaismoradi, M., Turunen, H., \& Bondas, T. (2013). Content analysis and thematic analysis: Implications for conducting a qualitative descriptive study. Nursing \& 
health sciences, 15(3), 398-405. doi:10.1111/nhs.12048

Vaismoradi, M., Jones, J., Turunen, H., \& Snelgrove, S. (2016). Theme development in qualitative content analysis and thematic analysis. Journal of Nursing Education and Practice, 6(5), 100. doi:10.5430/jnep.v6n5p100

Van Uden, A., Knoben, J., \& Vermeulen, P. (2016). Human capital and innovation in Sub-Saharan countries: A firm-level study. Innovation, 19(2), 103-124. doi:10.1080/14479338.2016.1237303

Vissak, T. (2010). Recommendations for using the case study method in international business research. The Qualitative Report, 15(2), 370-388. Retrieved from https://nsuw orks.nova.edu/tqr/vol15/iss2/8

Vivarelli, M. (2014). Innovation, employment and skills in advanced and developing countries: A survey of economic literature. Journal of Economic Issues, 48(1), 123-154. doi:10.2753/jei0021-3624480106

Walker, S. (2015, July). Literature reviews: Generative and transformative textual conversations. Forum: Qualitative Social Research, 16(3). Retrieved from http://www.qualitative-research.net/index.php/fqs/article/view/2291/3859

Waloszek, T. (2017). Controversial issues of research methodology taking into account social work. Czech \& Slovak Social Work / Sociální Práce / Sociálna Práca, 17(4), 58-71. Retrieved from https://eds-b-ebscohostcom.ezp.waldenulibrary.org/eds/pdfviewer/pdfviewer?vid=2\&sid=3b84ef2bdbfd-4aaf-980e-962896cfa370\%40pdc-v-sessmgr03 
Wang, Y., Bai, X., \& Cheng, Y. (2017, July). Endowment structure, technological innovation and industrial structure upgrading. Paper presented at the 2017 Portland International Conference on Management of Engineering and Technology (PICMET), Portland, OR.

Warf, B. (2017). Geographies of African corruption. PSU Research Review, 1(1), 20-38. doi:10.1108/prr-12-2016-0012

Wheeler, S. (2009). Regions, megaregions, and sustainability. Regional Studies, 43(6), 863-876. doi:10.1080/00343400701861344

White, D. S., Labarta, R. A., \& Leguía, E. J. (2005). Technology adoption by resourcepoor farmers: considering the implications of peak-season labor costs. Agricultural Systems, 85(2), 183-201. doi:10.1016/j.agsy.2004.07.018

Whitfield, L., Therkildsen, O., Buur, L., \& Kjær, A. M. (2015). The politics of African industrial policy: A comparative perspective. Cambridge University Press.

Wilson, V. (2014). Research methods: triangulation. Evidence Based Library and Information Practice, 9(1), 74-75. Retrieved from https://journals.library.ualberta.ca/eblip/index.php/EBLIP/article/download/21469 $/ 16225$

Yin, R. K. (2017). Case study research design and methods (2nd ed.). Thousand Oaks, CA: Sage Publications.

Zachary, G.P. (2011). Jobless innovation [Spectral Lines]. IEEE Spectrum, 48(4), 8. doi:10.1109/MSPEC.2011.5738381 
Zainal, Z. (2007). Case study as a research method. Jurnal Kemanusiaan, 9(2), 1-6.

Retrieved from

https://www.researchgate.net/publication/41822817_Case_study_as_a_research_ method

Zanello, G., Fu, X., Mohnen, P., \& Ventresca, M. (2015). The creation and diffusion of innovation in developing countries: A systematic literature review. Journal of Economic Surveys, 30(5), 884-912. doi:10.1111/joes.12126

Zucker, D. (2014). The Belmont Report. Wiley StatsRef: Statistics Reference Online. doi:10.1002/9781118445112.stat06924 


\section{Appendix A: Recruitment Letter}

Good day, my name is Édney Santos, a doctoral student at Walden University, inviting you to participate in my research project concerning your views on the rapid diffusion of technological innovation and its implications on labor market challenges within Angolan impoverished regions such as yours. As an Angolan citizen, your participation, contributions as well as life experiences acquired concerning the diffusion of technological innovations and the socioeconomic situations across your region will be of great value and will make great impact in this study.

The purpose of this study is to gain deeper understanding of the views of Angolan stakeholders, residing within impoverished communities in Angola, on the rapid technology diffusion and its implications on labor market challenges within their regions. I believe that your experience as a citizen and as a stakeholder in your region would be of great value to this study. Eligibility for participation in this study includes the following criteria: 1) adults over the age of 18;2) male and female; 3) born and residing in impoverished communities in Angola; and 4) possessing knowledge regarding their experiences with the topic of the study. Therefore, I am reaching out to discern if you might have interest in participating in the research.

This study will attempt to bring to the research foreground the voices of local populations on technology diffusion in impoverished areas of Angola, representing a promising avenue of social change by innovation and technology diffusion. The findings may also guide further research in technology adoption and innovation diffusion within Angola, a nation faced with poor human capital development and an increasing proportion of the world's poorest people as well as unemployment. Finally, the social change impact of this study may potentially result from improving the socioeconomic well-being of your particular province and the entire Angolan society.

If you would be interested in being a part of this study please review and return the signed consent form to me personally or if possible to the email provided here.

Respectfully,

Édney Santos. 
Appendix B: Interview Protocol

Participant No. Identifier:

Region

Age

Gender

Occupation

Earns a Sustainable Livelihood

Owns a Mobile phone:

\section{Owns other Mobile Device?}

1. What types of productive activities are you most involved in on a daily basis?

2. Why do those activities work best for you?

3. What encourages your participation in activities of technology innovation?

4. What limits your participation in activities of technology innovation?

5. How do you explain the tendency of rural communities with high unemployment to shun participation in technology development opportunities?

6. What do you believe to be a viable solution to the unemployment in your region? 
Appendix C: Map of Angola with Research Site Provinces Indicated in Green

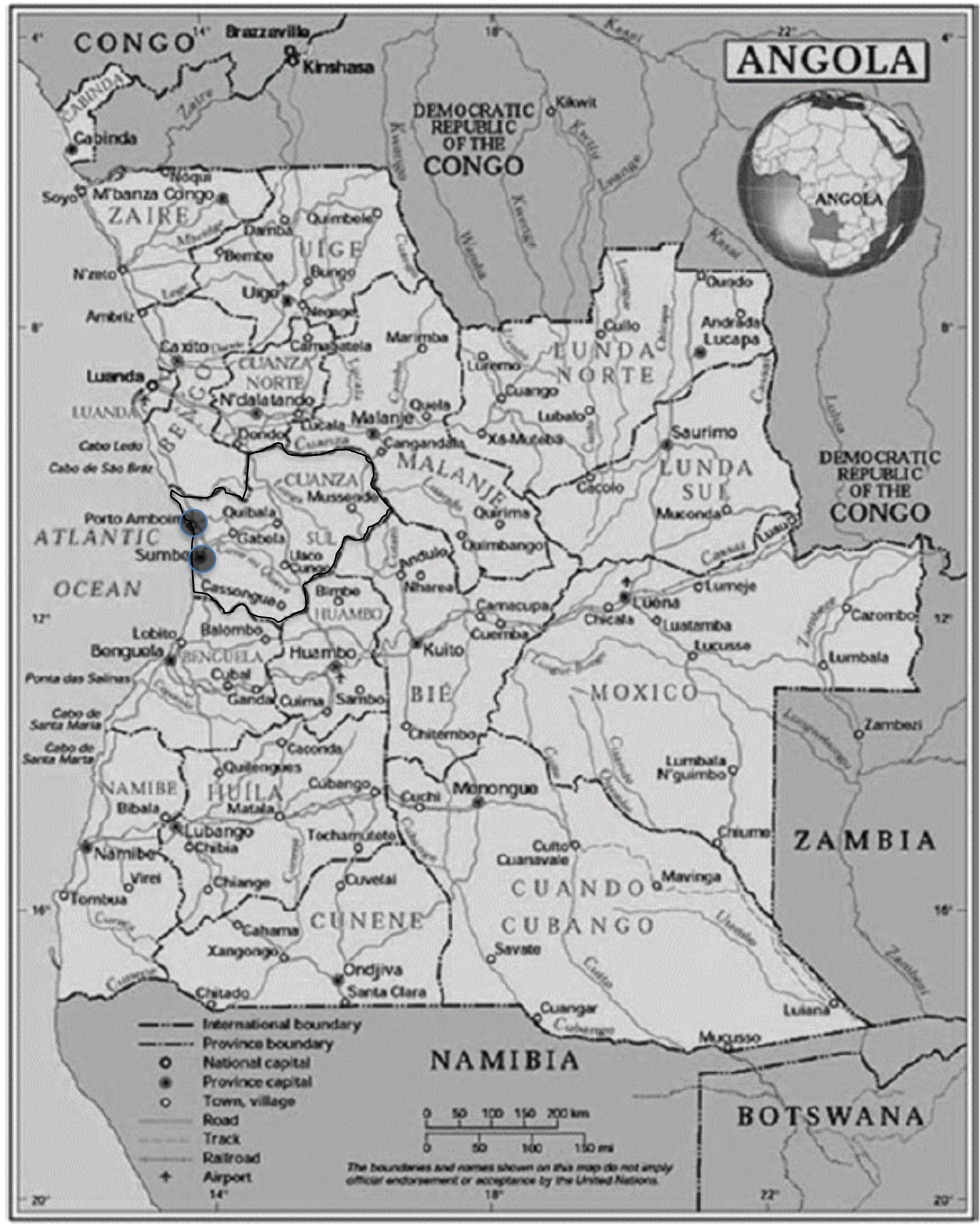

